\title{
Leadership styles of department chairs and faculty utilization of instructional technology
}

\author{
Tongshan Chang \\ West Virginia University
}

Follow this and additional works at: https://researchrepository.wvu.edu/etd

\section{Recommended Citation}

Chang, Tongshan, "Leadership styles of department chairs and faculty utilization of instructional technology" (2004). Graduate Theses, Dissertations, and Problem Reports. 2553.

https://researchrepository.wvu.edu/etd/2553

This Dissertation is protected by copyright and/or related rights. It has been brought to you by the The Research Repository @ WVU with permission from the rights-holder(s). You are free to use this Dissertation in any way that is permitted by the copyright and related rights legislation that applies to your use. For other uses you must obtain permission from the rights-holder(s) directly, unless additional rights are indicated by a Creative Commons license in the record and/ or on the work itself. This Dissertation has been accepted for inclusion in WVU Graduate Theses, Dissertations, and Problem Reports collection by an authorized administrator of The Research Repository @ WVU.

For more information, please contact researchrepository@mail.wvu.edu. 
Leadership Styles of Department Chairs and

Faculty Utilization of Instructional Technology

Tongshan Chang

\author{
Dissertation submitted to the \\ College of Human Resources and Education \\ at West Virginia University \\ in partial fulfillment of the requirements \\ for the degree of
}

\title{
Doctor of Education
}

in

Educational Leadership Studies
Richard Hartnett, Ed. D., Chair
William Deaton, Ph. D.
Earnest Goeres, Ph. D.
Elizabeth Jones, Ph. D.
Peter Li, M.R.E.

\author{
Department of Advanced Educational Studies \\ Morgantown, West Virginia \\ 2004
}

Keywords: Leadership, Department Chairs, Faculty Instructional Technology Use Copyright 2004 Tongshan Chang 


\section{ABSTRACT \\ Leadership Styles of Department Chairs and Faculty Utilization of Instructional Technology}

Tongshan Chang

This study examined the relationship between the leadership styles of academic department chairs of Curriculum and Instruction, Educational Leadership Studies, Teacher Education, and Educational Psychology in Colleges of Education at doctoral/research public universities by Carnegie Classification and faculty utilization of instructional technology in teaching. Two-stage random sampling was used to sample the population. The instrument of Faculty Utilization of Instructional Technology was sent to 93 chairs and 843 faculty, respectively. Bolman and Deal's Leadership Orientation (other) was also sent to 843 selected faculty. Thirty-seven chairs and 230 faculty responded to the survey. Descriptive statistics, Chi-square test, $t$ test, ANOVA, MNOVA, Pearson's correlation coefficients, and canonical analysis were used to analyze data.

The major findings included: (1) department chairs in colleges of education used the structural frame the most frequently, followed by the human resource, political, and symbolic frames; (2) chairs in colleges of education were more likely to use no leadership frame style (56.8\%), followed by the single (14.8\%), multi-frame (14.8\%) and pairedframe style (13.6\%); (3) Demographic variables (department type, size, chairs' gender, length of tenure) had a significant influence on chairs' use of leadership frames, (4) chairs' use of all four leadership frames were significantly correlated with technology domains (technology infrastructure, faculty use of technology, technical support, administrative support, and key issues); (5) chairs' leadership styles (no, single, paired, and multi-frame) were significantly associated with technical and administrative support: chairs using multiple frames were more likely to provide these two kinds of support for faculty use of technology; (6) chairs' use of leadership frame patterns was also associated with faculty utilization of technology with chairs' use of the structural frame, or a combination of the structural and political frames, or a combination of the structural, human resource, and political frames being more helpful for chairs' use of technology; and (7) department type, size, and chairs' length of tenure along with chairs' leadership styles were associated with faculty utilization of instructional technology.

Chairs in Colleges of Education should learn to use the multi-frame leadership style in order to effectively facilitate faculty utilization of instructional technology. 


\section{ACKNOWLEDGEMENTS}

I would like to express my appreciation to the members of my dissertation committee and for their commitment, advice, and suggestions. To Dr. Richard Hartnett, my dissertation chairperson and advisor, for his continual guidance, advice, motivation, and consistently thought-provoking dialogue during the process of this study. To Dr. William Deaton, for his advice as well as willingly and patiently sharing his expertise during the statistical analysis of this study. To Dr. Ernest Goeres, for his kind encouragement and friendly advice. To Dr. Elizabeth Jones, for her direction, encouragement, expertise, and motivation. To Mr. Peter Li, for his many positive comments, and suggestions in regard to this study. To Mr. Jon Reed, for his agreement to serve as a substitute for the oral defense of my study.

I would also like to express my thanks to my mentor and professional role model, Dr. Min Weifang, Vice-President at Beijing University, who recommended for study at West Virginia University, and to Dr. Ed Kinley, Associate Vice President and Chief Information Officer at Indiana State University, for his advice and comments at the very beginning of this study.

My heartfelt thanks are also extended to my entire family. To my parents, for their encouragement at a very young age to achieve all I can and to challenge myself educationally. To my parents-in-law, for their continual encouragement and consideration. To my brothers, sisters, and brothers-in-law, for their looking after my parents or parents-in-law, so I was able to keep my mind on this study.

I owe this accomplishment to my wonderful wife Lin and my son Hansen. Without their love, support, and patience, this project would not have been possible. Thank you. 
Table of Contents

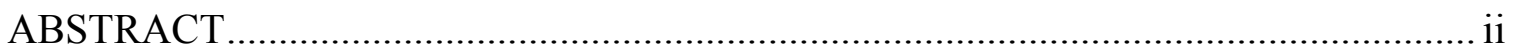

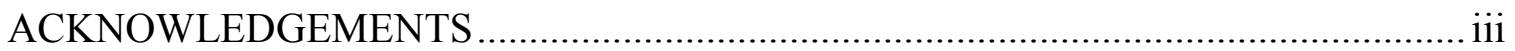

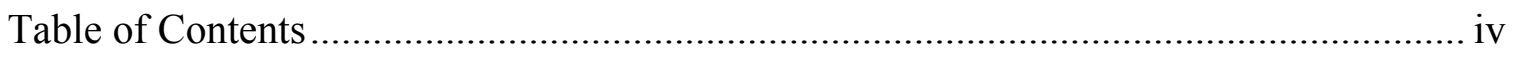

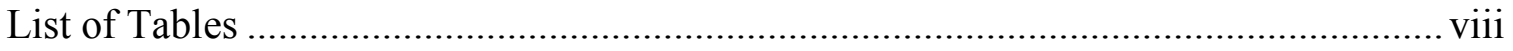

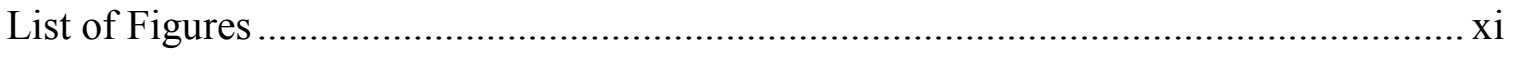

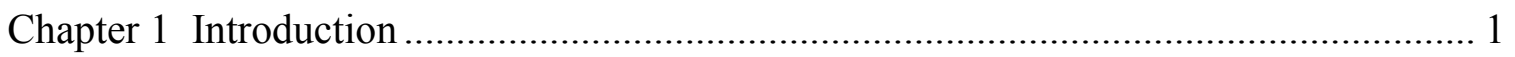

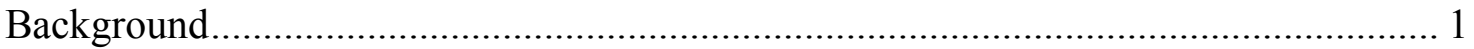

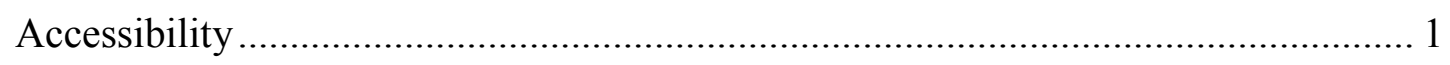

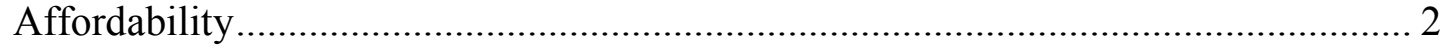

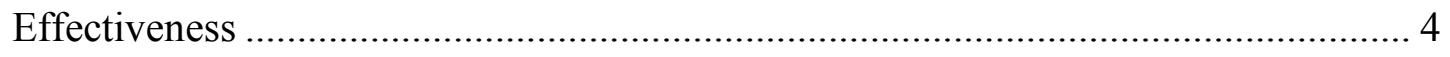

Current Challenges and Major Issues........................................................... 5

Statement of the Problem ..................................................................................... 8

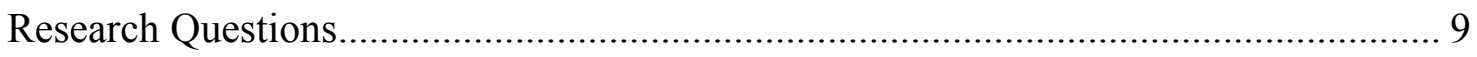

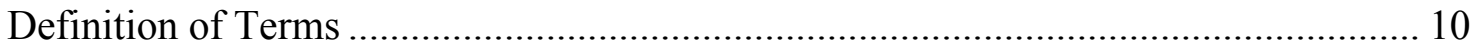

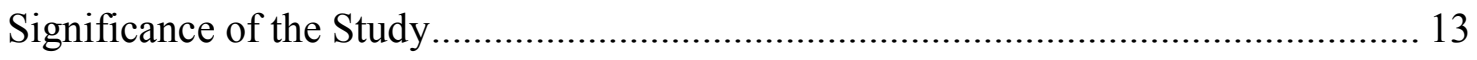

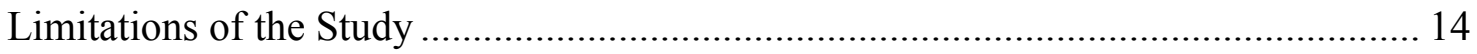

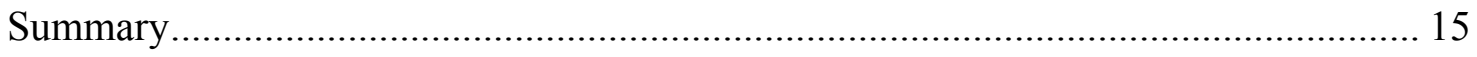

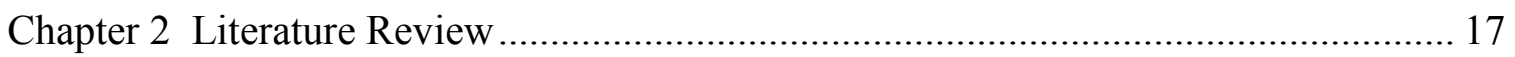

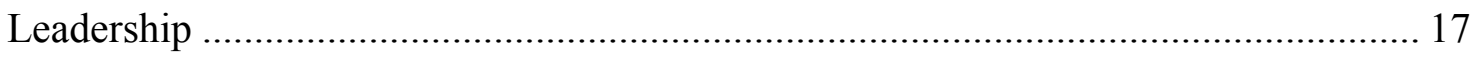

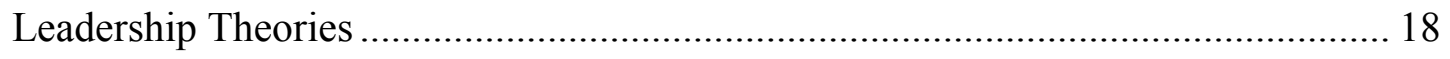

Bolman and Deal's Four-Frame Leadership Model............................................... 33 
Bolman and Deal's Research on the Four-Frame Model ...........................................36

Research Using Bolman and Deal's Four-Frame Model .......................................... 38

Leadership of Academic Department Chairs .......................................................... 43

Utilization of Instructional Technology in Teaching Courses and the Chair's

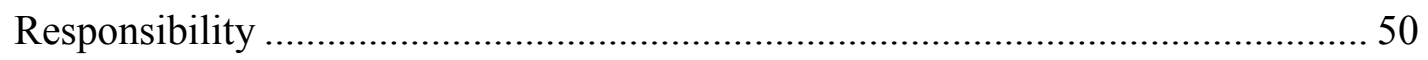

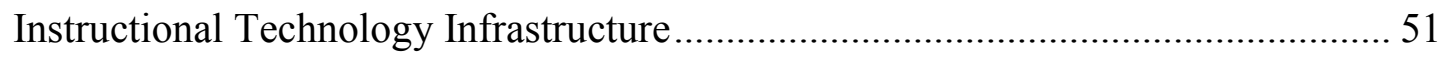

Faculty Utilization of Instructional Technology in Teaching Courses ....................... 53

Technical and Administrative Support for Faculty Utilization of Instructional

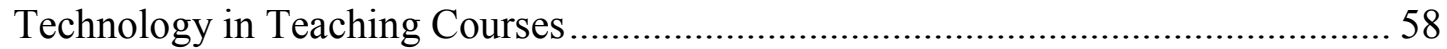

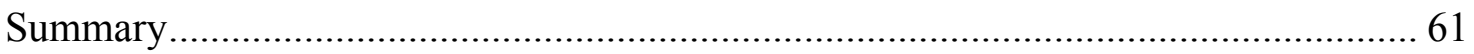

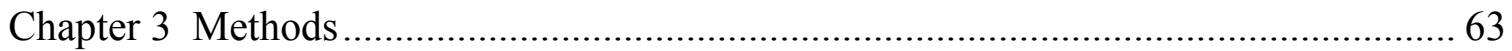

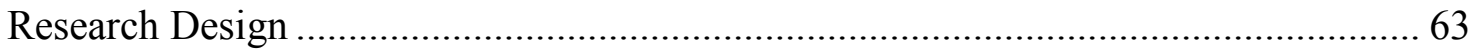

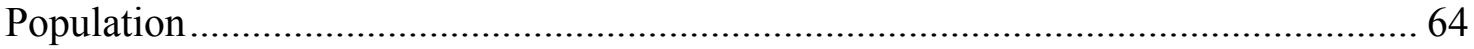

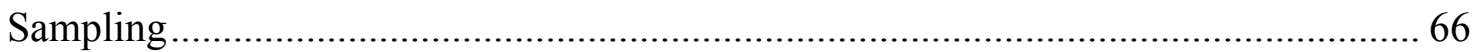

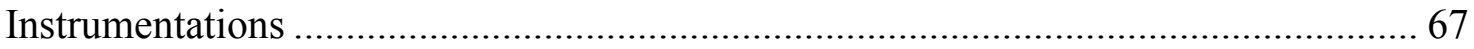

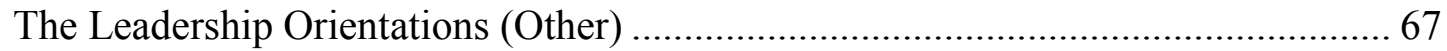

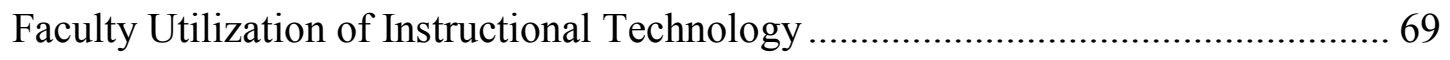

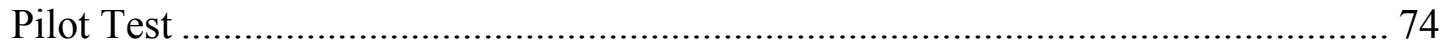

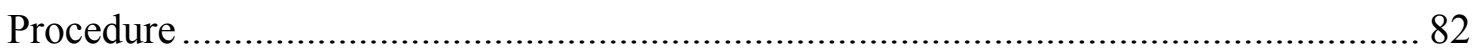

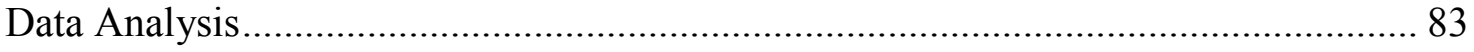

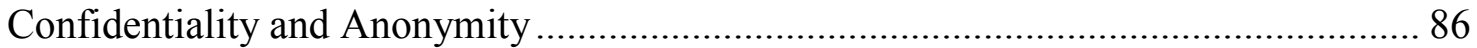

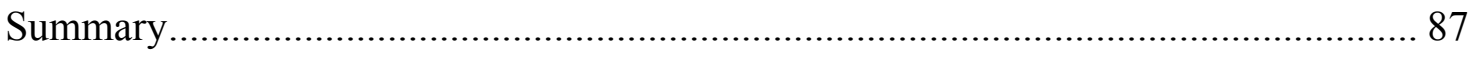

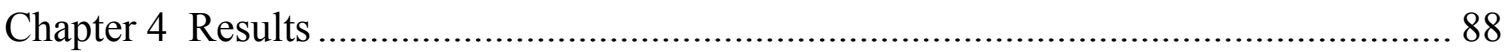




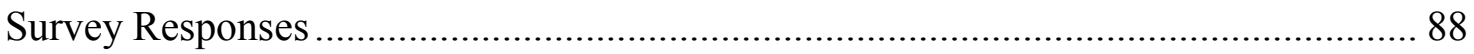

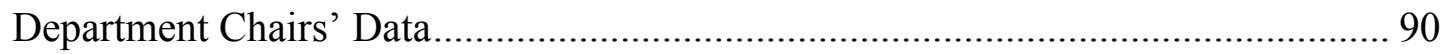

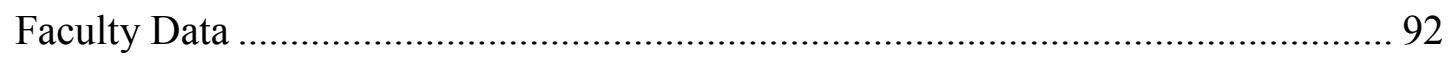

Approaches to Dealing with Missing Values ................................................................ 94

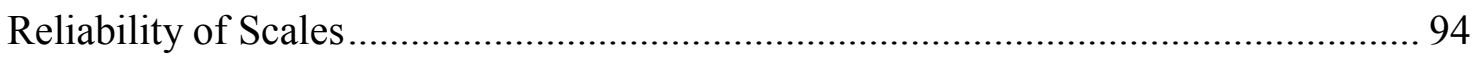

Leadership Orientation (other) ............................................................................ 95

Faculty Utilization of Instructional Technology in Teaching (chair) ........................ 96

Faculty Utilization of Instructional Technology in Teaching (faculty) ...................... 98

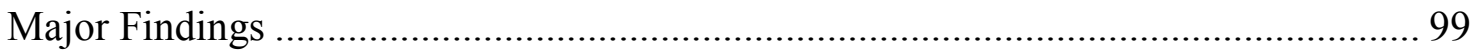

Summary

Chapter 5 Conclusions and Recommendations............................................................ 145

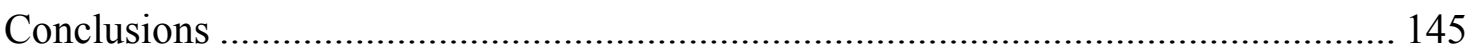

General Pattern of Chairs' Leadership Styles ........................................................ 145

Demographic Effect on Leadership Styles............................................................ 147

Relationship of Individual Leadership Frames with Faculty Use of IT ................... 149

Leadership Styles and Faculty Use of IT ............................................................... 151

Leadership Styles by Demographic Variables and Faculty Use of IT ..................... 153

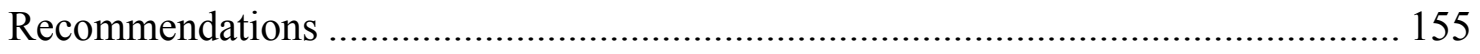

Recommendations for Practice.......................................................................... 155

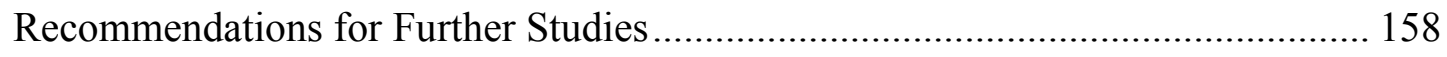

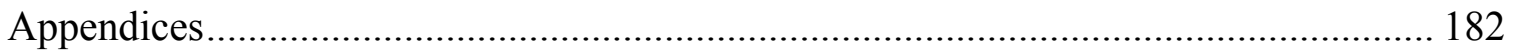

A. Letter to Dr. Bolman for Permission of Use of the Leadership Orientations

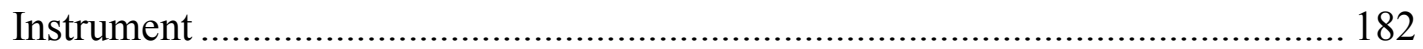


B. Permission to Use the Leadership Orientations Instrument............................... 183

C. Bolman and Deal Leadership Orientations (others).......................................... 184

D. Faculty Utilization of Instructional Technology in Teaching Courses (chair) ....... 186

E. Faculty Utilization of Instructional Technology in Teaching Courses (faculty) .... 189

F. A Cover Letter for Pilot Test Participants....................................................... 192

G. Pilot Test Questionnaire for Utilization of Instructional Technology ................... 193

H. Cover Letter to the Selected Faculty .............................................................. 194

I. A Cover Letter to the Selected Chairs............................................................... 195

J. Item-Total Correlations on the Scale of Leadership Orientations ........................ 196

K. Item-Total Correlations on the Scale of Faculty Utilization of IT (chair)............. 197

L. Item-Total Correlations on the Scale of Faculty Utilization of IT (faculty) .......... 199

M. Profile for Faculty Utilization of IT by Department ....................................... 201 


\section{List of Tables}

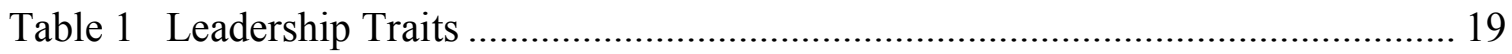

Table 2 Leadership Traits of Academic Department Chairs ..................................... 46

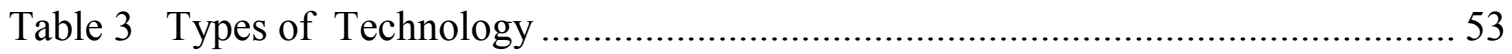

Table 4 Faculty Use of Instructional Technology in Teaching in 1995 and 2000......... 57

Table 5 Number of Four Academic Departments in the Colleges of Education at Doctoral/Research Extensive Public Universities by Carnegie Classification .. 65

Table 6 Number of Subjects by Four Academic Departments in the Colleges of Education at Doctoral/Research Extensive Public Universities by Carnegie

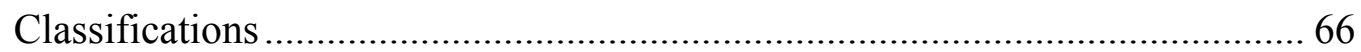

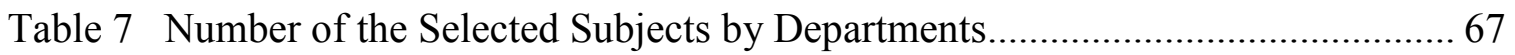

Table 8 Instrument Items and Literature Sources ................................................. 71

Table 9 Frequency Distribution of Disagree/Strongly Disagree and Agree/Strongly

Agree on the Items of Pilot Test Questionnaire .......................................... 76

Table 10 Item-Total Statistics for Section A of the Instrument................................ 78

Table 11 Item-Total Statistics for Section B of the Instrument ............................... 79

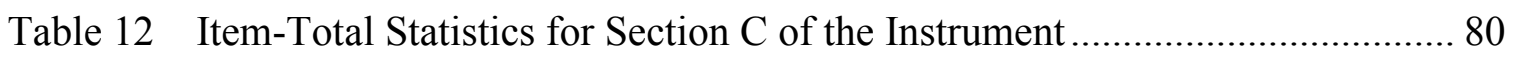

Table 13 Item-Total Statistics for Section D of the Instrument............................... 81

Table 14 Item-Total Statistics for Section E of the Instrument ….......................... 82

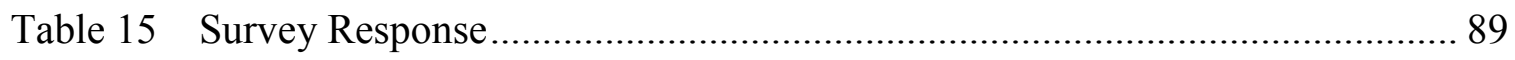

Table 16 Chair and Faculty Survey Response Rate by Deparment ............................ 90

Table 17 Chair Responses by Demographic Variables.......................................... 91

Table 18 Faculty Survey Reponses by Demographic Variables.................................. 93 
Table 19 Cronbach's Alpha Coefficients by Leadership Frame................................ 96

Table 20 Cronbach's Alpha Coefficients by Factor of IT (chair).............................. 97

Table 21 Cronbach's Alpha Coefficients by Factor of IT (faculty)............................ 98

Table 22 Means and Standard Deviations of Chairs' Four Leadership Frames Rated by

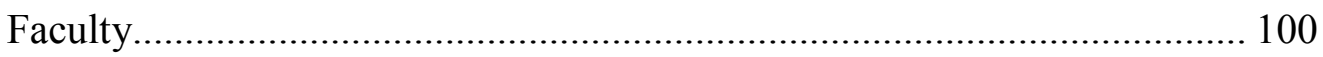

Table 23 Frequency Distribution for Frame Use by Chairs................................... 101

Table 24 Frequency Distribution by Frame Pattern.............................................. 103

Table 25 Effects of Demographic Variables on Chairs' Leadership Frame Use........ 106

Table 26 Correlations between Four Leadership Frames ...................................... 108

Table 27 Effects between the Selected Demographic Variables and Chairs' Use of Leadership Frames ......................................................................... 109

Table 28 Effects of the Selected Interactions on the Four Leadership Frames ........... 112

Table 29 Frequency Distribution of Cateogries of Chairs' Leadership Frames by Demographic Variables ................................................................... 114

Table 30 Correlation Matrix for the Variables between Leadership Frames and IT ... 120

Table 31 Canonical Variables and Significance ................................................ 121

Table 32 Statistics of Canonical Correlation Analysis ........................................... 122

Table 33 Difference in IT Utilization by Category of Leadership Frames ................. 125

Table 34 Difference in Faculty IT Utilization between ST and HR ........................ 127

Table 35 Difference in Faculty IT Use by Paired-Frame Pattern ............................. 129

Table 36 Difference in Faculty IT Use by Multi-Frame Pattern .............................. 131 
Table 37 Unifariate F's for the Difference of Ingteractions between Category of Leadership Frame and Chairs' Demographic Variables in Faculty Utilization

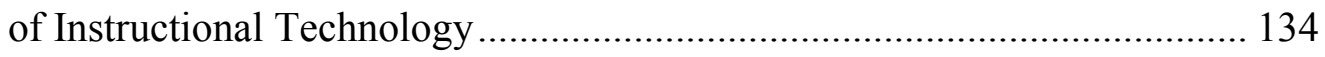

Table 38 Difference of IT by Category for Each of the Four Departments................. 136

Table 39 Difference of IT by Category for Different Size of Departments................. 138

Table 40 Difference of IT by Category for Chairs' Length in the Position.................. 141 


\section{List of Figures}

Figure 1 Hersey and Blanchard's Situational Leadership Theory ............................... 24 


\section{Chapter 1}

Introduction

\section{Background}

Instructional technology has had a major impact on teaching and learning in American higher education since the first computer system solely dedicated to instruction and research on learning was introduced in 1966 (Robley, Edward \& Havriluk, 1997). Its use in teaching courses by faculty has increased substantially over the past decade. It has played an unprecedented role in assisting in higher education reform, or supporting the goal of shifting the instructional paradigm to the learner-centered paradigm. It has the potential to help improve effectiveness and efficiency in administration, enhance faculty research capabilities, empower faculty in teaching, prepare students to succeed in a rapidly changing world, and fulfill institution's duty to serve the public. Van Dusen (1998) noted that technology is seen as academe's "magic bullet" that silences higher education's critics by making the academy more accessible, more affordable, and more effective.

\section{Accessibility}

Access to American higher education began to increase substantially in the late 1960s and early 1970's, and by 1995 enrollment reached about 14 million students (up from 8 million in 1970). According to Van Dusen (1998), one reason for this change is due to the increase of "non-traditional" students, 25 years of age and older. "Traditional" students between the ages 18 to 22 , living on campus and attending classes full time, today account for only 25 percent of the total enrollment. 
To meet special needs of non-traditional students, many universities are offering distance education courses at various degrees and program levels. For example, the University of Maryland University College created a program, called Better Opportunities through Online Education, to lead the working poor in Baltimore and Washington to better jobs by giving them help, resource, and distance-education courses that teach marketable skills (Carlson, 2003). The program provided 67 students with a computer, a printer, Internet access, books, and courses in business management and computer skills, all without charging them a cent. Apparently, without the help from such a special program, these 67 people would not have an opportunity to study in college.

At the same time, many "for-profit" institutions have emerged. They are delivering courses and conferring degrees, particularly in professional and technical fields, to the expanding over-23 cohort of working adults. For instance, the University of Phoenix Online Program began in 1976 to broaden outreach and increase access. Today the program enrolls 26,000 students in their pursuit of bachelor's, master's or doctoral degrees (“The Nation's Leading Online University”). The University offers 10 bachelor's degree programs, 18 master's degree programs, 3 doctoral programs, and 21 continuing teacher education programs. Since 1976, more than 171,600 working professionals have earned their degree from this "non-traditional" university.

\section{Affordability}

Another major objective of the reform movement propelled by the adoption of instructional technology is affordability. Tuition and fees increased significantly from 1976 to 1996 . As a consequence or coupled with state funding cuts, tuition on average increased from 642 to 3,151 dollars in public universities; at private universities, from 
2,881 to 15,581 dollars; and at community colleges, from 245 dollars to 1,245 dollars (College Board, 1996). For adult students, the new majority in higher education, instructional technology solutions can conceivably reduce some student expenses (Van Dusen, 1997).

Costs can be partially mitigated by improved scheduling of classes and better allocation of resources. A class can be convened in real time at remote locations such as work sites or libraries or can be conducted asynchronously over the Internet. This approach can greatly reduce or eliminate customary expenses associates with travel, child care, meals, for part-time and nonresident adult students. More importantly, those who have a job do not need to worry about the loss of their job due to attending class in the work time. Another variable that results in affordability includes faculty and other college personnel, such as administration and staff. On the administrative side, investments in technology have already proven cost-effective. Technology helps streamline admission, financial aid, registration, and other transaction processes. Administrative expenditures, as a percent of total educational and general expenditures, have been flat or declining since 1987 because of adoption of technology (Van Dusen, 1997). On the academic side, according to the report of the National Commission on the Cost of Higher Education (1998), institutions have hired more part-time and nontenured faculty. The proportion of part-time faculty and staff increased from $33 \%$ of all instructional faculty and staff in 1987 to $42 \%$ in 1992 while in the same period, the percentage of instructional faculty and staff with tenure declined from 58 to 54 percent (NCCHE, 1998). A decline in the relative proportion of tenured full-time faculty to untenured part-time faculty often results in budget savings to the institution. 


\section{Effectiveness}

A third reform objective of utilization of instructional technology in teaching is institutional effectiveness, defined here as meeting academic goals and objectives. Although the various stakeholders hold different perspectives on this challenging issue, faculty are using new technologies to change the way they teach and the methods by which students learn. As Bates (2000) stated, there are many advantages of new technology over traditional face-to-face meetings. Learners are now increasingly able to access teaching and learning at any time, at any place through computers and the Internet. Well-designed multimedia learning materials can be more effective than traditional classroom methods; students can learn more easily and more quickly through the use of integrated illustration and animation, through different structuring of materials, and through increased control of and interaction with learning materials. For example, in the classroom, scientific visualization software may put students in the middle of a complex mathematical chemical, or biological process, so students have opportunity to experience, often interact, with a process from divers angles such that their understanding becomes multi-dimensional (Van Dusen, 1998). New technologies can be designed to develop and facilitate higher-order learning skills, such as problem solving, decision making, analytical reading, creative writing, and critical thinking (Bates, 2000; Ewing, Dowling \& Coutts, 1997). Interaction with instructors can be structured and managed through on-line communications to provide greater access and flexibility for both students and teachers. Computer-mediated communication facilitates team teaching, the use of guest faculty from other institutions, and multicultural and international classes. 
Dolence and Norris (1995) stress that the integration of instructional technology will transform higher education and increase its effectiveness. The strategic plan for information technology at University of Hawaii (2002) states that, "while technology alone cannot turn a weak institution into a strong one, inadequate instructional technology facilities, services or support will limit the ability of a knowledge-based institution like a university to flourish in the $21^{\text {st }}$ century" (p. 3).

\section{Current Challenges and Major Issues}

Currently, one of the issues facing higher education is how to create a positive instructional technological environment in which teaching and learning will be enhanced. This is also one of the most difficult challenges facing academic department chairs (Bates, 2000). Bates pointed out that although chairs do not need to be experts in the use of technology for teaching, a good understanding of the relationship between technology and teaching will be immensely helpful. It is important that chairs have strategies for dealing with the impact of new technologies on instruction.

Successful incorporation of instructional technology into teaching courses requires additional organizational features. Higher education is facing many problems in integrating instructional technology into teaching and learning. The lack of a strategic plan for instructional technology is one problem that has a negative impact on the effort to assist the instructional integration of instructional technology in higher education. Setting appropriate goals and developing sound plans for reaching them are prerequisites for success in any endeavor that someone might want to adopt instructional technology in higher education (Robley, Edward and Havriluk, 1997). Unfortunately, according to Green's 2001 Campus Computing Survey, only 63.3 percent of the campuses have a 
strategic plan for instructional technology, down from 64.9 percent in 2000, and only up slightly from 61.0 percent in 1999. More unfortunately, many of these strategic plans do not have the key components that an overall instructional technology strategic plan should include. For example, only 52.2 percent of the plans have addressed the financial issue about the need to "acquire and retire" aging equipment (Green, 2001).

Frayer (1999) notes that adequate technology and support of its use is a necessary condition for success. No individual faculty member, department, or campus will be able to fully realize the potential of educational technology to enhance teaching and learning without a robust instructional technology infrastructure (facility, system, and personnel infrastructure). The National Education Association ("Focus on Distance Education", 2001) found that the reliability of the technology is problematic. Faculty participated in the survey complained of limited, unreliable, incompatible, expensive and/or no equipment at all. Gatlin-Watts, Arn and Kordsmeier's research (1999) shows that 49.1 percent of the chairs participating in their survey disagreed or strongly disagreed that appropriate space and facilities for classroom multimedia use were available. Only about 46 percent of the chairs thought the equipment was adequate. With regard to the provision of computer technology for faculty, only 74 percent of them own desktop or notebook computers (Green, 2001). The percentage of the 4-year replacement cycle for faculty's desktop or notebook computers is 37 percent and about 20 percent of them are unable to update their computers for five years. The survey does not show any information as to whether these 20 percent faculty upgraded their computers within five years. If not, their computers are outdated and there is no way to ensure the successful integration of instructional technology into teaching. 
Instructional technology is changing so quickly that it is impossible for faculty to keep pace with its innovations. Accordingly, user support is becoming more important to integrate instructional technology into teaching. In terms of Green’s survey (2001), campus officials identified "assisting faculty efforts to integrate information technology into instruction" as the single most important instructional technology confronting their campuses. Unfortunately, staffing issues are a continuous obstacle that prevents the instructional technology personnel from providing enough assistance for the faculty. Green's survey research (2001) found that the ratio of instructional technology personnel to users (without including faculty, administrators and staff) is 1 to 256 for all institutions. Although in public universities, this ratio is lower, 1 to 166 , there still exists a big gap in contrast to the suggested ratio 1 to $50-75$ by the Gartner Group (2002). Gatlin-Watts, Arn and Kordsmeier (1999) also point out that only 50 percent of the chairs agree that experienced personnel were available to assist new multimedia users in their colleges.

Failure to provide suitable leadership is another problem that negatively influences the integration of instructional technology in higher education. Encouraging faculty to use educational technology is a social or contextual issue that the institutional administrators must address. Frayer's research (1999) indicates that not all the faculty are likely to use instructional technology to support their teaching because developing cutting-edge uses of instructional technology requires a significant time commitment. The reason for that is that junior faculty are unlikely to make this commitment if they believe this will jeopardize their promotion or tenure, while senior faculty for whom promotion and tenure are not an issue generally select to spend their time in ways that are 
rewarded by their college or university and their disciplinary area (Fray, 1999). This problem can be further witnessed by Green's findings (2001), which show that the percentage of classes that use computer-based classrooms/labs is only 27.2 and the percentage of classes that use web pages for class materials and resource is 30.7 . Surprisingly, only 59.5 percent of classes use email as a tool to enhance teaching and learning. According to Gatlin-Watts, Arn and Kordsmeier (1999), only 39.4 percent chairs surveyed believed that their faculty evaluation processes reward such efforts.

The problems addressed above have, to different degrees, affected the effective use of instructional technology in teaching. Although the strategic plan is usually developed by the instructional technology officers, academic chairs play a significant role in achieving the goals set in the strategic plan, especially the goals related to instruction. To resolve these problems, academic department chairs' leadership is imperative to realize the objectives in the plan.

\section{Statement of the Problem}

This study will examine the relationship between leadership at the department level and the degree of utilization of instructional technology by faculty in teaching courses. The major hypothesis examines whether there is a statistically significant relationship between the leadership style of academic department chairs and faculty utilization of instructional technology in teaching courses. The leadership styles are classified on the basis of Bolman and Deal's $(1984,1990)$ cognitive frames (structural, human resource, political, and symbolic) to understand organizational behavior and governance patterns. A frame helps the administrator determine what is important and what can be safely ignored (Bensimon, 1987). 


\section{Research Questions}

This research explores the leadership style of department chairs and faculty utilization of instructional technology in four academic departments within the Colleges of Education in doctoral/research extensive public universities by Carnegie Classifications (Bassinger, 2000). Department chairs and faculty from Curriculum and Instruction (C\&I), Education Leadership Studies (EDLS), Teacher Education (TEd), and Educational Psychology (EdP) will be invited to participate in this study. These four departments are the most frequent and largest departments in all colleges of education at these universities.

1. What are the leadership styles (as measured by the four frames) of the chairs in the departments of C\&I, EDLS, TEd, and EdP?

2. How does the leadership style of chairs vary by academic department, discipline, gender, size of a department, and chairs' length of tenure?

3. Is there a statistically significant relationship between the leadership frame(s) of department chairpersons and faculty reports of utilization of instructional technology in teaching courses?

4. Is there a statistically significant difference between the various patterns (single, paired, and multiple) of leadership frames of chairpersons and faculty reports of utilization of instructional technology in teaching courses?

5. Is there a statistically significant difference in the instructional technology utilization by single, paired-, and multi-frame for each of the chairs of the four academic departments, size of departments, age, gender, chairs' length of tenure, and the selected interactions? 


\section{Definition of Terms}

Four Leadership Frames. According to Bolman and Deal (1984, 1990), leadership behavior can be characterized according to four perspectives or frames: structural, human resource, political and symbolic.

The Structural Frame. Leaders who follow the structural frame emphasize rationality, goals and efficiency. They clearly define the goals in order to be effective. They are more likely to conduct activities by following the predetermined rules and policies. They have power to execute their decisions.

The Human Resource Frame. Leaders using this frame pay more attention to human needs and how organizations can meet those needs. Within this frame, organizational members are viewed as the primary resource and only when these resource are the highest priority, can the organization improve its effectiveness. Human resource leaders try to build and maintain a harmonious relationship between the organization and individual. They seek to lead the organization through openness, participation, and empowerment.

The Political Frame. Leaders adopting the political frame see organizations as arenas of continuing conflict and competition for scarce resource among different groups with diverse agendas and interests. Political leaders are advocates and negotiators who value realism and pragmatism. They spend much of their time networking, creating coalitions, building a power base, and negotiating compromises.

The Symbolic Frame. Leaders espousing the symbolic frame believe the world is chaotic, in which meaning and predictability are social creations, and facts are interpretative rather than objective. They provide a shared sense of mission and identity. 
Symbolic leaders instill a sense of enthusiasm and commitment through charisma and drama. They focus on myth, ritual, ceremony, stories, and other symbolic forms. The No Frame Orientation Leadership Style. The department chairs who do not espouse any frame orientation are assumed to demonstrate a leadership style with no frame orientation.

The Single-Frame Orientation Leadership Style. This leadership style means that a chair only uses a single frame.

The Paired-Frame Orientation Leadership Style. A chair using any two of the four frames is designated to have this leadership style.

The Multiple-Frame Orientation Leadership Style. The multiple-frame orientation leadership style means that the chairs espouse more than two frames. Instructional Technology. Instructional technology in higher education includes computing and communications technology, which is used to enhance an institute's leadership position and reputation for innovation in high technology programs and research, support and improve teaching and learning, achieve ongoing efficiencies in the daily communications, operations, and administration of the university.

Integration of Instructional Technology in Teaching. Integration of instructional technology in teaching refers to the appropriate application of various instructional technologies in teaching courses to improve instructional quality on the basis of learning theory, teaching practice, and specific learning needs.

Instructional Technology Infrastructure. An instructional technology infrastructure is composed of a facility, system, and personnel. Facility infrastructure, which makes any technology operate effectively, includes these components: available 
space, conduits or raceways in which computer and network cables are laid, cables and electrical wiring, electrical power, and related building features. Systems infrastructure consists of various technology components including hardware and software. Personnel infrastructure includes the human resource necessary for the efficient operation of the overall technology infrastructure such as system managers, training and technical assistants, administrative supporters, online-course designers, and student technologyrelated service supporters.

Instructional Paradigm. The instructional paradigm refers to transferring knowledge to students according to a teacher-directed and teacher-centered model (Barr \& Tagg, 1995; Roblyer et al., 1997).

Learner-Centered Paradigm. The learner-centered paradigm produces learning by creating environments and experiences that encourage students to discover and construct knowledge for themselves. It is student-centered and learner-directed (Barr \& Tagg, 1995; Roblyer et al., 1997).

Faculty. An instructional faculty member who is not a department chair and holds a full-time position (tenure track or non-tenure track) as a professor, associate professor, assistant professor, or instructor in the Departments of C\&I, EDLS, TEd, and EdP of the Colleges of Education at the doctoral or research public universities by Carnegie Classifications (Besinger, 2002).

Faculty Utilization of Instructional Technology in Teaching Courses. Faculty utilization of any instructional technologies (computer, the Internet, video, audio, E-mail, presentation tools, chat room, fax, film, electronic discussion lists, computer conferencing) to teach either a distance learning course or support a face-to-face course. 
Colleges of Education. All the colleges (schools) of Education, Education and Human Resource, Education and Services, Education and Information Studies, Education and Psychology, Teacher Education, and Education and Human Development at the Doctoral/Research Extensive universities.

Academic Department Chair. An individual who is currently chairing any one of the departments mentioned previously. This person may also be known as Department Head.

\section{Significance of the Study}

This study will investigate the leadership style of academic department chairpersons in the Colleges of Education at the Doctoral/Research Extensive public universities by Carnegie Classifications (Basinger, 2000) and faculty utilization of instructional technology in teaching. It has been suggested (Kinley, 2002) that to successfully implement and sustain distance education within their departments, chairs must set a context and build a framework so faculty understand the direction the department is taking, and articulate a vision of how distance education fits into the department's goals. There is little research regarding department chairs' roles in the success of distance education and no research relating chairs' leadership style to faculty utilization of instructional technology in teaching. No research about the leadership style of the chairpersons in Colleges of Education has been done using Bolman and Deal's frame of analysis. This study is significant for the following reasons:

1. The research results may help chairpersons better understand the influence of their leadership styles on faculty utilization of instructional technology in teaching. 
2. The findings may assist academic department chairs in Colleges of Education in examining and adapting their own leadership behaviors. Chairs can benefit from knowing what leadership frames are more likely to promote faculty utilization of instructional technology in teaching.

3. The results may contribute to building a more systematic base of information about the chairperson's role in higher education.

\section{Limitations of the Study}

1. Faculty utilization of instructional technology is measured as a self-perception by using Faculty Utilization of Instructional Technology in Teaching Courses survey instrument. A self-perception will limit the accuracy of the study (Kerlinger, 1986).

2. Faculty Utilization of Instructional Technology in Teaching Courses (faculty and chair versions) will be used for the first time. The validity and reliability of the instrument will pose a limitation of the results of the study.

3. The different experiences and academic specializations of chairpersons may influence their perceptions and the results of the study.

4. Data in this study are gathered from the chairpersons of four departments in the Colleges of Education at Doctoral/Research Extensive public universities. So the results of the study may not be generalized to other departments, colleges and institutions outside of this classification.

5. This research only investigates the influence of department chairs' role as a leader on faculty utilization of instructional technology and will not consider 
the influence of the roles as a faculty developer, a manager, and a scholar. This may limit the accuracy of the study.

6. The decisions related to the financial resource for instructional technology may be made at the university, or college, or department level. Examining the influence only at the department level will impose a limitation on the results of this study.

\section{Summary}

The expanding use of instructional technology is commonly regarded as constituting the latest revolution in American higher education. However, higher education is facing many problems in integrating instructional technology into teaching and learning, particularly providing appropriate leadership at the departmental level. Using Bolman and Deal's four-frame leadership model, this study explores the relationship of the leadership style of academic department chairs and faculty utilization of instructional technology in teaching courses.

This chapter has briefly introduced the utilization of instructional technology in higher education, developed the statement of the problem, posed the research questions to be answered in this study, and described the significance and the limitations of the study. In chapter 2, a detailed literature review related to the study variables (leadership and faculty utilization of instructional technology in teaching) is presented. Chapter 3 describes the methodology employed in this study. It is organized into six sections: participants, instrumentations, research design, procedure, data analysis and a brief summary. Chapter 4 presents the results of the study. In Chapter 5, the research findings 
are discussed, and a set of conclusions of the study and suggestions for further research are made. 


\section{Chapter 2}

\section{Literature Review}

This chapter reviews the major literature related to leadership and utilization of instructional technology in teaching courses. It is organized into such topics as the concept of leadership, leadership theories, Bolman and Deal's $(1984,1990)$ four frame model, research using four-frame model, leadership of academic department chairs, utilization of instructional technology in teaching courses, and possible relationship between academic department chairs and faculty utilization of instructional technology in teaching courses

\section{Leadership}

Burns (1978) states that, "Leadership is one of most observed and least understood phenomena on earth" (p.2). Leadership is defined according to individual perspectives. So the number of definitions of leadership might be the same as the number of people who have attempted to define the concept (Fincher, 1987; Yukl, 1981; Stodgill, 1974). Dill and Fullagar (1987) stated that, "In the field of leadership, definitions tend to vary depending upon the orientation or purpose of the author." Leadership is also defined on the basis of purpose and collective needs; otherwise, leadership is meaningless (Burns, 1978). Nevertheless, this study adopts the operational definition consistent with most conceptual and empirical studies: the behavior of an administrator, which influences subordinates to accomplish goals or objectives in a particular situation. The subsequent summary of leadership studies is consistent with key variables in the definition and the criteria of leadership effectiveness. 


\section{Leadership Theories}

Many theories of leadership have evolved since the earliest discussion of these concepts in antiquity. According to Dill and Fullagar (1987), there are five models of leadership: (1) power-influence models of leadership; (2) trait models; (3) behavior models; (4) situational models; and (5) transformational models. In addition, this review will also cover cultural and symbolic theories and the cognitive approach.

Trait Theories. The earliest theorists explained leadership in terms of the innate physical qualities, personalities and characters of leaders (Smith \& Peterson, 1988). They analyzed numerous famous leaders in the history of America and worldwide, hoping to find certain special personal traits these leaders had in common. The approach assumed that certain innate characteristics possessed by leaders were different from their followers (Bass, 1990; Bensimon et al., 1989b; Bryman, 1996; Yukl, 1998).

Katz's (1974) typology of three managerial skills (technical, human, and conceptual) has provided an influential model within the trait approach. Technical skills are defined as the professional expertise; human relation skills refer to being interpersonal; and conceptual skills are considered to be innate. It is necessary to note here that management is significantly different from leadership. According to Hackman and Johnson (2000), managers are more likely to attend to the status quo while leaders are more concerned with the ultimate direction of the group. Bennis and Nanus (1985) stressed that "managers are people who do things right and leaders are people who do the right thing" (p. 21).

Stodgill (1981) found by reviewing 163 trait studies in 1970's that a leader possessed the following characteristics: vigor and persistence in pursuit of goals, drive 
for responsibility and task completion, initiative, self-confidence, willingness to accept consequences and tolerate frustration, and the ability to influence others' behavior. Table 1 shows the prominent traits listed by Jago (1982). According to Bensimon et al., (1998), the most often cited characteristics are confidence, courage, fairness, respect for the opinions of others and sensitivity. However, it is nearly impossible to develop an inclusive list of leader traits because the impact of traits on leadership ability varies from situation to situation (Stodgill, 1948).

Table 1

\section{Leadership Traits}

\begin{tabular}{llll}
\hline $\begin{array}{c}\text { Physical and } \\
\text { Constitutional Factors }\end{array}$ & \multicolumn{1}{c}{ Skill and Ability } & Personality Characteristics & Social Characteristics \\
\hline Activity, energy & Administrative ability & Achievement drive, ambition & Cooperativeness \\
Appearance, grooming & Intelligence & Adaptability & Interpersonal skills, \\
Height & Judgment & Adjustment, normality & Popularity, prestige \\
Weight & Knowledge & Aggressiveness & Sociability \\
& Technical competence & Alertness & Socioeconomic position \\
& Verbal fluency & Antiauthoritarianism & Talkativeness \\
& & Dominance & Tact \\
& & Emotional balance, control & \\
& Enthusiasm & \\
& Extraversion & \\
& Independence, nonconformity & \\
& Initiative & \\
& Insightfulness & \\
& Integrity & \\
& Objectivity & \\
& Originality & \\
& Persistence & \\
& Responsibility & \\
& Self-confidence & \\
& Sense of humor & \\
& Tolerance of stress & \\
& &
\end{tabular}

Jago (1982) wrote that, "Presumably the more qualities or attributes contained in the list a person possesses, the more he or she is likely to be an effective leader." However, the methodologies of the early trait researchers chiefly involved observation rather than measurement (Bass, 1990; Yukl, 1998). Consequently, the judgments made using these methods on the presence or absence of these characteristics were highly 
subjective (Bensimon et al, 1989a). Trait theories also neglected situational determinants of leadership success (Yukl, 1981), and were unable to decipher the connection between a particular trait and leadership effectiveness (Fisher, Tack, \& Wheeler, 1988). Furthermore, Taylor (1994) reviewed the early research related to the trait theories and concluded that many of the traits that were tentatively identified as crucial to leadership in one study were not found to be crucial in another.

Although the search for specific traits in leaders has not yielded a list that can be used for predictive purposes, it is apparent from the literature search that lists of attributes of "successful" or "effective" leaders continue to be generated and that, among those attributes listed, some will appear that resemble those generated during research based on the trait theories. As one of the earliest models for studying leadership, trait theories continue influencing effective leadership in higher education (Bensimon et al, 1989a). It may be the case that despite research findings, employment reviews are unable to resist measuring personality potentials. Some contemporary theories continue to link personality traits with leadership (Gardner, 1999; Hogan, Curphy \& Hogan, 1994; Maccoby, 2000).

Behavior Theories. During the 1950s, stimulated by the writings of such theorists as Taylor (1911), who discussed the scientific production-oriented leader, and Mayo (1933), who discussed the need for leadership that focused on human relations, many researchers (Hemphill, 1955; Blake \& Mount, 1976; Stogdill 1948; Halpin, 1957; Halpin \& Winer, 1957) focused on studying of the behaviors of individuals in leadership positions. Among a substantial body of research, the Ohio State Leadership Studies are the most influential on the studying of behavior theories of leadership (Bensimon et al, 
1989a; Dill \& Fullagar, 1987). Halpin and his associates (1957) contended that the behavior of leaders that can be changed, rather than the leader's personal and intrinsic characteristics (Bass, 1990; Bensimon et al, 1989; Bryman, 1996; Fleishman, 1973; Jago, 1982). This approach tends to identify what leaders do rather than what traits they possess (Taylor, 1994). From such a perspective, leadership exists primarily in the actions of the leader (Jago, 1982).

From the Ohio Leadership Studies, two positive patterns of behavior (Dill \& Fullagar, 1987; Schermerhorn, 1997; Yuk1, 1998) emerged: consideration or relationshiporiented (friendliness, consultation, and openness of communication with subordinates) and structure-initiating or task-oriented (directing and clarifying subordinates' roles, problem solving, or criticizing poor work). Relationship-oriented structure involves the degree of two-way communication and consultation, mutual trust, respect, and warmth a leader exhibits toward his or her followers (Hoy \& Miskel, 1996; Jago, 1987). Taskoriented structure was defined as the degree to which a leader delineates his or her own role and the roles of subordinates to accomplish the group's task (Bass, 1957), and establishes well-defined patterns of organization, methods of procedure, and channels of communication (Jago, 1987). The Ohio State Leadership Studies used the Leadership Behavior Description Questionnaire (LBDQ) (Stogdill \& Coons, 1957) and the Supervisory Behavior Description (SBD) (Yukl, 1998).

The two patterns of behavior (initiating structure and consideration) were found to be separate and distinct in the Ohio State Leadership studies. For example, a leader could be high in initiating structure and high or low on consideration or the opposite might occur. The degree to which a leader exhibited one behavior was not related to the degree 
to which he or she exhibited the other behavior. However, Halpin (1957) contended that an effective leader had to demonstrate maximum success in both dimensions. Hoy and Miskel (1986) used four quadrants of leadership identified by the Ohio State Leadership Studies (Halpin \& Croft, 1966) to depict the behavior of effective leaders. They stated that effective leader behavior is most often associated with behaviors in both domains of initiating structure and consideration. Blake and Mouton (1964) agued that the two patterns of behavior are integral rather than distinct dimensions. Their Managerial Grid (Blake \& Mouton, 1975, 1976) model proposed that effective managers were those who showed extremely higher concern for both the people with whom they work and for task performance, rather than trading off one dimension against the other.

In addition to the Ohio State Leadership Studies and the Managerial Grid, Mintzberg's (1973) study has a substantial influence on behavior theories. By employing observational techniques, Mintzberg (1973) recorded the daily activities of five male executives to understand what managers actually do and discern what behaviors lead to effective management and leadership.

Although the behavioral model of research has provided substantial insight into the process of managerial work and those behaviors that appear to be influential, the limitations of the behavioral theories have been described in the literature. Yukl's (1998) study found that most research focused on individual behavior rather than examining them in combination or analyzing interactions between behaviors. Dill and Fullagar (1987) pointed out that the behavioral research had raised two critical questions: What is the process by which the activities other than relating to subordinates are carried out? What are the situational constraints that influence the success of a leader's relationships 
with subordinates? Although the later research attempted to address these questions, the trend in leadership studies began moving towards the contingency approach in the 1970s.

Contingency Theories. The situational approach, often called contingency theory (Bass, 1990), was first developed by Hersey and Blanchard (1969) in the late 1960s. The basic premise of this theory is that different situations demand different kinds of leadership. From this perspective, to be an effective leader means being able to adapt one's style of leadership to meet the demands of different situations (Bensimon et al, 1989).

Several different theories comprise this line of leadership research. Hersey and Blanchard's $(1969,1982)$ model developed directly dependent upon the key variables of the Ohio State Leadership Studies (Dill \& Fullagar, 1987) links relationship-oriented and task-oriented behaviors to the maturity of subordinates and their work experience. Immature subordinates receive more task-oriented behavior and less relationship-oriented behavior, while more mature subordinates receive the reverse. This model was used to determine the degree of subordinate maturity and help leaders select a corresponding style of leadership (Tucker, 1981). Four quadrants illustrated by Figure 1 (Hackman \& Johnson, 2000) have been used to depict the relationship between the two behavioral dimensions and the situational characteristics. In Quadrant 1, followers need specific guidance because they have low maturity, so the most effective leader behavior is high task-directed communication and low relationship-directed communication. Leaders in this quadrant must provide specific instruction and closely supervise performance. In Quadrant 2, the followers are moderately mature: they lack skills but have performance willingness. The most effective leader behavior with the followers in this quadrant is high 
task and high relationship. The followers need leaders' explanation and clarification of decisions. Those in Quadrant 3 are also skilled but unwilling to perform, so the most effective leader must encourage followers' involvement by using low task and high relationship behavior. The followers in Quadrant 4 have high maturity in both skills and willingness. The most effective leader behavior is low task and low relationship.

\section{Figure 1.}

Hersey and Blanchard's Situational Leadership Theory

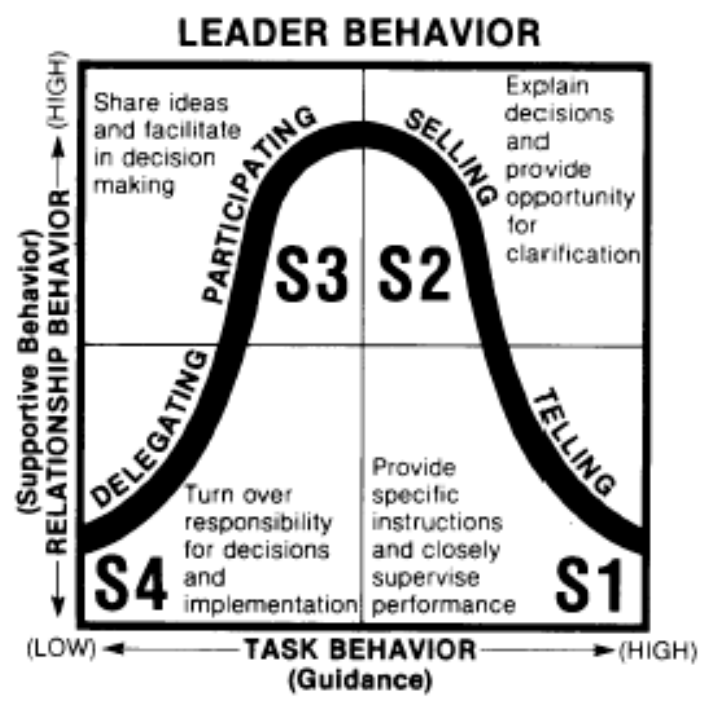

Another model is Fiedler's Contingency Model of Leadership Effectiveness, which claims that group productivity depends on the match between task as opposed to relationship behavior and the "favorableness" of the leadership situation (Fiedler, 1976, 1971; Fiedler \&Chemers, 1974). Fiedler's Least Preferred Co-worker (LPC) scale (Fiedler \& Chemers, 1974) was used to measure task versus relationship motivation. Fiedler (1967) defined favorable situation in terms of three critical dimensions: leadermember relations (i.e., trust, confidence, loyalty, following), task structure (i.e., clarity of goals and responsibilities, specificity of solution or outcome for the task), and position power (i.e., direction, evaluation, reward, punishment). Fiedler's research (1967) revealed 
that task-oriented leaders tend to perform best in very favorable or in very unfavorable situations and the relationship-oriented leaders tend to perform best in moderately favorable situation. Jago (1987) summarized Fiedler's findings (1967) and stated that, "Leaders perform best when there exists a match between person and situation" (p. 323). Fiedler's Contingency Model of Leadership Effectiveness has been subjected to many empirical tests.

Two other models are House and Mitchell's $(1974,1978)$ path-goal theory, and the Vroom-Yetton model (1773). The path-goal theory focuses on subordinate motivation and need satisfaction. Jago (1987) wrote that, "It is labeled a path-goal approach in that leader behavior is expressed in terms of the leader's influence in clarifying the paths or routes followers travel toward work and personal goal attainment." Like Fiedler's contingency model, House and Mitchell's path-goal approach prescribes a task-oriented leader who would do whatever is necessary to drive the group to complete a job (Bensimon et al, 1989). The Vroom-Yetton model departs from the previously-mentioned models and analyzes the decision-making component of leadership to identify the situational factors that determine the type of problem solving a leader should employ (Dill \& Fullagar, 1987).

Although these situational models provide useful contingencies and better insights into the processes required for leadership, the complexity of these models raises additional issues. Dill and Fullagar (1987) questioned why the situational model so consistently focuses on relationships with subordinates if relating to one's subordinates is only a part of the activity of managerial leadership. Like behavior theories, the research 
results of contingency theories were found to be inconsistent (Bryman, 1996). In the early 1980s, this approach became less popular.

Power and Influence Theories. Emerging in the late 1950s, power and influence theories focus on how effective leaders use power (Bensimon et al, 1989). Within this body of literature the terms influence, power, and authority are used in particular ways (Yukl, 1981). Dill and Fullagar (1987) wrote that, "Influence is the more generic term, defined as the effect of one party on the behavior of another party. Power is the potential of an agent to influence the behavior of a specified target person in the direction desired by the agent. Authority is the agent's right to exert influence; in organizations, authority most typically relates to the agent's position in the organizational hierarchy" (p. 392).

Power and influence theories fall into two types: social power theory and social exchange theory. Social power theory considers leadership in terms of the influence or effects that leaders may have on their followers (Bensimon et al, 1989; Ehrle \& Bennett, 1988). In this theory, leadership is viewed as unidirectional and focuses on sources or bases from which leaders can obtain power (Turley, 2002). French and Raven's (1968) typology of power has been frequently cited (Bass, 1990; Birnbaum, 1988; Birnbaum, 1992; Bolman \& Deal, 1997; Dill and Fullagar, 1987; Hughes, Ginnet \& Curphy, 1999; Yukl, 1998). French and Raven (1968) defined five bases of power. Reward power is used by leaders to shape and control behavior through reward dispersal. Coercive power provides leaders with opportunities to control their followers through use of sanctions or punishments. Legitimate power gives the leader the right through the acquired position to make requests of followers. Expert power refers to the leader has specialized knowledge and skills exceeding those of followers. Referent power means that the leader, by virtue 
of personal attributes, inspires followers to seek approval and emulate his or her behavior.

These five types of power can be grouped into organizational and personal categories (Hoy and Miskel, 1996). Legitimate, reward, and coercive power comprise the organizational category, where the higher the position, the greater the potential for power. In contrast, referent and expert power are more dependent on personal characteristics of the administrator such as knowledge and interpersonal skills.

Understanding of power can enhance an individual's effectiveness (Pfeffer, 1981), and understanding of the distinctions among the five types of power may make the most effective use of power (French \& Raven, 1968). Bachman's (1968) study in higher education found that use of expert and referent power by deans was significantly and positively associated with job satisfaction but had no effect on faculty productivity, whereas the other three types of power were significantly but negatively associated with job satisfaction. Other studies (Yukl, 1998) also found that expert and referent power have been positively correlated with subordinate performance and satisfaction.

While the social power approach emphasizes one-way influence, the social exchange approach focuses on mutual influence and reciprocal relationships between leaders and followers (Bensimon et al, 1989; Blau, 1964; Ehrle \& Bennett, 1988). It is developed on the basis of the exchange of rewards and costs to quantify the values of outcomes from different situations for an individual (Thibault \& Kelley, 1952). Selfinterest and interdependency are central properties of social exchange theory (Lawler \& Thye, 1999). Two or more actors, each of whom has something of value to the others, 
decide whether to exchange and in what amount. In this sense, the follower plays a critical and more active role in the leadership process.

Compared to trait, behavioral, and situational, the power and influence approaches are useful in studying of leadership because they recognize the follower's role in the leadership equation and the interactive nature of leadership. Power and influence theories also contributed to the emergence of transformational theories in the 1970s. However, the power and influence theories haven't considered the effects of context on leadership, and also have ignored the process by which influence is managed.

Transformational and Transactional Theories. The concept of transformational theories has been attributed to Burns (1978). Leadership is in evidence "when one or more persons engage with others in such a way that leaders and followers raise one another to higher levels of motivation and morality. Transforming leadership ultimately becomes moral in that it raises the level of human conduct and ethical aspiration of both leader and led, and thus it has a transforming effect on both" (Burns, 1978, p. 20). The five characteristics of transformational leaders are: creative, interactive, visionary, empowering, and passionate (Hackman \& Johnson, 2000).

Leaders should be able to create and promote a vision, and mobilize necessary commitments (Bensimon et al, 1989; Dill \& Fullagar, 1987). Bennis (1984) stressed that leaders should reach the souls of others by raising levels of consciousness, building meaning, and inspiring intent. To achieve this goal, the leader must exhibit vision (Bennis, 1984), charisma, individualized consideration, and intellectual stimulation (Bass, 1985). Transforming leaders are visionary leaders and appeal to their followers' "better nature and move them toward higher and more universal needs and purposes" 
(Bolman \& Deal, 1997, p. 314). In other words, the transformational theories consider a leader as a catalyst of change (Bennis, 1989; Covey, 1989; Kouzes \& Posner, 1995) who communicates high expectations and inspires followers through motivation to become committed. Charisma separates leaders from managers through infusion of loyalty, respect, enthusiasm, and a unique sense of determining priorities and mission (Bass, 1985). Charismatic leaders seek to convince the followers of their special gifts and of their solutions to address the crisis or problem. Thus, the followers feel safer and directed. In turn, leaders are respected and trusted by followers. Leaders stimulate and support followers to be creative and innovative. Leaders consider each individual or employee in a way that is particular to his or her needs is important.

Cameron and Ulrich (1986) proposed a five-step agenda for transformational leadership, a concrete application of theoretical works such as those of Burns (1978) and Selznick (1957): create readiness, overcome resistance, articulate a vision, generate commitment, and institutionalize implementation. However, Bensimon et al (1987) argued that in higher education, "following these steps might result in changes that make the campus more adaptable to the demands of the environment; it might not result in changes in the perceptions, beliefs, and values of campus constitutions that are at the core of transformational leadership as initially proposed" (p. 345).

By contrast, the transactional theory was described as a relationship between leaders and followers in that "leaders approach their followers with an eye to exchanging one thing for another" (Burns, 1978, p. 2). It focuses on the exchanges between leaders and followers. In the transactional leadership environment, leaders and followers are both engaged in a "bargaining process" (Small, 2002). Bass (1990) stressed that 
transformational leadership augmented the effects of transactional leadership in promoting the efforts, satisfaction and effectiveness of subordinates. In this sense, transformational leadership is an extension of transactional leadership with greater leader intensity and follower arousal (Hollander, 1993). In sum, transactional leadership results in expected outcomes. Transformational leadership results in performance that goes well beyond what is expected, getting followers to transcend their own self-interests for the good of the organization.

The transformational approach helps to expand the concept of leadership to better fit the variety of roles played by both leaders and followers, rather than just exchanges between them. It gives leadership a moral dimension, and provides a basis for comprehending the "irrational" aspects of organizational leadership, which can lead to outstanding performance (Dill \& Fullagar, 1987). The model, however, has some shortcomings: (1) it does not conceptually clarify whether transformational leadership is learned or simply discovered, (2) it views leaders as visionaries that may have a tendency to transform leaders' qualities to others, and (3) it lacks clarity as to who will determine whether the vision is good for the organization.

Cultural and symbolic theories. Cultural and symbolic theories of leadership focus on "shared meaning, paradigms, and shared languages and cultures" (Pfeffer, 1981, p. 9). Organizations are socially constructed and subjective entities, rather than rational and objective features (Tierney, 1989). From this perspective, leaders should create and maintain organizational paradigms and cultures (Schein, 1985). Leaders use the organization's tradition and values as a base for building a culture that provides cohesiveness and meaning. 
The symbolic approach emphasizes the communication and manipulation of symbols, myths, and sagas used by leaders to increases organizational commitment and individual motivation. Bass (1990) defined symbols as "signs that represent sets of cognitions" (p. 209). According to Tierney (1989), there are six categories of symbols that leaders may use to exhibit their leadership roles: metaphorical, physical, communicative, structural, personification, and ideational. Metaphors are figures of speech, which is used by a leader to provide participants with a portrait of how the organization functions. Physical symbols refer to the objects that are meant to mean something other than what they really are. Communication entails not only symbolic acts of oral discourse but also written communicative acts and nonverbal activities that convey particular meanings from a leader to a constituency. Symbolic structures refer to organization's structures. Symbolic personification refers to a leader's intent to represent a message with an individual or group. Ideas as symbols refer to images leaders convey about the mission and purpose of the organization. They "reside in a wide variety of discursive and nondiscursive message units: an act, event, language, dress, structural roles, ceremonies, or even spatial positions in an organization" (Peterson et al, 1991, p. 433). In the context of leadership, symbols are more than just "objectifications of meaning" (Turley, 2002, p. 51). Hence, leaders must know how to use symbols to "create and interpret their organizational reality" (Peterson et al, 1991, p. 433).

The cultural and symbolic theories made important contributions to the understanding of leadership, by emphasizing the subjective nature of reality. However, Tierney (1989) cautions that an effective leader should use the symbols that are consistent with the institution's culture. Bensimon et al. (1989) stress that a cultural or 
symbolic approach alone is not effective, but that it should be used as only one of several tools in the successful leader's repertoire.

Cognitive Theories. Cognitive theories are closely related to symbolic theories. Bensimon et al. (1989) explain that "leadership is a social attribution that permits people to make sense of an equivocal, fluid, and complex world" (p. 7). From the perspective of the cognitive approach, leadership is perceived by the participants in terms of their understanding of meanings in organizational occurrences (Markus \& Zajonc, 1985). Each person involved in the leadership process is considered to have his or her own implicit theory of leadership in that particular situation (Turley, 2002) expressed in frames, lenses, metaphors, cognitive maps and schema (Marcus \& Zajonc, 1985).

Cognitive models propose that people with low cognitive complexity tend to see things in black and white, whereas those with high cognitive complexity are able to discriminate many shades of gray, identify complex patterns of relationships, and predict future events from current trends (Turley, 2002; Yukl, 1998). A high degree of cognitive complexity tends to help leaders conform to prototypical models of what followers expect leaders to be, and understand critical factors and the relationship embedded in them.

In summary, the review of the leadership theories in this section has examined key definitions of what a leader should be, what a leader does, how a leader becomes more effective in particular situation, and what weaknesses each theory has. It is clear that some aspects of the earlier theories are still a part of the newer theories. It is also evident from above review that synthesis of theories emerging at the same time also continues to occur. It is important to recognize that none of the seven categories of theories is mutually exclusive or totally time-bound. Drawing on the cognitive theories, 
Boman and Deal (1989) argue that to be an effective leader, one should develop an awareness of the various theories of leadership and conceptual models of organizations to generate multiple descriptions of situations and multiple approaches to solutions. Understanding Bolman and Deal's leadership frame model will be helpful in this regard.

\section{Bolman and Deal's Four-Frame Leadership Model}

In this section, first, Bolman and Deal's four-frame leadership model is discussed in detail, followed by research on the model including within the higher education context.

Boman and Deal (1984) synthesized the major categories of organizational theories into "four relatively coherent perspectives" or "frames" (p. 4). Frames are considered as windows on the world and can be used to filter out some things while allowing others to pass through easily. They help leaders to decide what actions they should take to increase their effectiveness and get things done. The four frames defined by Bolman and Deal $(1984,1991 a, 1991 b, 1997)$ are the structural frame, the human resource frame, the political frame, and the symbolic frame. The structural and human resource frames are similar to the behavior approach by including task or initiating structure and consideration, respectively. The model also includes one significant feature of the transformational approach, namely, the cultural and symbolic frame. The Bolman and Deal's model also introduce a new dimension to leadership studies by adding the political frame. A discussion of each of these four frames follows.

Structural frame. The structural frame is derived from behavior theories by including the characteristics of task or initiating structure (directing and clarifying subordinates' roles, problem solving, criticizing poor work). The frame emphasizes the 
importance of goals, formal roles, relationships, and productivity (Bolman \& Deal, 1984, 1991a, 1993, 1997, 1999). Structural leaders focus on structure, strategy, environment, implementation, experimentation, and adaptation. From the perspective of the structural frame, organizations assign responsibilities to participants and make policies, develop plans, create procedures and hierarchies to coordinate activities. The productivity of an organization depends on the degree of the clarity of organizational goals and roles for people defined by leaders, and the coordination of individuals and groups through both vertical (command, rule) and lateral (face-to-face, informal) strategies (Balman \& Deal, 1993).

Human resource frame. The human resource frame is similar to the considerationoriented pattern of behavior. The fundamental assumption for this frame is that organizations are inhabited by people who have feelings, prejudices, skills and limitations (Bolman \& Deal, 1984, 1997), and need concern (Bolman \& Deal, 1993), respect and trust. It focuses attention on human needs. Human resource leaders believe in people and communicate their belief; they are visible and accessible; they motivate participation, support, share instructional, and move decision making down into the organization. To be an effective leader, he or she must understand how to "tailor organizations to people" (Bolman \& Deal, 1984, p. 5), and also "adjust the people to fit the organization" (Bolman \& Deal, 1991, p. 4) in order to enable participants to feel good when they are doing their job (Bolman \& Deal, 1984). The organization works best when the participants' needs are met.

Political frame. The political frame borrows ideas from political science (Bolman \& Deal, 1991, 1997). The frame focuses on the individual and group interests, which 
cause a continuous competition for scarce resource. Conflict is inevitable, and even becomes a normal by-product of collective action (Bolman \& Deal, 1984, 1991, 1993, 1997). Political leaders clarify what they want and what they can get. They assess the distribution of power and interests, build linkages to other stakeholders, and use persuasion first, then negotiation, coercion and compromise.

Symbolic frame. Similar to cultural and symbolic theories of leadership, symbolic frame centers on symbols, meaning, and faith (Bolman \& Deal, 1991). Organizations are considered to be held together more by shared values and culture than by goals and policies. In turn, organizations create symbols and culture that shape human behavior and provide participants with a shared sense of mission and identity. Symbolic leaders view organizations as a stage or theater to play certain roles and give impressions. These leaders use symbols, myth, ritual, ceremony, stories to capture participants' attention. Finally, they discover and communicate a vision.

To sum up, each of Bolman and Deal's frames represents a distinctive lens that help leaders to determine what is important and what can be safely ignored (Bensimon et al. 1989). Together, they provide a more complete picture of leadership than the single leadership theories. They can be used by leaders to view organizations and diagnose situations. The frames can also be used in decision-making in order to maintain effective organizations, and to interpret the results of their actions. However, Bolman and Deal (1997, p. 266) wrote that, "Organizational life is always full of simultaneous events that can be interpreted in a variety of ways." Therefore, any one of these frames alone would be inadequate. When used in combination, the approach can provide leaders with a more 
complete organizational image on which leaders can make clear judgments and improve effectiveness (Bensimon, 1989; Birnbaum, 1988; Bolman \& Deal, 1984, 1991a, 1997). Bolman and Deal's Research on the Four-Frame Model

Bolman and Deal and others (Bensimon, 1989) have conducted a series of empirical investigations related to the use of four-frame leadership model. The questions they addressed basically in these investigations included how many and which frames leaders use. The methods they used are both qualitative and quantitative. According to Boman and Deal (1991, p.5), "Qualitative methods are particularly effective in getting at the subtleties of how leaders think and how they frame their experience. Qualitative methods are particularly useful in examining the relationship between the frames of leaders and their constituents."

Bolman and Deal $(1991,1992)$ have used a qualitative method to determine how many frames leaders use and which frames they use, focusing on the frames embedded in narratives that leaders provide about their experience. The criteria for coding frame responses are split into two categories for each frame: frame-related issues and framerelated actions (Bolman \& Deal, 1992). Examples using this approach are Florida School Administrators ( $n=48)$ (Bolman \& Deal, 1992), Singapore School Administrators ( $n=220)$ (Bolman \& Deal, 1992), Higher Education Administrators $(n=75)$ (Bolman \& Deal, 1991a), and Midwestern State School Administrators ( $n=15)$ (Bolman \& Deal, 1991a). The results in all four samples show that leaders rarely use more than two frames and hardly any use all four frames: in every sample the percentage of leaders who used more than two frames was less than 19 (Florida School Administrator), and the number who used four frames was 6 percent or less. All four studies found that more than half of 
leaders used two frames (55\%). With respect to which frame was employed, Florida School Administrators and Singapore School Administrators were different from the other two populations. In both Florida and Singapore, the human resource frame was dominant in principals' critical incidents (58\% for Florida and 55\% for Singapore), whereas participants in the studies of Higher Education Administrator and Midwestern State School Administrator most frequently used political frame (59\% for higher education and $70 \%$ for Midwestern State). In all four samples, the symbolic frame was least often used.

In the quantitative investigations, Bolman and Deal (1990, 1991, 1992, 1993) utilized a survey instrument, "Leadership Orientation." Described in detail in Chapter 3, the instrument has two parallel forms (self and others), and two sections for each form. The first section is organized into eight separate dimensions of leadership, two for each frame. The second section contains a series of forced-choice items. Bolman and Deal (Bolman \& Deal, 1991b, 1992) have employed their instrument to collect data from respondents in schools (140 school administrators from the United States, and 274 school administrators from Singapore), higher education (145 higher education administrators), government, and the private sector (90 senior managers from a multinational corporation).

Bolman and Deal's (1992) quantitative research found that individual or combined frames were significantly associated with the measure of effectiveness. The structural frame is a better predictor of managerial than leadership effectiveness, while the reverse was true for the symbolic frame. The human resource and political frames are significantly associated with success of both leaders and managers. The findings did not 
support the conventional stereotypes that women would score higher on the human resource frame (warm, supportive, participate) and lower on the political frame (powerful, shrewd, aggressive) than men (Bolman \& Deal, 1992).

In summary, the frames can be measured using both qualitative and quantitative methods. The Leadership Orientation instrument is able to predict effectiveness as both manager and leader. Both qualitative and quantitative results suggest that the ability to use multiple frames is critical to effectiveness as both manager and leader.

\section{Research Using Bolman and Deal's Four-Frame Model}

An increasing body of research has used the Bolman and Deal's four-frame leadership model, either qualitative or quantitative approach or both, to investigate leadership. It has examined in higher education (Bensimon, 1989; Bethel, 1998; Borden, 2000; Cantu, 1997; Crist, 1999; Echols Tobe, 1999; Gilson, 1994; Mathis, 1999; McClellan-Holt, 2000; Mosser, 2000; Redman, 1991; Reichard, 1990; Scott, 1997; Small, 2002; Turley, 2002; Van der Veer, 1991), elementary and secondary school studies (Bigham \& Reavis, 2001; Burks, 1992; Cote, 1999; Eckley, 1997; Harlow, 1994; Kniewel, 1999; Messer, 2002; Miro, 1993; Strickland, 1992; Suzuki, 1994), and government and business studies (Bolman \& Deal, 1991b; Childress, 1994; Eck, 1997; Knudsen, C. K., 2000). The major results and findings of the selected studies in higher education are discussed in this section to help understand leadership from the frame perspective.

Bensimon (1989) examined the utilization of the leadership frame of 32 college presidents. The results indicated that 13 presidents utilized a single frame (40.6\%), 11 utilized two frames (34.4\%), 7 utilized three frames (21.9\%), and 1 utilized four frames 
(3.1\%). Findings show that the theories of leadership presidents espoused were more likely to have a single or paired-frame orientation than a multi-frame orientation. The findings also revealed that new presidents were likely to use a single-frame orientation. Also the frames used were associated with the institutional type of control: the university presidents tended to use paired- and multi-frame theories, while community college presidents most likely utilized single-frame theories.

Turley (2002) used qualitative and quantitative methods to examine the extent to which radiation therapy program directors exhibit multi-frame leadership. The study found that the human resource and structural frames showed the greatest frequency of use on both the qualitative and quantitative measures. Forty-four percent of respondents espoused multi-frame leadership on the quantitative instrument, whereas $60 \%$ were rated multi-frame leaders on critical incidents. Significant relationships were discovered between gender and consistent use of the human resource, political, and symbolic frame. Turley (2002) suggested in this study since leadership effectiveness is most associated with use of the political and symbolic frames, it is important for radiation therapy program directors to develop greater strengths in these frames.

Borden (2000) investigated the utilization of leadership frames by area campus administrators as well as the relationship between frame usage and size of campus, campus type, highest level of coursework offered, highest level degree program, years in current position, current position title, years as an administrator, administrators' highest level of education, gender and age. The area campus administrators' self-ratings of leadership effectiveness and managerial effectiveness were also examined. The results indicated that the human resource frame was the primary frame used by the area campus 
administrator; the symbolic frame was the second most frequently used frame; the political frame was the least used one. Nearly half (47.2\%) of the administrators used multi-frame leadership. Campus type, highest level of coursework offered, and highest degree offered (in its entirety) all exhibited a significant relationship with frame usage. Age didn't have an impact on political frame usage. Frame usage for the area campus administrators did not differ based on size of campus, years in current position, position title, years of experience as an administrator, and gender. Area campus administrators rated themselves slightly higher on managerial effectiveness than leadership.

Bassoppo-Moyo (1999) examined the relationship between leadership orientations or frames of department chairs at the four-year Tennessee Board of Regents (TBR) institutions and chairs' usages of academic program review results as part of the state's performance funding program. The findings indicated that the symbolic leadership frame had a statistically significant positive relationship with three types of usages for program review results: conceptual usage, direct usage, and incremental usage. Department chairs exercising symbolic leadership that inspires others and communicates a strong sense of vision are more likely to use academic program review results to understand the academic program (conceptual), make decisions in the short-term (direct), and do long-term planning (incremental).

Mathis (1999) analyzed the relationship between faculty job satisfaction and the leadership frame use of the departmental chair, as perceived by the faculty member. The chairs in this study most frequently used the human resource frame (47.7\%). The political and symbolic frames, together, only accounted for $23.3 \%$ of all the observations. Significant differences were found between the predominant leadership frame of the chair 
and all three categories of the subordinate faculty member's job satisfaction. Faculty with chairs using a symbolic predominant frame expressed higher intrinsic and overall job satisfaction scores than that of faculty with chairs using any other predominant frame. In the case of extrinsic job satisfaction, both the symbolic and the human resource frames were superior to the structural frame while the symbolic frame also was superior to the political frame. This study also found significant differences between the number of frames that the chair used (frame score above the fiftieth percentile for the given frame) and all three categories of faculty job satisfaction. Faculty with chairs using multiple frames expressed higher intrinsic, extrinsic, and overall job satisfaction scores than that of faculty with chairs using either only one frame or no frame.

Cantu's (1997) study was designed to investigate whether significant differences existed among the leadership frames of randomly selected academic deans and academic deans nominated as exceptionally effective from 426 public master's colleges and universities and doctorate-granting Institutions across the United States. The research results indicated that academic deans predominantly utilized the human resource frame in their leadership orientations. Next, deans tended to use the structural, political, and symbolic leadership frames. Comparisons between dean groups revealed that effective academic deans had a significantly higher political frame orientation than did randomly select academic deans. Significant differences also existed in the political frame of randomly selected academic deans with less experience (5.1 to 7.5 years) compared to randomly selected academic deans with more experience (10.1 or more years). Randomly selected academic deans with less experience had a lower political frame orientation than did randomly selected academic deans with more experience. 
In his research, Presidential Administrative Teams' Leadership Styles at Public University in Illinois, Carter (1995) found that the strongest leadership orientations by the administrators were the human resource and structural frames. The political category was seldom used. Several, but not all of the organizations that participated in this study were identified with administrators practicing all four leadership frames. The team with only three leadership frames present was found to be just as effective as the teams with all four leadership frames present.

Small (2002) examined the relationship between the leadership frames of nursing chairpersons as perceived by the faculty and the organizational effectiveness of nursing departments as perceived by faculty and chairpersons. The findings demonstrated that chairs are perceived by faculty members as using no frames the most, followed by all four frames, single frame, multi-frame, and paired frame. Of the single leadership frames, faculty perceived chairs to use the human resource frame the most. This was followed by the structural frame, symbolic frame, and political frame. Statistically significant relationships were demonstrated between the single frame and all four domains of organizational effectiveness. Additionally, there were significant differences between the organizational effectiveness scores of low versus high leadership frame scores.

Mosser's (2000) study examined the relationship between the leadership frames of nursing chairpersons and the organizational climate of nursing departments as perceived by the nursing faculty. The findings indicated that faculty members perceived their chairpersons to use the human resource frame the most followed by the structural frame, the symbolic frame, and the political frame. Statistically significant relationships were demonstrated between single frame nursing chairperson leadership styles and 
organizational climate domains and between the various combinations of leadership frames of nursing chairpersons and organizational climate domains. Nine low, but statistically significant correlations were found between chairperson leadership frames, organizational climate domains, and selected demographic variables.

From the review of these studies, it was found that human resource frame is the mostly used frame by higher education administrators (Borden, 2000; Cantu, 1997; Carter, 1995; Mosser, 2000; Small, 2002; Turley, 2002). This result is the same as that of Bensimon (1989) and Bolman and Deal (1992) discovered in their studies. The political frame is the least used one (Borden, 2000; Carter, 1995; Mathis, 1999; Mosser, 2000; Small, 2002). However, the symbolic frame has a significantly positive influence on leaders' effectiveness (Turley, 2002), and faculty intrinsic, extrinsic and overall job satisfaction (Mathis, 1999). Many studies (Borden, 2000; Mosser, 2000; Small, 2002; Turley, 2002) indicated that about 50 percent of higher education administrators use multi-frame leadership theories. Compared with Bolman and Deal's $(1991,1992)$ finding, this proportion is much larger. However, the conclusions are the same in that leaders using multiple frames are more effective.

\section{Leadership of Academic Department Chairs}

The academic department is the base unit of universities and colleges. It provides a useful structure for the day-to-day activities that shape faculty members' attitudes, behaviors, and performances (Seagren \& Others, 1993). Department chairs make approximately $80 \%$ of all decisions on college campuses, and are primarily responsible for both the budgeting and planning activities of the academic enterprise (Dyer \& Miller, 1999; Knight \& Holen, 1985). Therefore, the academic department chair position is one 
of the most important positions in academe (Ehrle, 1975; Barge \& Musambira, 1992), and vital to the operation of higher education institutions (Dyer \& Miller, 1999). Tucker (1984) wrote that, "A brilliant university or college administration with inept chairs cannot survive; an inept administration, with the help of a group of brilliant chairs, usually can" (p. 4). Bennett (1988) claimed that the quality of an institution's educational program depends almost entirely on the effectiveness of its department chairpersons. In this section, literature related to leadership of academic department chairs is reviewed and discussed from the perspective of various leadership theories.

Department leadership is more important today than ever before because of the public scrutiny of college faculty, and increasing complexity and a corresponding need for change in higher education (Lucas, 1994). A vast body of research (Bowman, 2002; Creswell, Wheeler, Seagren, Egly, \& Beyer, 1990; Gmelch \& Miskin, 1993; Leaming, 1998; Lindholm, 1999; Litecky, 1988; Lucas, 1994; Seagren, Creswell \& Wheeler, 1993; Stark, Briggs \& Rowland-Poplawski, 2000) provides a detailed picture of the challenging roles and responsibilities of effective department leaders, and also how to enhance department leadership.

Chairs of academic departments in 1990s were expected to perform in an increasingly complex, diverse, and changing environment, with ever-increasing expectations from the institution and the faculty. Ehrle and Bennett (1988) state that chairs are challenged by the issue of "divided loyalty" (p. 10). This is most evident in how chairs handle relations between their deans and faculty. Seagren et al. (1993) concluded,

The chair is squeezed between the demands of upper administration and institutional expectations on the one side and 
the expectations of faculty, staff, and students on the other, with both attempting to influence and shape the chair. This chair is caught in the middle, required to provide the most sophisticated leadership and statesmanship to avoid being crushed by these tow opposing forces (p. iii).

Academic department chairs play four main roles in achieving academic results (Carroll \& Gmelch, 1992; Gmelch \& Miskin, 1993). As a faculty developer, chairs are involved in selecting and evaluating faculty and strengthening faculty moral and their professional development by providing the informal faculty leadership. Acting as a manager, chairs spend most of their time in managing department activities. The role of a leader is described to provide direction and vision for the department, solicit idea to improve the department, plan and evaluate curriculum development, conduct department meetings, and participate in college and university committees to keep faculty informed of external concerns. The last role of chairs is that of a scholar who continues to teach, and for those in research universities, maintains an active research program. Of these four roles, the roles of leader and faculty developer are key to effective departmental functioning (Heimler, 1972; Lucas, 1994).

Creswell et al. (1990) studied 200 department chairs and identified five strategies for the roles as an academic leader: creating a collective department vision; developing faculty ownership of the vision; initiating changes slowly; allocating resource of time, instructional, and assignments to encourage vision; and monitoring the progress toward vision achievement. They also discovered seven strategies academic chairs can employ to create a positive interpersonal work environment: establishing an open atmosphere to build trust; considering faculty needs, interests and aspirations; collaboratively setting goals; enhancing the pride and self-esteem of the faculty member; representing faculty to 
colleagues and senior administrators; serving as a role model and mentor; and motivating and supporting faculty.

Academic chairs function as managers when they focus on structures, policies, processes, and paperwork; otherwise they function as leaders when they focus on key aspects of organizational culture: mission, vision, engagement, and adaptability (Bowman, 2002; Collins \& Porras, 1994). Table 2 presents 17 traits of effective department leaders identified by Leaming (1998). Although traits can not ensure strong leadership, the existence of certain traits is likely to increase a leader's effectiveness (Luthans, 1992).

Table 2

Leadership Traits of Academic Department Chairs

\section{Traits}

Not coveting the job

Having a sense of humor

Having vision

Staying focused

Delegating responsibility

Knowing yourself

Not being fearful of making mistakes

Being Self-confident

Being decisive

Accepting blame for failure and sharing credit for success

Embracing change

Being sensitive and caring

Possessing strong communication skills

Providing ideas and being flexible

Having a good work ethic

Being honest and fair

Knowing when to spend your political capital

Coates' (2000) study of interpersonal behavior and the community college department chairperson found that effective chairs are those who perceive themselves as 
being included by others in their interactions and associations. The significance of the inclusion indicates that mutual trust and respect, and openness of communication with faculty must be established. This finding is consistent with the pattern of consideration of behavior leadership theories.

According to Hecht, Higgerson, Gmelch and Tucker (1999), academic department chairs have some positional power, and this presents an opportunity to influence the direction of the department. However, Riley and Baldridge (1997) argued that department chairs ranked lowest in positional power among college administrative officials, lower even than regular faculty members. Therefore, knowing how to use personal power is important for an effective chair. The academic department chairperson's personal power is derived from peer's respect for and the commitment to the chair (McArthur, 2002). In this sense, faculty interests must be considered and followed. (Roach, 1976).

Research (Austin, 1994; McArthur, 2002) in the study of the academic department chairs acknowledges the significance of culture and climate at the departmental level for the effectiveness of academic leadership. Bowman (2002) stated that a department is "a culture of dispersed leadership" (p. 158). Austin (1994) emphasized that departmental culture is also called 'institutional subculture' and characterized as by norms, values, and behavior patterns. The culture has various components: departmental mission and goals, the leadership style of the chair, the characteristics of students and faculty, and the physical environment (Austin, 1994). Exploring the departmental culture and climate helps chairs better understand the faculty 
with whom they work and help the faculty better understand each other. In addition, department chairs are also the key figures to create and maintain departmental culture.

Treadwell (1997), from a symbolic perspective, suggested two advances that are essentially relevant to the chair's role as an effective leader. First, the chair should recognize the need for departments to have a long-term vision, or image of the future that can be compelling and motivational to others by distinguishing the routine maintenance and future-oriented leadership (visionary). Secondly, the chair should understand the importance of an individual's subjective responses to the department. Chairs have relatively little control over tangible resource such as budgets and facilities (Pfeffer, 1977), so the effective tools for the chair to influence the department are not spreadsheets, but myth, stories, interpretations, symbols, images and culture (Treadwell, 1997).

Department chairs should be creative team leaders. They are responsible for developing a climate conducive to motivating faculty and encouraging scholarship. They also need to create a supportive communication climate that emphasizes good listening skills, thus demonstrating respect and empowerment for faculty and students. In addition, team leadership is the foundation on which successful change or creativity or innovation projects are built (Litterst, 1993; Lucas, 2000). Many researchers have identified numerous qualities of a creative or innovative leader. A creative leader should be responsive to the nature of the creative faculty (Brown, 1977), and have a willingness to experiment and buck convention (Yukl, 1998; Conger 1989), and to take risks (Sinetar, 1985). A creative leader should also see himself or herself as change agent (Tichy \& Dvanna, 1986) and encourage difference of opinion (Hall, 1980). Hackman and Johnson 
(1991) stress that a creative leader should practice lateral thinking, allowing integration of right brain and left brain functions.

The academic department, as the primary educational enterprise on campus or a context for teaching and learning (Trow, 1977), is responsible for providing most of an institution's instruction. Therefore, the department must play a key role in improving the quality of students' educational experiences. The mantle of frontline leadership for this change falls on the shoulders of the department chair (Gardiner, 2000). Lucas (1994) emphasized that chairs must make teaching effectiveness a high-priority goal of the department. Greenfield (1985) defined this as value leadership, in which values are considered to be the conception of what is held to be desirable by individuals, group or organization. The values are composed of the organizational and instructional arrangements and achievements associated with effective teaching and learning. Being a value leader means developing commitment among faculty toward the pursuit of both organizational and educational goals. Greenfield (1985) stresses that it is important to note that an effective value chair tries to share the organizational meaning with others and encourage them to involve in a critical dialogue rather than impose his or her own values on faculty.

In summary, the nature of an institution comprising a wide spectrum of disciplines, educational goals, and research activities requires dependence on academic department leaders. Therefore, they are expected to demonstrate a diverse set of leadership capabilities: well-honed communication skills, problem-solving skills, conflict-resolution skills, cultural-management skills, coaching skills, and transitionmanagement skills. In essence, effective department chairs are anticipated to use multi- 
frame leadership in dealing with increasingly complicated issues in higher education. The chair's role in and the possible relationship associated with faculty utilization of instructional technology in teaching is discussed in detail in the third section of this chapter.

Utilization of Instructional Technology in Teaching Courses and the Chair's Responsibility

American higher education has long experimented with various technological innovations to deliver instruction, including radio, television, videotape, and computers (Bullock \& Ory, 2000). However, how to effectively incorporate instructional technology into the teaching-learning process is still an important component across all areas of higher education (Groves \& Zemel, 2000). To accomplish this goal, the U. S. Department of Education (1996) established meeting the challenge of technology as a critical goal for American educational system. In recent year, a vast of body of research (Bullock \& Ory, 2000; Green, 2002) has found that the use of instructional technology has greatly increased. In this section, the literature related to instructional technology in higher education is reviewed in the areas of definition, instructional technology infrastructure, faculty utilization, technical and administrative support for faculty utilization of instructional technology in teaching courses, and current issues and challenges to adopt instructional technology for teaching. In addition, a discussion of an academic department chair's responsibility to motivate faculty utilization of instructional technology in teaching courses is incorporated into each area.

Although the term "instructional technology" appeared as early as in 1963, there is no single, acceptable definition of instructional technology dominating this field 
(Roblyer et al., 1997). For most of faculty, any mention of technology in education immediately brings to their mind the use of some device or a set of equipment, particularly computer equipment. However, instructional technology is not just a collection of machines; it focus on the process of applying tools for educational purposes, as well as the tools and materials that are used (Muffoletto, 1994; Roblyer et al., 1997). Haines, Belland, Concelcano-Runlee, Santos and Rothenberg (2000) wrote that the Association for Educational Communications and Technology (AECT) officially adopted the following definition of instruction technology: "Instructional (educational) technology is the theory and practice of design, utilization, management and evaluation of processes and resource of learning” (Seels \& Richey, 1994, p. 1).

\section{Instructional Technology Infrastructure}

As defined in Chapter One, instructional technology infrastructure consists of facility infrastructure, system infrastructure, and personnel infrastructure. According to the explanation of Survey on How Technology Infrastructure Is Financed (2003), facility infrastructure, also called building infrastructure, includes those components that need to be incorporated into a facility to make any technology operate effectively. They are: (1) conduits/raceways through which computer and computer network cables are laid in the building, (2) the cables and electrical wiring for computers and other communications technology, and (3) the electrical power and related building features such as electric outlets. Systems infrastructure links up various technology components. For example, computer network infrastructure consists of the software that runs the networking function. It links all computers in a class or in a college, or the computer in the college with computers in the outside world-as well as special pieces of hardware such as servers 
(computers with large information storage capabilities that allow many users to share information) whose purpose is to run the network. Internet service providers (ISPs), licensing and authentication systems are another element. Modems-devices that allow computers to communicate with each other through the phone lines-are another basic component of systems infrastructure, in addition to routers, switches, and hubs. Systems infrastructure links data, voice, and video and even multimedia systems. Wireless technology would be included in the category. Personnel infrastructure includes the human resource necessary for the efficient and effective operation of the Technology Infrastructure. Specifically, personnel infrastructure encompasses the human resource included for (1) network management, (2) training and technical assistance, (3) course content development, (4) administrative support, and (5) student support services related to technology mediated instruction.

Dolence and Norris (2000) note that technology infrastructure is key to transformation of higher education. Daniel's research (2002) identifies that there is a significant correlation between deans' satisfaction with technology infrastructure and faculty efforts to integrate technology into their teaching courses. This finding suggests that having an adequate technology infrastructure is an essential precursor to faculty integrating technology into the classroom. Metz (1998) highlights that higher education must build and maintain a robust, comprehensive technology infrastructure to provide the foundation for services required today and into the next century. The successful adoption of an instructional technology infrastructure by a college or university will cause fundamental changes in the culture of the organization (Siegel, 2003). 


\section{Faculty Utilization of Instructional Technology in Teaching Courses}

To keep informed about how technology can improve education, one must remain aware of the equipment configurations that are available. Roblyer et al. (1997) stated that there are four types of hardware/software configurations in instructional use in education: standalone personal computers, networked stations, interactive video and multimedia stations, and virtual reality systems. Most computing resources in education today are variations or combinations of these configurations. With these configurations, many types of technologies can be used in combination for the purpose of teaching and learning. Table 3 shows a list of these technologies that have been used by faculty to enhance education (Hashem, 2000; Hashem, Crawford \& Stohkirch, 2000).

\section{Table 3}

Types of Technologies

\section{Types of Technology}

Voice mail
Facsimile
Digital instructional services
Teleconferencing
Data-conferencing
Video-conferencing
Groupware
Internet
Electronic mail
Usenet news-groups
Internet relay chat
Telephoning on the Web
File transfer
Group support system
Computer/data communication

Evaluation of instructional technology on the impact on teaching and learning is another significant component that influences the adoption of new technology by faculty. 
Over the years many associated efforts have been made to study this impact using multiple data collection methods and various evaluation models or approaches (Bullock \& Ory, 2000; Groves \& Zemel, 2000; Huff \& Malcolm, 1985; Spotts \& Bowman, 1995). Bullock and Ory (2000) cited McKenna that the common methods used include exams and quizzes, audit trails, tracking tools, teacher and student journals, classroom observations, videotaping, questionnaires, interviews, and focus groups. Bullock and Ory (2000) also generalized six commonly used models by the researchers in this field. Quasiexperimental comparative approach is one of the most often used models. It focuses on the comparison of one instructional innovation approach to another or to a traditional method of instruction. The second model is objective-based evaluation, which emphasizes the assessment of predefined student outcomes, whereas the third approach, goal-free evaluation, attempts to assess all program attainments, both intended and unintended. Using observations, questionnaires, and documents, illuminative evaluations are most commonly used to interpret the impact of the technology rather than measure the impact. The integrative model focuses on the evaluation of how computer assisted learning material can be more effectively integrated into the overall learning situation.

The findings of the relevant studies were not always consistent. Russell (1999) reviewed 355 studies that evaluate the impact of technology-enhanced instruction and concluded that there is no significant difference on a variety of outcome measures between students taught using technology and those who were not. However, other investigators (Ester, 1995; Khali \& Shashaani, 1994; Kulik \& Kulik, 1991; Martin \& Rainey, 1993) argued that some studies did not find significant difference because they were inadequately designed. Bates (2000) stressed that compared with the traditional 
classroom teaching, new technologies have many advantages by developing and facilitating higher-order and constructivist learning skills, such as problem solving, decision making, analytical reading, creative writing, and critical thinking. Draude and Brace (1999) investigated student perspectives about the impact of instructional technology on teaching and learning, and concluded that use of instructional technology positively affects student learning by increasing student interest and satisfaction, and facilitating learning activities. Holdren and Balnenship's (1998) study found that advances in technology are increasing the capacity to communicate greater quantities of instruction to students in a manner that increases learning while providing a more efficient use of time. Many educators also believe that well-designed simulations can provide an opportunity for students to apply classroom knowledge to more complex, realistic situations, improving the learning process (Gatlin-Watts, Arn and Kordsmeier, 1999). Obviously, to successfully determine the effectiveness of technology-based teaching and learning, more and better studies need to be done (Van Dusen, 1998). In spite of the controversy of its effectiveness, the use of instructional technology in higher education has been growing rapidly, and a vast line of research has been done to investigate faculty use of instructional technology. The most often used method to investigate the use of instructional technology is survey research. One of the most famous projects is the Campus Computing Project, which was founded in 1990 by Green and focuses on the use of instructional technology in higher education. Every year, the survey is sent to the chief academic officer at two-year and four-year colleges and universities across the United States to collect data. Many other studies collected data from faculty directly. In 1995, Spotts and Bowman (1995) used the instrument developed by 
themselves to examine faculty use of instructional technology in teaching. In 2000, Groves and Zemel (2000) utilized the revised instrument developed by Spotts and Bowman (1995) to investigate faculty and GTA (graduate teaching assistant) use of instructional technology in teaching.

The results of these studies reveal that an increasing number of faculty members have been integrating instructional technology into their teaching. Green (2000) found that 59.5 percent of all college courses utilized E-mail, up from 54.0 percent in 1999, 44.0 percent in 1998, and 20.1 percent in 1995. Similarly, 42.6 percent of college courses used Internet-based resource, up from 10.9 percent in 1995, 33.1 percent in 1998 and 38.9 percent in 1999. Almost a third (30.7) percent of all college courses have a Web page, compared to 28.1 percent in 1999, 22.5 percent in 1998 and 9.2 percent in 1996. A comparative result of the studies of Spotts and Bowman (1995), and Groves and Zemel (2000) is presented in Table 4. Among eight variables examined by both studies, seven reveal growth of the use from 1995 to 2000. Only one variable, computer-aided instruction, remains relatively stable. However, this is probably because Groves and Zemel (2000) added two more variables, Intenet/World Wide Web and Electronic Discussion Lists, which actually overlap. 
Table 4

Faculty Use of Instructional Technology in Teaching in 1995 and 2000

\begin{tabular}{|c|c|c|c|c|c|c|}
\hline \multirow[t]{2}{*}{ Technologies } & \multicolumn{2}{|c|}{$\begin{array}{c}\text { Weekly to Every } \\
\text { Class }(\%)\end{array}$} & \multicolumn{2}{|c|}{$\begin{array}{c}\text { Once/Semester to } \\
\text { Monthly (\%) }\end{array}$} & \multicolumn{2}{|c|}{$\begin{array}{l}\text { Never } \\
(\%)\end{array}$} \\
\hline & 1995 & 2000 & 1995 & 2000 & 1995 & 2000 \\
\hline Word processing & 55 & 80 & 20 & 15 & 25 & 5 \\
\hline Computer spreadsheets & 19 & 39 & 22 & 23 & 59 & 38 \\
\hline Video & 18 & - & 64 & - & 18 & - \\
\hline Electronic email & 16 & 40 & 15 & 33 & 69 & 27 \\
\hline Computer-aided instruction & 13 & 6 & 16 & 22 & 71 & 72 \\
\hline Statistical computing & 12 & 18 & 27 & 55 & 61 & 27 \\
\hline Audio & 12 & - & 43 & - & 45 & - \\
\hline Film & 8 & - & 57 & - & 35 & - \\
\hline Computer conferencing & 7 & - & 6 & 一 & 87 & 一 \\
\hline Presentation software & 6 & 43 & 18 & 27 & 76 & 30 \\
\hline Distance learning & 3 & 0 & 4 & 9 & 93 & 91 \\
\hline Multimedia use in class & 2 & 6 & 15 & 22 & 83 & 72 \\
\hline $\begin{array}{l}\text { Multimedia for individual student } \\
\text { learning }\end{array}$ & - & 4 & - & 17 & - & 79 \\
\hline Internet/World Wide Web & - & 45 & - & 32 & - & 23 \\
\hline Electronic Discussion Lists & - & 18 & - & 27 & - & 56 \\
\hline
\end{tabular}

Although instructional technology has the potential to enhance teaching and improve learning, faculty cannot adopt a combination of new teaching approach, application of technology, and instructional materials as easily as they might pick a new textbook for a course. Frayer (1999) advocated that colleges or universities should create a campus culture to support a teaching and learning revolution. Within this culture, faculty should be encouraged to learn about the successful use of educational technology, stimulated to think about how technology might be used to help students attain their learning goals. They must also be provided with information about the teaching and 
learning process, effective technology-based pedagogical strategies, the availability of technology resource appropriate to their needs, and rewarded for their successful use of instructional technology. To successfully establish this kind of culture, the role of academic departments is critical. In the following sections, the roles of department chairs in integrating instructional technology into teaching are described.

Technical and Administrative Support for Faculty Utilization of Instructional Technology in Teaching Courses

Besides the factors discussed previously, there are many other factors that potentially affect the adoption of instructional technology in teaching in higher education (Bates, 2000). Marcus' (1995) research found that social context variables are as important as resource in encouraging integration of technology. One of these factors is the technical support from the technical staff and administrative support from academic department chairpersons (Frayer, 1999).

Bates (2000) defined the significant roles of the department chairs in technology decision making as follows.

- Define priority subject and topic areas for the use of technology.

- Identify new target groups that could be reached through the use of technology.

- Identify areas of support available elsewhere in and outside the institution, and determine the organizational and support staffing for technology-based teaching that needs to be provided by the department.

- Identify the role of and priorities for face-to-face teaching in an increasingly sophisticated technology-based learning environment.

- Decide on key areas of investment and resource allocation for technology-based teaching (Lucas \& Associates, p. 227).

Leaming (1998) also pointed out that a chairperson should make decisions as to what technology they must purchase for faculty, and also needs to exercise leadership to 
encourage them to utilize technology in teaching. He continued stressing that it is equally important for department chairs to make sure that technology is used effectively so that the investment will not be wasted. He developed the following strategies for chairpersons to "sell" technology to faculty.

- Keep your faculty engaged with new technological tools.

- Counsel and educate faculty who are possibly feeling displaced by new technology, especially new technology in the classroom.

- Develop a mentoring system, so that faculty who are already sold on the advantages of technology can work with faculty who remain skeptical.

- Develop a system of rewards for early adopters and innovators of new technology, especially new instructional technology.

- Develop a method to determine whether new instructional technology approaches are working in the classroom.

- Enlist the support of departmental staff in implementing new technologies and new instructional technology tools.

- Track and freeing up of time that the use of instructional technology brings and how this additional time is being used.

- Inform department members about positive uses of technology by their colleagues.

- Encourage faculty to share instructional, expertise, and discoveries about technology (p. 247).

As mentioned previously, distance education is one of the two types of instructional technology commonly used in higher education instruction. However, without the chair's support and encouragement, it is difficult for faculty to develop and teach distance courses because they may feel that devoting effort to something that could take time away from research or service might not be worth the risk ("Chair-Faculty Distance Education Partnership”, 2002).

Another study about the distance education and department chairs found that department chairs play crucial roles in implementing and sustaining distance education initiatives regardless of institution type and concluded that distance education is creating new responsibilities for department chairs ("Department Chairs Play...Distance 
Education Initiatives," 2002). This research provided the following recommendations for chairs to successfully implement and sustain distance education.

- Set a context and build a framework so faculty understand the direction the department is taking.

- Articulate a vision of how distance education fits into the department's goals.

- Lead by example. It is important to demonstrate an acceptance of technology at the chair level.

- Encourage faculty to experiment by providing a safe environment.

- Provide support and resource to make it easy for faculty to engage in distance education (pp. 5).

Gatlin-Watts et al. (1999) investigated the perceptions of department chairs about the multimedia as an instructional tool. They recommended: (1) chairs should continue to support the integration of multimedia into the classrooms, (2) time and resource should be allocated for faculty development in instructional design using multimedia, and (3) multimedia software and hardware should be continually upgraded to provide state-ofthe-art instruction.

Parsons and Beauchamp (2000) claimed that many of faculty members know how to teach traditional classes, but are less comfortable with new instructional technology. Leaming (1998) added that experimenting with new teaching technology should be a major development activity provided by chairs. Bates (1999) stressed that a major problem in higher education related to instructional technology in teaching is the lack of appropriate policies for the use of new technologies and insufficiency of technical support for instructors rather than lack of technical skill. Vacik (1997) found that advancing technology is one of five thematic categories of 29 incidents that affect the effective leadership of department chairpersons. 
In short, the leadership of academic department chairs has an enormous impact on the integration of instructional technology in teaching. However, whether or not different leadership style will influence faculty utilization of instructional technology differently remains studied. No research related the leadership style of the academic department chair to faculty utilization of instructional technology in instruction; neither has research been done to explore the relationship between the leadership style of academic department chairs and faculty utilization of instructional technology in instruction using Bolman and Deal's leadership frame model.

\section{Summary}

This chapter has reviewed the literature related to this study: leadership, faculty utilization of instructional technology in teaching, and the possible relationship between chair leadership and instructional technology utilization. A focused review of leadership literature included seven basic approaches (trait, behavior, contingency, power and influence, cultural and symbolic, transactional and transformational and cognitive) to studying leadership, Bolman and Deal's four-frame leadership model as well as research using this model, and the leadership of academic department chairs.

The review of the literature also described the most significant components dominating the integration of instructional technology into higher teaching and learning. They include instructional technology infrastructure and utilization of instructional technology, process of management and evaluation, advantage and disadvantage of instructional technology over traditional method in teaching, and current issues and challenges to adopt new technology for teaching. 
Finally, the review addressed the involvement of department chairs in instructional technology utilization. Effective and non-effective leadership of academic department chairs have different influence on the integration of instructional technology into teaching. However, no research has been undertaken to discover the relationship of the leadership style of chairs and faculty utilization of instructional technology in teaching employing any methods including Bolman and Deal's four-frame leadership model. 


\section{Chapter 3}

Methods

This research examined the relationships between the leadership style of academic department chairpersons of Curriculum and Instruction (C\&I), Educational Leadership (EDLS), Teacher Education (TEd), and Educational Psychology (EdP) in the Colleges of Education at the Doctoral/Research Extensive universities by Carnegie Classifications (Basinger, 2000) and faculty utilization of instructional technology in teaching courses. This chapter discusses the methods used in this study. They are organized into the following eight sections: research design, population, sampling, instrumentations, procedure, data analysis, confidentiality and anonymity, and summary

\section{Research Design}

To determine whether there was a statistically significant relationship of the leadership style of academic department chairs in the colleges of education in the Doctoral/Research Extensive universities and faculty utilization of instructional technology in teaching, the chair's leadership style was identified first. Secondly, that style (no, single, paired- and multi-frame use) was analyzed with respect to faculty utilization of instructional technology to improve the quality of instruction. The design for this research and why it is appropriate for this research are described as follows.

In this study, the two variables are the leadership style of academic department chairpersons and faculty utilization of instructional technology in teaching courses in higher education. The independent variable is categorical while the dependent variable is quantitative. According to previous research (Bensimn, 1987; Carter, 1995; Chiang, 1996; Cantu, 1997; Bethel, 1998; Echols Tobe, 1999; Bassoppo-Moyo, 1999; Mathis, 
1999; Borden, 2000; Mosser, 2001; Small, 2002), the academic administrators'

leadership styles vary in Bolman and Deal's four frames. They may either espouse single frame, or paired-frame, or multi-frame or even no frame orientations. Consequently, causal-comparative design can be utilized in this research because it determines the cause or consequences of differences that already exist between or among groups of individuals (Fraenkel and Wallen, 2000).

\section{Population}

The population of this study was chairs or heads and full time faculty (professors, associate professors, assistant professors, and instructors) of all the academic departments of C\&I, EDLS, TEd, and EdP in the Colleges (Schools) of Education at Doctoral/Research Extensive Public Universities by Carnegie Classifications (Basinger, 2000). The Colleges of Education in these universities may vary in name. They may be called Schools of Education, Graduate Schools of Education, Colleges of Education and Human Resources, Colleges of Education and Services, Graduate School of Education and Information Studies, Colleges of Education and Psychology, Teachers Education, or Colleges of Education and Human Development in those universities. For the purpose of simplicity, they are all designated as Colleges of Education in this research.

The departments in these colleges also vary in name and number of the programs they offer. Table 5 presents the number of the departments and the programs that each type of departments contains. There are 232 departments in total, of which 48 are C\&I, 75 EDLS, 56 TEd, and 63 EdP. Some departments may offer one program while others may offer more than one program. However, in this research, they are classified into four academic areas or departments as designated previously. 
Table 5

Number of Four Academic Departments in the Colleges of Education at Doctoral/Research Extensive Public Universities by Carnegie Classifications

\begin{tabular}{|c|c|}
\hline Department & Total \\
\hline Curriculum and Instruction & 41 \\
\hline \multicolumn{2}{|l|}{ Curriculum and Instruction } \\
\hline \multicolumn{2}{|l|}{ Curriculum and Teaching } \\
\hline \multicolumn{2}{|l|}{ Curriculum Design } \\
\hline Leadership & 72 \\
\hline \multicolumn{2}{|l|}{ Administration } \\
\hline \multicolumn{2}{|l|}{ Leadership } \\
\hline \multicolumn{2}{|l|}{ Policy Studies \& Analysis } \\
\hline \multicolumn{2}{|l|}{ Foundations } \\
\hline \multicolumn{2}{|l|}{ Organization } \\
\hline Teacher Education & 57 \\
\hline \multicolumn{2}{|l|}{ Teacher Education } \\
\hline \multicolumn{2}{|l|}{ Early Childhood Education } \\
\hline \multicolumn{2}{|l|}{ Elementary Education } \\
\hline \multicolumn{2}{|l|}{ Secondary Education } \\
\hline \multicolumn{2}{|l|}{ Teaching and Learning } \\
\hline Educational Psychology & 62 \\
\hline \multicolumn{2}{|l|}{ Educational Psychology } \\
\hline \multicolumn{2}{|l|}{ Counseling Psychology } \\
\hline \multicolumn{2}{|l|}{ Measurement and Research } \\
\hline \multicolumn{2}{|l|}{ School Psychology } \\
\hline Total & 232 \\
\hline
\end{tabular}


Table 6 shows the number of the subjects by four academic departments. The total number of chairs and faculty is 232 and 4726, respectively. The department of TEd has the most faculty members (1364) followed by C\&I (1329), EDLS (1057) and EdP (961).

Table 6

Number of Subjects by Four Academic Departments in the Colleges of Education at Doctoral/Research Extensive Public Universities by Carnegie Classifications

\begin{tabular}{lcc}
\hline \multicolumn{1}{c}{ Department } & Chair & Faculty \\
\hline Curriculum and Instruction & 41 & 1329 \\
Educational Leadership & 72 & 1075 \\
Teacher Education & 57 & 1364 \\
Educational Psychology & 62 & 961 \\
Total & 232 & 4726 \\
\hline
\end{tabular}

\section{Sampling}

Two-stage random sampling (Fraenkel \& Wallen, 2000) was used to take a sample from the population in this study. First, a number was assigned to each department and then a table of random numbers was used to select 40 percent of the chairs from each type of the four academic departments. The total number of the selected departments was 93, of which 16 C\&I, 29 EDL, 23 TEd, and 25 EdP. The total number of faculty from these 93 selected departments was 2108 , accounting for 44.6 percent of the faculty population. Then, a random sample of 40 percent of the faculty taken from each of the 93 departments resulted in a sample of 843 faculty. The number of the selected chairs and faculty by department was presented in Table 7. The total was 936, of which C\&I contributed 228, EDLS contributed 244, TEd contributed 255, and EdP contributed 209. 
Table 7

Number of the Selected Subjects by Departments

\begin{tabular}{lccc}
\hline \multicolumn{1}{c}{ Department } & Chair & Faculty & Total \\
\hline Curriculum and Instruction & 16 & 212 & 228 \\
Educational Leadership & 29 & 215 & 244 \\
Teacher Education & 23 & 232 & 255 \\
Educational Psychology & 25 & 184 & 209 \\
Total & 93 & 843 & 936 \\
\hline
\end{tabular}

Instrumentations

This research used two instruments: the Bolman and Deal's Leadership Orientations (Others) (see Appendix C) and Faculty Utilization of Instruction Technology in Teaching Courses (see Appendix D for chairs and Appendix E for faculty). The Leadership Orientation instrument was used to collect data to identify chairpersons' leadership style, while the instrument of Faculty Utilization of Instruction Technology in Teaching Courses was used to measure the degree of faculty utilization of instructional technology in teaching courses.

\section{The Leadership Orientations (Other)}

The Leadership Orientations (Other), developed by Lee Bolman and Terry Deal in the 1980 s, is a survey instrument that measures individuals' orientations toward leading through each of the four frames. The "other version" means that the investigated administrators are rated by their colleagues. This instrument consists of three sections. The first section contains rating scales, and the items are used to determine the frame or frames that the investigated administrator espouses. Each of the four frames of leadership 
is represented by eight items. The items are in a consistent frame sequence: structural (item 1, 5, 9, 13, 17, 21, 25, 29), human resource (item 2, 6, 10, 14, 18, 22, 26, 30), political (items 3, 7, 11, 15, 19, 23, 27, 31) and symbolic (items 4, 8, 12, 16, 20, 24, 28, 32). The second section contains six forced-choice items. The options under each item are arranged in the same sequence as the first section. The last section has two one-item measures: effectiveness as a manager, and effectiveness as a leader. Respondents use a five-point Likert scale to rate the degree to which they exhibit each leader behavior ( $1=$ Never, $2=$ Occasionally, $3=$ Sometimes, $4=$ Often, and $5=$ Always $)$. A chairperson with a mean score on the questions of a section equal to or above 4.0 is classified as using that leadership frame.

The validity of the Leadership Orientations (Other) survey was established and reported by the authors in an unpublished paper in 1990. A factor analysis of 681 higher education administrators, using principal components and varimax rotation, yielded a high degree of internal consistency (Bolman \& Deal, 1992b). With regard to the reliability, the statistics for Leadership Orientations on the basis of 1309 colleague ratings for a multi-sector sample of managers in business and education reported on his Web page titles as Potential Users of Leadership Orientations Instruments show that the splithalf correlation for four frames is beyond 0.8 , the Spearman-Brown coefficient, and Buttman (Rulon) coefficient exceed 0.9. Additionally, Cronbach's alpha for the frame measures were very high, ranging from .91 to .93 (Bolman \& Deal, 1991b). The Leadership Orientations (Other) survey instrument has been used in numerous studies (Bensimon, 1989; Bethel, 1998; Bolman \& Deal, 1991b; Carter, 1995; Crist, 1999; Eck, 
1997; Eckley, 1997; Gilson, 1994; Harlow, 1994; Mathis, 1999; Mosser, 2000; Small, 2002; Scott, 1997; Strickland, 1992; Suzuki, 1994; Van der Veer, 1991).

In this study, only the first section of the Leadership Orientation (Other)

instrument is used. Permission to use this instrument was granted by Dr. Lee Bolman (Appendix B).

\section{Faculty Utilization of Instructional Technology}

The instrument of Faculty Utilization of Instructional Technology (see Appendix D for chair version and Appendix E for faculty version) was developed by the researcher to measure faculty utilization of instructional technology in teaching courses. Developing this instrument was a complex and time-consuming process. Questions or statements in the survey were rewritten and revised many times throughout the study.

The Construction of the Survey. Faculty Utilization of Instructional Technology has two versions: chair version (see Appendix D) and faculty version (see Appendix E). The only difference between these two versions is that the chair version includes more questions about the demographic information than the faculty version does. The survey consists of six sections: (1) Technology Infrastructure, (2) Faculty Utilization of Instructional Technology, (3) Technical Support, (4) Administrative Support, (5) Perspectives of Key Issues in Integration of Instructional Technology in Teaching Courses, and (6) Demographic Information. The first section represented by 11 items is used to determine the overall quality of the technology infrastructure of the department surveyed. Item 1 investigates the situation about the facility infrastructure. Items 2 to 9 collect the information of the system infrastructure. They include software (operating system and application software), hardware such as equipment (computer, copy machine, 
ect), networks, video and audio system, and telecommunications and phone system, and accessibility to instructional technology. Items 10 and 11 are used to examine if the department has adequate human resource necessary for the efficient operation of the overall technology infrastructure. The response format is a 5-point Likert scale where $1=$ poor, $2=$ fair, $3=$ good, $4=$ very good, and $5=$ excellent. Section 2 consists of 13 items used to determine the frequency of faculty utilization of 13 types of instructional technologies with ratings ranged from 1 (never), 2 (occasionally), 3 (sometimes), 4 (often) to 5 (always). Section 3 (6 items) and Section 4 (10 items) are used to determine the technical and administrative support for faculty utilization of instructional technology in teaching courses, respectively. The response format for these items is a 5-point scale where $1=$ strongly disagree, $2=$ disagree, $3=$ neutrally agree, $4=$ agree, and $5=$ strongly agree. The fifth section has 9 items, used to gather participants' perspective about the key issues affecting faculty utilization of instructional technology in teaching courses. The ratings for those items are ranged from 1 (not important), 2 (somewhat important), 3 (important), 4 (very important) to 5 (extremely important). To obtain information about participants' background, 8 items were designed and incorporated in the survey for chair version and 6 for faculty version. These items are age, gender, chairs' length of tenure, the size of a department (the number of faculty in the department), the highest degree, discipline, academic rank, and faculty tenure status. Table 8 presents all the items included in the first five sections of the instrument. 


\section{Table 8}

Instrument Items and Literature Sources

\begin{tabular}{|c|c|c|}
\hline Section & Items & Literature Sources \\
\hline \multirow[t]{11}{*}{ A. Infrastructure } & 1. Facilities for instructional technology utilization & Green, 2001 \\
\hline & 2. Equipment for instructional technology & Green, 2001 \\
\hline & 3. Operating system & Green, 2001 \\
\hline & 4. Application software & Green, 2001 \\
\hline & 5. Computer networks & Green, 2001 \\
\hline & 6. Wireless networks & Green, 2001 \\
\hline & 7. Video and audio system & Spotts \& Bowman, 1995 \\
\hline & 8. Telecommunications and phone system & Green, 2001 \\
\hline & 9. Faculty access to instructional technology & Green, 2001 \\
\hline & 10. User support service & Green, 2001 \\
\hline & 11. Instructional technology training for faculty & Green, 2001 \\
\hline \multirow[t]{13}{*}{ B. Utilization } & 12. Word processing & Sportts \& Bowman, 1995 \\
\hline & 13. Internet/World Wide Web & Groves \& Zemel, 2000 \\
\hline & 14. Presentation software & Sportts \& Bowman, 1995 \\
\hline & 15. E-mail (Student Contact) & Sportts \& Bowman, 1995 \\
\hline & 16. Computer spreadsheet & Sportts \& Bowman, 1995 \\
\hline & 17. Statistical computing & Sportts \& Bowman, 1995 \\
\hline & 18. Electronic discussion lists & Groves \& Zemel, 2000 \\
\hline & 19. Chat room & Hashem, 2000 \\
\hline & 20. Multimedia use in class & Groves \& Zemel, 2000 \\
\hline & 21. Computer conferencing & Sportts \& Bowman, 1995 \\
\hline & 22. Video & Sportts \& Bowman, 1995 \\
\hline & 23. Audio & Sportts \& Bowman, 1995 \\
\hline & 24. Distance education & Sportts \& Bowman, 1995 \\
\hline \multirow[t]{4}{*}{$\begin{array}{l}\text { C. Technical } \\
\text { Support }\end{array}$} & $\begin{array}{l}\text { 25. My department offers faculty training in the } \\
\text { use and application of instructional technologies. }\end{array}$ & Leaming, 1998 \\
\hline & $\begin{array}{l}\text { 26. My department offers faculty training in the } \\
\text { design of curricula for distance education courses. }\end{array}$ & Leaming, 1998 \\
\hline & $\begin{array}{l}\text { 27. My department has instructional technology } \\
\text { support staff (teaching assistant, instructional } \\
\text { technologist) to provide assistance for faculty in } \\
\text { solving hardware/software/network problems. }\end{array}$ & Green, 2001 \\
\hline & $\begin{array}{l}\text { 28. My department provides continuous } \\
\text { maintenance of instructional technology } \\
\text { equipment. }\end{array}$ & Green, 2001 \\
\hline
\end{tabular}


Table 8 (Cont'd)

Instrument Items and Literature Sources

\begin{tabular}{|c|c|c|}
\hline Section & Items & Literature Sources \\
\hline & $\begin{array}{l}\text { 29. My department provides technical assistance to } \\
\text { assist faculty in developing instructional software. }\end{array}$ & Green, 2001 \\
\hline & $\begin{array}{l}\text { 30. My department provides technical assistance to } \\
\text { assist faculty in developing a course Web page. }\end{array}$ & Green, 2001 \\
\hline \multirow[t]{10}{*}{$\begin{array}{l}\text { D. Administrative } \\
\text { Support }\end{array}$} & $\begin{array}{l}\text { 31. My department has a formal plan for integrating } \\
\text { instructional technology into teaching. }\end{array}$ & "Department," 2002 \\
\hline & $\begin{array}{l}\text { 32. My department has a plan for teaching faculty } \\
\text { how to make effective use of instructional } \\
\text { technology as a tool to support instruction and } \\
\text { learning outcomes. }\end{array}$ & "Department," 2002 \\
\hline & $\begin{array}{l}\text { 33. My department provides rewards (e.g. funding, } \\
\text { release time) to assist faculty in developing } \\
\text { instructional software. }\end{array}$ & $\begin{array}{l}\text { Leaming, } 1998 \\
\text { Green, } 2001 \\
\text { Dolence \& Norris, } 1995\end{array}$ \\
\hline & $\begin{array}{l}\text { 34. My department provides rewards (e.g. funding, } \\
\text { release time) to assist faculty in developing course } \\
\text { Web page. }\end{array}$ & $\begin{array}{l}\text { Leaming, } 1998 \\
\text { Green, } 2001\end{array}$ \\
\hline & $\begin{array}{l}\text { 35. My department has developed a system of } \\
\text { rewards for innovators of new instructional } \\
\text { technology. }\end{array}$ & $\begin{array}{l}\text { Leaming, } 1998 \\
\text { Dolence \& Norris, } 1995\end{array}$ \\
\hline & $\begin{array}{l}\text { 36. My department formally recognizes the use of } \\
\text { instructional technology as part of the faculty tenure } \\
\text { and promotion process. }\end{array}$ & $\begin{array}{l}\text { Leaming, } 1998 \\
\text { Dolence \& Norris, } 1995\end{array}$ \\
\hline & $\begin{array}{l}\text { 37. There are funding opportunities available within } \\
\text { my department for development of distance } \\
\text { education curriculum. }\end{array}$ & Green, 2001 \\
\hline & $\begin{array}{l}\text { 38. My department has a faculty member or staff } \\
\text { person primarily responsible for the development of } \\
\text { distance education course curricula. }\end{array}$ & Green, 2001 \\
\hline & $\begin{array}{l}\text { 39. I frequently inform the department members } \\
\text { about positive uses of technology by the colleagues. }\end{array}$ & Leaming, 1998 \\
\hline & $\begin{array}{l}\text { 40. I frequently encourage faculty to share } \\
\text { information, expertise, and discoveries about } \\
\text { instructional technology. }\end{array}$ & Leaming, 1998 \\
\hline \multirow[t]{5}{*}{ E. Issues } & $\begin{array}{l}\text { 41. Providing adequate instructional technology } \\
\text { equipment }\end{array}$ & $\begin{array}{l}\text { Butler \& Sellbom, } 2002 \\
\text { Green, } 2001\end{array}$ \\
\hline & $\begin{array}{l}\text { 42. Providing timely repair of instructional } \\
\text { technology facilities and equipment }\end{array}$ & Green, 2001 \\
\hline & $\begin{array}{l}\text { 43. Providing continuous maintenance of } \\
\text { instructional technology equipment }\end{array}$ & Green, 2001 \\
\hline & $\begin{array}{l}\text { 44. Financing the replacement of aging } \\
\text { hardware/software }\end{array}$ & $\begin{array}{l}\text { Butler \& Sellbom, } 2002 \\
\text { Wilson, } 2003\end{array}$ \\
\hline & $\begin{array}{l}\text { 45. Creating a clear vision for instructional } \\
\text { technology integration into instruction. }\end{array}$ & “Department," 2002 \\
\hline
\end{tabular}


Table 8 (Cont'd)

Instrument Items and Literature Sources

\begin{tabular}{|c|c|c|}
\hline Section & Items & Literature Source \\
\hline & $\begin{array}{l}\text { 46. Developing a strategic plan for instructional } \\
\text { technology integration into instruction }\end{array}$ & $\begin{array}{l}\text { Green, } 2001 \\
\text { "Department," } 2002\end{array}$ \\
\hline & $\begin{array}{l}\text { 47. Providing incentives and rewards for faculty to } \\
\text { support instructional technology integration into } \\
\text { instruction }\end{array}$ & Wilson, 2003 \\
\hline & 48. Providing adequate time to learn new technology & $\begin{array}{l}\text { Butler \& Sellbom, } 2002 \\
\text { Wilson, } 2003\end{array}$ \\
\hline & $\begin{array}{l}\text { 48. Providing adequate instructional technology } \\
\text { training for faculty }\end{array}$ & Butler \& Sellbom, 2002 \\
\hline & $\begin{array}{l}\text { 49. Providing adequate technical support for } \\
\text { integration of instructional technology into teaching }\end{array}$ & Butler \& Sellbom, 2002 \\
\hline
\end{tabular}

Validity. The items in this survey instrument were created based on the previous literature and instruments related to instructional technology utilization in teaching courses. The literature sources of each item are presented in Table 8. In order to further determine content-related validity of the instrument, the inventory was sent to two instructional technology professionals to judge whether the items were capable of measuring the support of the academic department chairpersons in the application of instructional technology in teaching. Both of them returned their feedback by email and provided valuable suggestions. Also, three interviews with the academic department chairpersons were conducted to further discuss the validity and applicability of the items. The inventory was also sent to experts in the field of survey design for advice and comments.

Reliability. To ensure the reliability of the items in the survey, a pilot test was conducted with faculty and department chairs who were not part of the regular study. A cover letter and Utilization of Instructional Technology in Teaching Courses (faculty version) was sent to the selected faculty, while a cover letter and Utilization of 
Instructional Technology in Teaching Courses (chair version) was sent to the selected chairs. In addition, both faculty and chairs also receive a pilot test questionnaire for Utilization of Instructional Technology in Teaching Courses (see Appendix F). The questionnaire consists of eight questions. The first seven questions are used to examine the clarity of the cover letter, the instrument layout, and the instructions to respondents; the applicability and the understandability of the survey items; and the capability of the survey to accurately yield the information about faculty utilization of instructional technology in teaching courses. The response format is a 4-point Likert scale where $1=$ strongly disagree, $2=$ disagree, $3=$ agree, and $4=$ strongly agree. The last item is to request the participants to give their comments on the survey and suggestions to improve the instrument.

Cronbach's alpha was computed to check on internal consistency of the instrument (Fraenkel and Wallen, 2000). The feedback was used to revise the instruments.

Pilot Test

The pilot test was conducted in the four departments of college of education. They were Departments of Advanced Educational Studies (AES), Counseling, Rehabilitation Counseling \& Counseling Psychology (CRCCP), Educational Theory \& Practice (ETP), and Speech Pathology \& Audiology (SPA). The AES consists of four programs: Educational Leadership Studies, Educational Psychology, Technology Education, and Social and Cultural Foundations. The CRCCP is composed of the Programs of Counseling, Counseling Psychology, and Rehabilitation Counseling. The ETP includes three programs: Curriculum and Instruction, Special Education, and Literacy Studies. The 
SPA consists of the Programs of Speech Pathology and Audiology. The survey of Faculty Utilization of Instructional Technology (faculty) with a cover letter was sent to 52 faculty members in these departments, and the survey of Faculty Utilization of Instructional Technology (chair) with a cover letter was sent to two department chairs. Twenty-one faculty and two chairs responded within two weeks. The response rates for faculty and chair were 40.4 percent and 100 percent, respectively. Due to the considerably small number of chair participants in the pilot test and the similarity of the two versions (faculty and chair) of the instrument, the statistical analysis was only done with faculty responses. However, chairs' feedback did provide some valuable information for the improvement of the instrument for the chair version.

Table 9 presents frequency distribution of disagree or strongly disagree and agree or strongly agree on the items of the pilot test questionnaire. One hundred percent of the respondents agreed or strongly agreed that the items of the instrument are easy to understand; 95 percent agreed or strongly agreed that the cover letter clearly defines the purpose of the surveying, the survey layout is clear and effective, and the survey items are defined clearly and accurately; and 90 percent agreed or strongly agreed that The instruction of the survey instrument to respondents are clear and unambiguous and the items are going to accurately yield the information about faculty utilization of instructional technology. However, 30 percent of the respondents disagreed or strongly disagreed that all the questions in the instrument are applicable for them to answer. This is because, according to some participants' comment on this concern, the technical support is usually organized by the college rather than departments and the department does not do anything about technology infrastructure. Actually, this result might be 
Table 9

Frequency Distribution of Disagree/Strongly Disagree and Agree/Strongly Agree on the Items of Pilot Test Questionnaire

\begin{tabular}{|c|c|c|c|c|c|}
\hline \multirow[t]{2}{*}{ Item } & \multirow[t]{2}{*}{$\begin{array}{l}\text { Total } \\
\text { Case }\end{array}$} & \multicolumn{2}{|c|}{$\begin{array}{l}\text { Disagree/ } \\
\text { Strongly } \\
\text { Disagree }\end{array}$} & \multicolumn{2}{|c|}{$\begin{array}{l}\text { Agree/ } \\
\text { Strongly } \\
\text { Agree }\end{array}$} \\
\hline & & $\mathrm{F}$ & $\%$ & $\mathrm{~F}$ & $\%$ \\
\hline $\begin{array}{l}\text { 1. The cover letter clearly defines the purpose } \\
\text { of the surveying. }\end{array}$ & 20 & 1 & 5.0 & 19 & 95.0 \\
\hline $\begin{array}{l}\text { 2. The survey instrument layout is clear and } \\
\text { effective. }\end{array}$ & 20 & 1 & 5.0 & 19 & 95.0 \\
\hline $\begin{array}{l}\text { 3. The instruction of the survey instrument to } \\
\text { respondents are clear and unambiguous. }\end{array}$ & 20 & 2 & 10.0 & 18 & 90.0 \\
\hline 4. Te items are sated clearly and accurately. & 19 & 1 & 5.3 & 18 & 94.7 \\
\hline 5. The items are easy to understand. & 19 & 0 & 0.0 & 19 & 100.0 \\
\hline 6. All the questions are applicable for me to answer. & 19 & 6 & 30.0 & 13 & 70.0 \\
\hline $\begin{array}{l}\text { 7. The items are going to accurately yield the } \\
\text { information about faculty utilization of instructional } \\
\text { technology. }\end{array}$ & 18 & 2 & 10.0 & 16 & 90.0 \\
\hline
\end{tabular}

biased due to the sampling error of the pilot test, for which all the participants were selected from one college of education. While colleges do have responsibilities to ensure the good quality of the technology infrastructure and provide adequate technical and administrative support for faculty utilization of instructional technology in teaching, departments are becoming increasingly important to assist faculty in using instructional technology to improve their teaching. A body of literature supporting this view has been reviewed and the evidences that a department chair's leadership is one of the major factors in higher education to influence faculty use of instructional technology have also been presented previously. Therefore, this result will not be a problem to influence the validity of the instrument. 
To further examine the reliability of the instrument, Cronbach's alpha coefficients were computed on each section. Table 10 reports the item-total statistics for Section A, the technology infrastructure. The coefficient alpha for all 11 items was .8538 , which is acceptable. However, Items 6 (wireless networks) and 8 (telecommunications and phone system) had a considerably low corrected item-total correlation, both below 3.0 before either one was removed. Item 6 investigates the quality of the wireless networks. The mean of this item reported by faculty was 1.81 with a standard deviation of 1.03 . This implies that the quality of this component of the technology infrastructure is generally low in the investigated departments, so no matter how the reported result of the other components varies, the mean of this item reported by faculty remains relatively stable. Therefore, it can be safely removed. After it was removed, the coefficient alpha for the remainders increased from .8538 to .8627 . The corrected item-total correlations of all the remaining 10 items were higher than .30 and, consequently, they will be used to examine the quality of the technology infrastructure. 
Table 10

Item-Total Statistics for Section A of the Instrument

\begin{tabular}{|c|c|c|c|c|c|c|}
\hline \multirow[t]{2}{*}{ Item } & \multirow[t]{2}{*}{ Mean } & \multirow[t]{2}{*}{ SD } & \multicolumn{2}{|c|}{ Items Not Removed } & \multicolumn{2}{|c|}{ Item 6 Removed } \\
\hline & & & $\begin{array}{c}\text { Corrected } \\
\text { Item-Total } \\
\text { Correlation }\end{array}$ & $\begin{array}{l}\text { Alpha If } \\
\text { Item } \\
\text { Deleted }\end{array}$ & $\begin{array}{l}\text { Corrected } \\
\text { Item-Total } \\
\text { Correlation }\end{array}$ & $\begin{array}{c}\text { Alpha If } \\
\text { Item Deleted }\end{array}$ \\
\hline 1 & 3.33 & 1.02 & .9051 & .8133 & .9014 & .8227 \\
\hline 2 & 3.24 & 0.99 & .7710 & .8244 & .8155 & .8305 \\
\hline 3 & 3.10 & 1.04 & .6520 & .8327 & .6522 & .8432 \\
\hline 4 & 2.86 & 1.06 & .6485 & .8330 & .6650 & .8420 \\
\hline 5 & 2.86 & 0.96 & .6132 & .8366 & .6165 & .8467 \\
\hline 6 & 1.81 & 1.03 & .2465 & .8627 & ---- & ---- \\
\hline 7 & 2.67 & 1.20 & .3560 & .8575 & .3233 & .8724 \\
\hline 8 & 3.24 & 1.09 & .2809 & .8613 & .3025 & .8717 \\
\hline 9 & 3.43 & 1.03 & .5965 & .8373 & .6068 & .8470 \\
\hline 10 & 2.95 & 1.16 & .5621 & .8399 & .5285 & .8539 \\
\hline 11 & 3.67 & 1.11 & .4382 & .8497 & .4491 & .8602 \\
\hline \multicolumn{7}{|c|}{$\begin{array}{l}\text { Reliability Coefficients Before Item } 6 \text { Was Removed } \\
\mathrm{N} \text { of Cases }=21 \quad \mathrm{~N} \text { of Items }=11 \\
\text { Alpha }=.8538\end{array}$} \\
\hline \multicolumn{7}{|c|}{$\begin{array}{l}\text { Reliability Coefficients After Item } 6 \text { Were Removed } \\
\mathrm{N} \text { of Cases }=21 \mathrm{~N} \text { of Items }=10 \\
\text { Alpha }=.8627\end{array}$} \\
\hline
\end{tabular}

The coefficient alpha for all 13 items in Section B, faculty utilization of instructional technology, was .8324 (see Table 11). As a whole, this coefficient is high enough to ensure internal consistency. However, when the individual corrected item-total correlation is considered, it is found that Items 12 and 15 were insignificantly correlated to the total with a correlation of .2472 and .1342 , respectively. These two items were used to investigate faculty utilization of word processing and E-mail as a tool to 
Table 11

Item-Total Statistics for Section B of the Instrument

\begin{tabular}{|c|c|c|c|c|c|c|}
\hline \multirow[t]{2}{*}{ Item } & \multirow[t]{2}{*}{ Mean } & \multirow[t]{2}{*}{$\mathrm{SD}$} & \multicolumn{2}{|c|}{ Items Not Removed } & \multicolumn{2}{|c|}{ Items Removed } \\
\hline & & & $\begin{array}{l}\text { Corrected } \\
\text { Item-Total } \\
\text { Correlation }\end{array}$ & $\begin{array}{l}\text { Alpha If } \\
\text { Item } \\
\text { Deleted }\end{array}$ & $\begin{array}{l}\text { Corrected } \\
\text { Item-Total } \\
\text { Correlation }\end{array}$ & $\begin{array}{c}\text { Alpha If } \\
\text { Item Deleted }\end{array}$ \\
\hline 12 & 4.52 & 0.87 & .2472 & .8512 & ---- & ---- \\
\hline 13 & 3.81 & 0.93 & .4990 & .8409 & .4986 & .8514 \\
\hline 14 & 2.90 & 1.22 & .4672 & .8476 & .4766 & .8587 \\
\hline 15 & 4.49 & 1.01 & .1324 & .8625 & ---- & ---- \\
\hline 16 & 2.90 & 1.18 & .4256 & .8561 & .4144 & .8598 \\
\hline 17 & 2.14 & 1.06 & .4660 & .8403 & .4788 & .8534 \\
\hline 18 & 2.05 & 1.28 & .6552 & .8170 & .6788 & .8445 \\
\hline 19 & 1.90 & 1.30 & .7234 & .8076 & .7433 & .8378 \\
\hline 20 & 2.81 & 1.25 & .5397 & .8420 & .5433 & .8456 \\
\hline 21 & 1.43 & 0.75 & .5188 & .8390 & .5345 & .8467 \\
\hline 22 & 3.14 & 1.11 & .6227 & .8344 & .7866 & .8311 \\
\hline 23 & 2.29 & 1.23 & .7524 & .8181 & .7455 & .8366 \\
\hline 24 & 1.90 & 1.30 & .6247 & .8338 & .6544 & .8445 \\
\hline \multicolumn{7}{|c|}{$\begin{array}{l}\text { Reliability Coefficients Before Items Were Removed } \\
\text { Number of Cases }=21 \quad \text { Number of Items }=13 \\
\text { Alpha }=.8324\end{array}$} \\
\hline \multicolumn{7}{|c|}{$\begin{array}{l}\text { Reliability Coefficients after Items Were Removed } \\
\text { Number of Cases }=21 \text { Number of Items }=11 \\
\text { Alpha }=.8533\end{array}$} \\
\hline
\end{tabular}

support their teaching. The mean and standard deviation of Item 12 were 4.52 on a fivepoint scale and .87. Similarly, the mean and standard deviations of Item 15 were 4.49 and 1.01. These statistics indicate that the rating of word processing and E-mail use by faculty was relatively high and stable. Actually, these technologies have been already commonly used by faculty in their course teaching, so the variance of the other technologies is not 
accounted for the variance of these two. As indicated in the table, if Item 12 was deleted, the alpha would increase by .0188; if Item 15 was deleted, the alpha would increase by .0301. The removal of these two items led the final coefficient alpha to .8533 and the corrected item-total correlations of all items were above .40. Finally, this section will only contain 11 items.

Table 12 presents the statistics of Cronbach's alpha analysis for Section C, the technical support for instructional technology use. The coefficient alpha for all 6 items was .8830 , which is acceptable. The corrected item-total correlations were all considerably high, ranging from .6364 to .7748 . Therefore, all six items are internally consistent and kept in the scale.

\section{Table 12}

Item-Total Statistics for Section C of the Instrument

\begin{tabular}{ccccc}
\hline Item & Mean & SD & $\begin{array}{c}\text { Corrected Item-Total } \\
\text { Correlation }\end{array}$ & Alpha if Item Deleted \\
\hline 25 & 2.81 & 1.36 & .6846 & .8665 \\
26 & 2.52 & 1.33 & .6364 & .8744 \\
27 & 2.67 & 1.32 & .6990 & .8628 \\
28 & 2.52 & 1.03 & .7601 & .8546 \\
29 & 2.19 & 1.03 & .6834 & .8656 \\
30 & 2.48 & 0.98 & .7748 & .8540 \\
\multicolumn{5}{l}{$\begin{array}{l}\text { Reliability Coefficients } \\
\text { Number of Cases=21 }\end{array}$} \\
$\begin{array}{l}\text { Alpha }=.8830 \\
\text { Number of Items }=6\end{array}$ \\
\hline
\end{tabular}

As demonstrated in Table 13, the alpha for all 10 items in Section D, the administrative support for instructional technology use, was .7173, which is high enough 
to be accepted. The corrected item-total correlations for all 9 items were above .30, with a minimum of .3238 and a maximum of .6625 . No items have been removed.

Table 13

Item-Total Statistics for Section D of the Instrument

\begin{tabular}{ccccc}
\hline Item & Mean & SD & $\begin{array}{c}\text { Corrected Item-Total } \\
\text { Correlation }\end{array}$ & Alpha if Item Deleted \\
\hline 31 & 2.29 & 0.96 & .5726 & .7944 \\
32 & 2.29 & 1.01 & .6625 & .7845 \\
33 & 2.62 & 1.07 & .5579 & .7946 \\
34 & 2.48 & 1.21 & .5524 & .7949 \\
35 & 2.29 & 1.06 & .4946 & .8013 \\
36 & 2.90 & 1.00 & .4298 & .8078 \\
37 & 2.52 & 1.12 & .5857 & .7912 \\
38 & 2.01 & 1.14 & .3519 & .8169 \\
39 & 3.05 & 1.20 & .3238 & .8213 \\
40 & 3.33 & 1.06 & .5054 & .8002 \\
Reliability Coefficients & & & \\
Number of Cases $=21$ & Number of Items $=10$ & \\
Alpha = 8173 & & & \\
\hline
\end{tabular}

The Cronbach's alpha analysis for Section E, the key issues affecting faculty utilization of instructional technology, was presented in Table 14. The alpha was .9482. The corrected item-total correlations ranged from .6691 to 9239. All items remain in the scale. 
Table 14

Item-Total Statistics for Section E of the Instrument

\begin{tabular}{ccccc}
\hline Item & Mean & SD & $\begin{array}{c}\text { Corrected Item-Total } \\
\text { Correlation }\end{array}$ & Alpha if Item Deleted \\
\hline 41 & 4.62 & 0.74 & .7942 & .9433 \\
42 & 4.67 & 0.80 & .8880 & .9386 \\
43 & 4.67 & 0.80 & .8880 & .9386 \\
44 & 4.48 & 0.81 & .9239 & .9366 \\
45 & 3.95 & 1.20 & .7679 & .9458 \\
46 & 3.81 & 1.21 & .7665 & .9460 \\
47 & 3.81 & 1.21 & .6691 & .9524 \\
48 & 4.57 & 0.81 & .8605 & .9396 \\
49 & 4.62 & 0.80 & .8879 & .9384 \\
Reliability Coefficients & & \\
Number of Cases=21 & Number of Items $=9$ & \\
Alpha = 9482 & &
\end{tabular}

On the basis of the previous analysis of Cronbach's alpha coefficients, three items were removed from the original scale. Finally, the instrument of Faculty Utilization of Instructional Technology consists of 46 items, excluding six items of the demographic information for the faculty version (see Appendix E) and eight items for the chair version (see Appendix D).

\section{Procedure}

This research used self-report survey procedure (Kerlinger, 1986) to collect data by mail. The participants' names of the sampled departments and their mailing and Email addresses were available on the web and various directories from the dean's office of the colleges. 
A letter to invite the selected department chairs and faculty to participate in the study was sent. Along with the letter, a hard copy of the instrument, Faculty Utilization of Instructional Technology in Teaching Courses (chair) was sent the selected chairs and a hard copy of two instruments, the Bolman and Deal's Leadership Orientations (Other) and Faculty Utilization of Instructional Technology in Teaching Courses (faculty) was sent to the selected faculty participants. They were asked to respond within two weeks by returning the questionnaire using the self-addressed, stamped-envelope.

A follow-up cover letter and another survey instrument(s) were sent to those who didn't respond within two weeks to further request their participation. They were given another two weeks to respond. A second-follow-up letter was sent to request the responses of those who did not respond within two weeks after the first follow-up letter was mailed. The goal is to reach 50 percent response rate across all categories.

\section{Data Analysis}

The data were generated from two instruments: the Bolman and Deal's Leadership (Other) and Faculty Utilization of Instructional Technology in Teaching Courses. The statistical methods used to analyze the data to determine the relationship between the leadership style of chairpersons (as measured by the four leadership frames) and faculty utilization of instructional technology in teaching are described by the five research questions in this section. The Statistical Analysis System (SAS) was used for statistical computations. An alpha level of .05 was the level of significance for this study, and .01 and .001 levels were reported as well.

Question 1. What are the leadership styles (as measured by the four frames) of the chairs in the departments of C\&I, EDL, TEd, and EdP? 
The Bolman and Deal's Leadership Orientations (Other) was utilized to collect data to answer this research question. The overall mean and standard deviation of each frame were computed. Then, the mean of each leadership frame was computed individually. A chair whose mean score reported by his or her colleagues was 4.0 or above on the 5-point Likert scale was considered to be espousing that frame. The overall mean, standard deviation by the four frames, and the number of the respondents who were designated as using each frame were reported. Frequencies and percentages of the chairpersons who utilized different patterns of no, single, paired, and multi-frame were also identified and presented.

Question 2. How does the leadership style of chairs vary by academic department, discipline, gender, size of a department, and chairs' length of tenure?

This research question was explained by using the data generated from the Bolman and Deal's Leadership Orientations (Other) and the demographic section of Faculty Utilization of Instructional Technology in Teaching Courses (chair version). The respondents of chairpersons were grouped by departments (C\&I, EDL, TEd, and EdP), discipline, gender, size of a department (small, medium, and large), and chairs' length on time in the position (long-term: more than 5 years, medium: 3 to 5 years, and short-term: less than 3 years), respectively. Frequency and percentage of the chairpersons who used no, single, paired-, or multi-frame are identified and reported by different sub-groups within each group. The chi-square test for goodness of fit was used to test if there was a statistically significant difference between males and females, by size of a department (small, medium, and large), by discipline, and by length of time in position (long-term: more than 5 years, medium: 3 to 5 years, and short-term: less than 3 years). 
Question 3. Is there a statistically significant relationship between the leadership frame(s) of department chairpersons and faculty reports of utilization of instructional technology in teaching courses?

The Bolman and Deal's Leadership Orientations (Other) and Faculty Utilization of Instructional Technology in Teaching Courses (faculty version) were used to obtain data to answer this research question. To determine if each of four leadership frames was significantly correlated to faculty instructional technology utilization in teaching, Pearson's product-moment correlation coefficients were computed and reported.

Question 4. Is there a statistically significant difference between the various patterns of leadership frames of chairpersons and faculty reports of utilization of instructional technology in teaching courses?

The data used to answer this research question were generated from the Bolman and Deal's Leadership Orientations (Other) and Faculty Utilization of Instructional Technology in Teaching Courses (faculty version). The mean scores and standard deviations of instructional technology utilization of all the patterns of leadership frames were reported. Then, the respondents of chairpersons were grouped by the category of patterns of no, single, paired- and multi-frame they were designated as using. The mean score and deviation of the same pattern were computed and reported by four categories. One-way ANOVA was used to examine if there was a statistically significant difference in instructional technology utilization by different patterns. A post hoc test was conducted to determine which groups differ.

Question 5. Is there a statistically significant difference in the instructional technology utilization by no, single, paired-, and multi-frame for each of the chairs of the 
four academic departments, discipline, size of departments, age, gender, and chairs' length of tenure?

The Bolman and Deal's Leadership Orientations (Other) and Faculty Utilization of Instructional Technology in Teaching Courses (faculty versions) were used to answer this research question. The means and standard deviations of instructional technology utilization in teaching by four patterns of no, single, paired- and multi-frame for each of different academic departments, the size ranges of departments, age ranges, gender, the chairs' length of tenure, and the selected interactions were computed and reported, respectively. MANOVA was used to examine if there was a statistically significant difference in instructional technology utilization by different categories and patterns. If a difference existed, a post hoc test was further utilized to identify which patterns differ.

\section{Confidentiality and Anonymity}

Since this study depended on response from human subjects and requires their voluntary participation, their anonymity and confidentiality was protected consistent with Institutional Review Board (IRB) standards and policies. In the cover letter, the subjects were provided with such information as: (1) the purpose of the research, (2) participation in whole is voluntary, (3) the participants have the right not to respond to every item, and (4) confidentiality and anonymity will be maintained. In both instruments, subjects' names are not requested. The method used to classify the participants by department was a group code that is incorporated in each survey before it was distributed. No other people understood the meaning of the code with the only exception of the researcher. The code was stored in a locked drawer and was deleted upon completion of the study when no longer needed. As this research qualified exemption status, a request for approval 
from the West Virginia University Institutional Review Board (IRB) for the Protection of Human Subjects was submitted, reviewed, and approved.

\section{Summary}

In this chapter, the method used to explore the relationship of the leadership styles of academic department chairs and faculty utilization of instructional technology in teaching was described. Two instrumentations were used to collect related data to answer the five research questions. The survey was mailed to the subjects and the participants responded by using the self-addressed, stamped-envelope. The statistical methods of $t$ test, ANOVA, post hoc tests, and Pearson's product-moment correlation coefficients were utilized to analyze data. The Statistical Analysis System (SAS) was used for statistical computations. An alpha level of .05 was the criterion level of significance for this study, and .01 and .001 levels were reported as well. The results are presented in Chapter 4. 


\section{Chapter 4}

Results

This chapter presents the results of the survey responses regarding the leadership styles of department chairs and faculty utilization of instructional technology in teaching. The first section contains demographic data for chairs and faculty respondents. The second section describes the approaches used to deal with missing values. The third section presents the results of the examination of the reliability of the survey instruments, Leadership Orientations (other) and Faculty Utilization of Instructional Technology in Teaching (both faculty and chair versions). The fourth section analyzes the data within the framework of the five research questions. A summary completes the chapter.

\section{Survey Responses}

The population of this study included 232 chairs and 4726 faculty members in 232 departments of Curriculum and Instruction (C\&I), Educational Leadership Studies (EDLS), Teacher Education (TEd), and Educational Psychology (EdP) in the Colleges (Schools) of Education at Doctoral/Research Extensive Public Universities by Carnegie Classifications (Basinger, 2000). Among these departments, 48 were C\&I, 75 EDLS, 56 TEd, and 63 EdP. The number of faculty in C\&I, EDLS, TEd, and EdP were 1364, 1329, 1057, and 961, respectively.

Two-stage random sampling (Fraenkel \& Wallen, 2000) was used to draw a sample from the population in this study. First, 40 percent of the chairs from each type of the four academic departments were selected. The total number of the selected departments was 93, of which 16 were C\&I, 29 EDLS, 23 TEd, and 25 EdP. The total number of faculty from these 93 selected departments was 2108, accounting for 44.6 
percent of the faculty population. Subsequently, a random sample of 40 percent of the faculty taken from each of the 93 departments resulted in a total of 843 faculty, of which C\&I contributed 212, EDLS contributed 215, TEd contributed 232, and EdP contributed 184.

After three mailings to invite the selected chairs and faculty to participate in this study, 37 chairs responded to IT survey, which included a section of chairs' demographic information and 230 faculty responded to IT and Leadership Orientation surveys (see Table 15). These 230 faculty evaluated 81 chairs. On average, about 3 faculty rated each chair's leadership frame use.

Table 15

Survey Response

\begin{tabular}{ccc}
\hline Respondent & IT Survey & Leadership Orientation \\
\hline Chair & 37 & - \\
Faculty & 230 & $230^{\mathrm{a}}$ \\
\hline
\end{tabular}

a. 230 faculty evaluated 81 chairs.

The response rate was 28.5 percent in total, 39.8 percent for chairs, and 27.3 percent for faculty, respectively (see Table 16). The response rate of the EDLS department chairs was the highest (48.3\%), followed by TEd (43.5\%), EdP (36\%), and C\&I (25.0\%). For the faculty responses, the EDLS departments had the highest response proportion (36.3\%), followed by TEd (31.3\%), then C\&I (27.8\%); EdP had the lowest response rate $(25.5 \%)$. 
Table 16

Chair and Faculty Survey Response Rate by Department

\begin{tabular}{cccc}
\hline & Invited & Responded & Response Rate (\%) \\
\hline Chair & 93 & 37 & 39.8 \\
C\&I & 16 & 4 & 25.0 \\
EDLS & 29 & 14 & 48.3 \\
TEd & 23 & 10 & 43.5 \\
EdP & 25 & 9 & 36.0 \\
Faculty & 843 & 230 & 27.3 \\
C\&I & 212 & 59 & 27.8 \\
EDLS & 215 & 78 & 36.3 \\
TEd & 232 & 46 & 31.3 \\
EdP & 184 & 47 & 25.5 \\
Total & 936 & 267 & 28.5 \\
\hline
\end{tabular}

\section{Department Chairs' Data}

Table17 reports the survey responses by chairs and the number of chairs whose four leadership frames were rated by the faculty respondents. Among the 37 chair respondents, 17.1 percent were from the departments of C\&I $(n=4), 31.6$ percent were from EDLS $(n=14), 29.3$ percent were from TEd $(n=10)$, and 23.0 percent were from EdP $(n=9)$. Two hundred and thirty faculty rated 81 department chairs, of which, about 20 percent $(n=16)$ were C\&I chairs, 32 percent $(n=26)$ EDLS chairs, 21 percent $(n=17)$ TEd chairs, and 27.2 percent $(n=22)$ EdP chairs. For the 37 department chairs who reported to the survey, there were 25 males $(67.6 \%)$ and 12 females $(32.4 \%)$. For the 81 chairs rated by 230 faculty, the ratio of males to females was virtually identical: $67 \%$ 
Table 17

Chair Responses by Demographic Variables

\begin{tabular}{|c|c|c|c|c|}
\hline & \multicolumn{2}{|c|}{ Response } & \multicolumn{2}{|c|}{ Rated Chairs } \\
\hline & $\mathrm{N}$ & Percent & $\mathrm{N}$ & Percent \\
\hline \multicolumn{5}{|l|}{ Department Type } \\
\hline C\&I & 4 & 17.1 & 16 & 19.8 \\
\hline EDLS & 14 & 31.6 & 26 & 32.1 \\
\hline TEd & 10 & 29.3 & 17 & 21.0 \\
\hline EdP & 9 & 23.0 & 22 & 27.2 \\
\hline Total & 37 & 100.0 & 81 & 100.0 \\
\hline \multicolumn{5}{|l|}{ Gender } \\
\hline Male & 25 & 67.6 & 54 & 66.7 \\
\hline Female & 12 & 32.4 & 27 & 33.3 \\
\hline Total & 37 & 100.0 & 81 & 100.0 \\
\hline \multicolumn{5}{|l|}{ Age } \\
\hline Below 51 years old & 9 & 24.3 & - & - \\
\hline 51 to 60 & 20 & 54.1 & - & - \\
\hline Above 60 & 8 & 21.6 & - & - \\
\hline Total & 37 & 100.0 & - & - \\
\hline \multicolumn{5}{|l|}{ Department Size (faculty members) } \\
\hline Small (fewer than 10) & 9 & 24.3 & 10 & 12.3 \\
\hline Medium (10 to 20$)$ & 10 & 27.0 & 26 & 32.1 \\
\hline Large (more than 20) & 18 & 48.7 & 45 & 55.6 \\
\hline Total & 37 & 100.0 & 81 & 100.0 \\
\hline \multicolumn{5}{|l|}{ Highest Degree } \\
\hline Master & 0 & 0.0 & - & - \\
\hline \multicolumn{5}{|l|}{ Doctorate } \\
\hline Ed. D. & 9 & 24.3 & - & - \\
\hline Ph. D. & 28 & 75.7 & - & - \\
\hline Total & 37 & 100.0 & - & - \\
\hline \multicolumn{5}{|l|}{ Tenure Status } \\
\hline Tenured & 37 & 100.0 & - & - \\
\hline Non-Tenured & 0 & 0.0 & - & - \\
\hline Total & 37 & 100.0 & - & - \\
\hline \multicolumn{5}{|l|}{ Chair's Length in the position } \\
\hline Short-Term (less than 3 years) & 10 & 27.0 & - & - \\
\hline Medium ( 3 to 5 years) & 17 & 45.9 & - & - \\
\hline Long-Term (more than 5 years) & 10 & 27.1 & - & - \\
\hline Total & 37 & 100.0 & - & - \\
\hline
\end{tabular}


male versus $33 \%$ female. About half of the chair respondents $(n=18)$ were from departments with more than 20 faculty, 27.0 percent $(n=10)$ were from departments with between 10 to 20 faculty, and 24.3 percent $(n=9)$ were from departments with fewer than 10 faculty. All the chairs responding to the survey had a doctoral degree: 24.3 percent ( $n$ $=9)$ with an Ed. D. and 75.7 percent $(n=28)$ with a Ph. D. All the 37 chairs were tenured. Ten of 37 chairs $(27.0 \%)$ had a length of less than three years in the position, another 10 $(27.0 \%)$ had served for more than five years, and fourteen $(45.9 \%)$ had served three to five years.

\section{Faculty Data}

Faculty demographics are featured in Table 18. Of the 230 respondents, 25.5 percent were from C\&I $(n=59), 33.9$ percent from EDLS $(n=78), 20$ percent from TEd $(n=46)$, and 20.4 percent from $\operatorname{EdP}(n=47)$. The average age of the respondents $(n=225)$ was 51, ranging from 29 to 74 . By gender, 126 were male $(54.8 \%)$ and 104 female (45.2\%). By department size, about 13 percent were from departments with fewer than 10 faculty $(n=29), 29.1$ percent $(n=67)$ from departments with between 10 to 20 faculty, and 58.3 percent $(n=134)$ from departments with more than 20 faculty. The vast majority possessed a doctoral degree and only four had a master's degree as the highest degree earned. Consistent with the profession in general, most faculty were in the senior ranks: 38.7 percent $(n=89)$ were professors; 29.6 percent $(n=68)$ were associate professors; 28.3 percent $(n=65)$ were assistant professors; and only four percent $(n=8)$ were instructors. 
Table 18

Faculty Survey Responses by Demographic Variables

\begin{tabular}{|c|c|c|}
\hline & $\mathrm{N}$ & Percen \\
\hline \multicolumn{3}{|l|}{ Department Type } \\
\hline C\&I & 59 & 25.7 \\
\hline EDLS & 78 & 33.9 \\
\hline TEd & 46 & 20.0 \\
\hline EdP & 47 & 20.4 \\
\hline Total & 230 & 100.0 \\
\hline \multicolumn{3}{|l|}{ Age } \\
\hline $29-44$ & 58 & 25.8 \\
\hline $45-60$ & 126 & 56.0 \\
\hline $61-75$ & 41 & 18.2 \\
\hline Total & $225^{\mathrm{a}}$ & 100.0 \\
\hline \multicolumn{3}{|l|}{ Gender } \\
\hline Male & 126 & 54.8 \\
\hline Female & 104 & 45.2 \\
\hline Total & 230 & 100.0 \\
\hline \multicolumn{3}{|c|}{ Department Size (faculty members) } \\
\hline Small (less than 10) & 29 & 12.6 \\
\hline Medium (10 to 20$)$ & 67 & 29.1 \\
\hline Large (more than 20) & 134 & 58.3 \\
\hline Total & 230 & 100.0 \\
\hline \multicolumn{3}{|l|}{ Highest Degree } \\
\hline Master & 4 & 1.7 \\
\hline \multicolumn{3}{|l|}{ Doctorate } \\
\hline Ed. D. & 46 & 20.0 \\
\hline Ph. D. & 180 & 78.3 \\
\hline Total & 230 & 100.0 \\
\hline \multicolumn{3}{|l|}{ Academic Rank } \\
\hline Instructor & 8 & 4.0 \\
\hline Assistant Professor & 65 & 28.3 \\
\hline Associate Professor & 68 & 29.6 \\
\hline Professor & 89 & 38.7 \\
\hline Total & 230 & 100.0 \\
\hline
\end{tabular}

a. The item of age had missing values and was not able to be imputed. 


\section{Approaches to Dealing with Missing Values}

Two types of missing values in this study were considered and imputed: item nonresponse, in which the complete survey or some items were not completed, and those cases, in which a respondent put "Do Not Know" as the answer to an item. The method of cell mean imputation (Lohr, 1999) was used to fill missing values in faculty surveys (Leadership Orientation and Instructional Technology Utilization). First, the mean of an item with a missing value or missing values for the respondents in the same department was calculated. If the value of that item was missing for all the respondents in the same department or if there was only one respondent in that department, the mean was computed by using the score of other items in the same section answered by that respondent. Then, the mean was substituted for each missing value. In addition, the method of cold-deck imputation (Lohr, 1999) was used to fill the missing values in the demographic section of the survey for chairs. For example, as mentioned in the preceding section, the total number of chairs rated by faculty and the number of chairs by department type were imputed from the faculty responses. The number of the rated chairs by gender and department size was imputed by using data from the institutions' Websites for the respondents to this study.

\section{Reliability of Scales}

The survey instrument of Leadership Orientations (other) has been used numerous times to investigate leadership styles of higher education administrators at different levels. However, it has not been used to examine the leadership styles of department chairs in the Colleges of Education at Doctoral/Research Extensive Public Universities by Carnegie Classifications (Basinger, 2000). Therefore, it was necessary to check the 
internal consistency of each of the four scales (frames). Because of the small sample size, this analysis was not conducted on the chair version of the instrument of Faculty Utilization of Instructional Technology in Teaching when it was piloted. The internal consistency of each scale on the faculty version of the instrument about instructional technology was examined. Since these two instruments were created for this study and used for the first time, a further check of the reliability on the data collected for the study was necessary. If the alpha for an item is lower than the acceptable level, it should be deleted to enhance the accuracy of data analysis. Cronbach's alpha coefficients were computed on each scale in the three survey instruments to examine the internal consistency. The results are presented as follows.

\section{Leadership Orientation (other)}

Leadership Orientation (other) is composed of 32 items, falling into four factors. Each of the four factors represents a leadership frame (the structural, human resource, political, and symbolic frame). Each factor consists of 8 items. Respondents use a fivepoint Likert scale to assess the degree to which the department chairs they rate exhibit each leader behavior ( $1=$ Never, $2=$ Occasionally, $3=$ Sometimes, $4=$ Often, and $5=$ Always).

Table 19 reports the results of Cronbach's alpha on each leadership frame. The alpha was calculated on the basis of 230 faculty responses. The coefficient alpha for all eight items on the scale of the structural frame was .916, which is almost the same as Bolman and Deal's reported alpha (.920). The item-total correlations ranged from .500 to .810 (see Appendix E). The scale of the human resource frame had an alpha of .939 for all eight items. This coefficient was also close to Bolman and Deal's alpha (.931). The 
minimum and maximum item-total correlations were .695 and .841 (see Appendix E). The alpha for all eight items of the political frame was .931, which was slightly higher than Bolman and Deal's alpha for this scale (.913). The lowest item-total correlation was .711 and the highest was .799 . The coefficient alpha for the last scale, the symbolic frame, was .939, which was also slightly higher than Bolman and Deal's alpha for this scale (.931). The range of the item-total correlations was from .701 to .871 (see Appendix E). The coefficient alpha for all four scales of Leadership Orientation (other) was high enough to be accepted. The item-total correlations indicated that all items on each scale were highly correlated with the remainders on that scale, so all the items were retained for analysis.

Table 19

Cronbach's Alpha Coefficients by Leadership Frame

\begin{tabular}{lccc}
\hline \multicolumn{1}{c}{ Frame } & Number of Items & Alpha & Bolman's Alpha $^{\mathrm{a}}$ \\
\hline Structural & 8 & 0.916 & 0.920 \\
Human Resource & 8 & 0.939 & 0.931 \\
Political & 8 & 0.931 & 0.913 \\
Symbolic & 8 & 0.939 & 0.931 \\
\hline
\end{tabular}

a. The data were from Lee Bolman's home page at http://www.bloch.umkc.edu/classes/bolman/new page 1.htm. Boman's reliability statistics for Leadership Orientation were computed based on 1309 colleague ratings for multi-sector sample of managers in business and education.

Faculty Utilization of Instructional Technology in Teaching (chair)

The instrument of Faculty Utilization of Instructional Technology in Teaching (chair version) is composed of five sections, 46 items. Cronbach's alpha was computed on each of the five sections for the examination of the internal consistency (see Table 20) 
on the basis of 37 chair ratings for the instructional technology use by faculty in their departments. The item-total correlation for an individual item on each of the five scales was also computed (see Appendix F). The alpha for all 10 items on the scale of instructional technology infrastructure was .955 with a range of the item-total correlations from .627 to .922 . The section of faculty utilization of instructional technology had an

Table 20

Cronbach's Alpha Coefficients by Factor of Instructional Technology (chair)

\begin{tabular}{lcc}
\hline \multicolumn{1}{c}{ Section } & Number of Items & Alpha for All Items \\
\hline Instructional Infrastructure & 10 & .955 \\
Technology Utilization & 10 & .861 \\
Technical Support & 6 & .957 \\
Administrative Support & 10 & .885 \\
Key Issues & 9 & .806 \\
\hline
\end{tabular}

alpha of .861 for all 10 items. The maximum item-total correlation was .814 and the minimum was .295 . Removing the item with the smallest item-total correlation only slightly improved the alpha by .006 , so it was not deleted. The section of technical support had the highest alpha among all five scales, .957 . The item-total correlations ranged from .777 to .930 . The alpha for all 10 items on the scale of administrative support was .8857 with a range of the item-total correlations from .494 to .804 . Deletion of any item was not able to raise the coefficient alpha. The scale of key issues had the lowest alpha in this instrument, .808, but far beyond the alpha level (.70) that can be accepted (Spector, 1992). On the basis of the high alpha and also the item-total correlations, all items in the five sections were retained. 
Faculty Utilization of Instructional Technology in Teaching (faculty)

Faculty Utilization of Instructional Technology in Teaching (faculty) consists of five sections, 46 items. Cronbach's alpha for all items on each section was calculated for the check of internal consistency (see Table 21) based on 230 faculty ratings for the instructional technology use in their departments. In addition, item-total correlations within each section were also computed to examine if an individual item was highly correlated to the remainders on the same scale (see Attachment $\mathrm{G}$ ). The alpha for all 10 items on the scale of instructional technology infrastructure was .950, which is acceptable. The item-remainder coefficients ranged from .665 to .874 . Deletion of any item was not able to increase the alpha for all items, so all 10 items were retained for

Table 21

Cronbach's Alpha Coefficients by Factor of Instructional Technology (faculty)

\begin{tabular}{lcc}
\hline \multicolumn{1}{c}{ Factor } & Number of Items & Alpha for All Items \\
\hline Instructional Infrastructure & 10 & .950 \\
Technology Utilization & 10 & .814 \\
Technical Support & 6 & .910 \\
Administrative Support & 10 & .878 \\
Key Issues & 9 & .879 \\
\hline
\end{tabular}

analysis on this scale. The scale of technology utilization had an alpha of .814 for all items, which was low, but higher than the suggested alpha level of .70 (Spector, 1992). The range of the item-total correlations was from .307 to .558 . Although the removal of Item 19, utilization of a chat room, actually would have slightly improved the scale's coefficient alpha (.815), it was not removed because the item-total correlation of this item was .300 , which indicated that there was a relationship of this item with the remaining 
items. The alpha for all 6 items in the section of technical support was .910. The itemtotal correlations ranged from .742 to .824 . No items were deleted from this scale. The alpha for all 10 items on the scale of administrative support was .878. The minimum and maximum item-total correlations were .482 and .717 , respectively. When Item 33 or Item 37 was deleted, the alpha increased slightly, so they were all retained for analysis on this scale. The last section, key issues about technology use, had an alpha of .879 with the item-total correlations ranging from .523 to .677 . In summary, the alpha for all five scales was acceptable and the most of the item-total correlations for each scale were high, indicating that each item was highly related to the remainders within that scale.

Thus, all the scales in the three instruments were internally consistent and reliable for investigating leadership styles of department chairs and faculty instructional technology utilization in teaching in colleges of education. Consequently, all the data collected were retained for data analysis.

\section{Major Findings}

In this section, the major findings of the data analysis are presented as they pertain to the five research questions.

Research Question One. What are the leadership styles (as measured by the four frames) of the chairs in the departments of C\&I, EDLS, TEd, and EdP?

The data used to answer this question were generated from Leadership Orientation (other) survey completed by the 230 faculty participants, who rated 81 different department chairs. The following results are presented according to the perception of the 230 faculty. 
- The mean and standard deviation of each of the four leadership frames of department chairs reported by faculty

- The frequency and percentage of each frame used by chairs reported by faculty

- The frequency and percentage of chairs' leadership styles by four categories (no, single, paired, and multi-frame)

- The frequency and percentage of leadership frame patterns within each category

Table 22 presents the means and standard deviations of chair's four leadership frames (structural, human resource, political, and symbolic) rated by faculty $(n=230)$. The human resource frame had the highest mean $(M=3.2, S D=1.41)$, followed by the structural frame $(M=3.1, S D=1.32)$ and the political frame $(M=3.0, S D=1.32)$. The symbolic frame had the lowest mean $(M=2.8, S D=1.36)$.

Table 22

Means and Standard Deviations of Chairs' Four Leadership Frames Rated by Faculty

\begin{tabular}{lcc}
\hline \multicolumn{1}{c}{ Frame } & Mean & Standard Deviation \\
\hline Structural & 3.1 & 1.32 \\
Human Resource & 3.2 & 1.41 \\
Political & 3.0 & 1.32 \\
Symbolic & 2.8 & 1.36 \\
\hline
\end{tabular}

Table 23 presents frequency distribution for the frame use by chairs perceived by their faculty. According to faculty ratings, only two chairs each never used the human resource frame and the political frame, eight chairs never used the symbolic frame, and no chairs ever used the structural frame. One quarter of the 81 chairs occasionally used 
Table 23

Frequency Distribution for Frame Use by Chairs

\begin{tabular}{lccc}
\hline Frame & Mean Score Range & Frequency & Percent \\
\hline Structural $(n=81)$ & $1-1.9$ & 0 & 0.0 \\
$2-2.9$ & 20 & 24.7 \\
$3-3.9$ & 39 & 48.1 \\
Human Resource $(n=81)$ & $4-5$ & 22 & 27.2 \\
Political $(n=81)$ & $1-1.9$ & 2 & 0.1 \\
& $2-2.9$ & 15 & 18.5 \\
& $3-3.9$ & 40 & 49.4 \\
Symbolic $(n=81)$ & $4-5$ & 24 & 29.6 \\
& $1-1.9$ & 2 & 0.1 \\
& $2-2.9$ & 22 & 27.2 \\
& $3-3.9$ & 40 & 49.4 \\
& $4-5$ & 17 & 21.0 \\
& $1-1.9$ & 8 & 9.8 \\
& $2-2.9$ & 26 & 32.1 \\
& $3-3.9$ & 34 & 42.0 \\
& $4-5$ & 13 & 16.0 \\
\hline
\end{tabular}

Note. The response scale for leadership frame: $1=$ never, $2=$ occasionally, $3=$ sometimes, $4=$ often, and $5=$ always.

$* p<.05$

the structural frame, nearly 19 percent occasionally used the human resource frame, about 27 percent occasionally used the political frame, and almost one-third occasionally used the symbolic frame. Approximately one half of chairs were perceived by their faculty to use the structural, human resource, and political frames sometimes, while 42 percent sometimes used the symbolic frame reported by their faculty. Faculty ratings indicated that 27.2 percent of chairs $(n=22)$ often used the structural frame; 29.6 percent $(n=24)$ 
often used the human resource frame; 21.0 percent $(n=17)$ often used the political frame; and 16 percent $(n=13)$ often used the symbolic frame. The chi-square statistic indicated that there was a significant difference on the leadership frame utilization by chairs perceived by faculty, $\chi^{2}(3, n=81)=8.667, p<.05$. Chairs were more likely to use the human resource frame, followed by the structural, political, and symbolic frames.

The faculty participants ratings of department chairs was analyzed according to whether they used one frame (single), two frames (paired), three or four frames (multiple), or no frame. Table 24 presents the frequency and percentage of the four categories of chairs' leadership frame use reported by faculty. Faculty rated most of the chairs $(n=46,56.8 \%)$ as not consistently using any frames. They believed that 14.8 percent $(n=12)$ each used a single-frame approach and a multi-frame approach and 13.6 percent $(n=11)$ utilized a paired-frame approach. The chi-square test showed a significant difference in the chairs' use of leadership approaches based on the leadership frame use perceived by faculty, $\chi^{2}(3, \mathrm{n}=81)=43.691, p<.001$. Chairs were more likely to adopt no style rather than the single, paired-, or multi-frame style.

The frequency distribution for frame patterns within each of the three categories (single, paired, and multiple) is also presented in Table 24. Within the single-frame category, the human resource frame was reported to be used the most by chairs $(n=5$, 41.7\%). This was followed by the structural frame $(n=4,33.3 \%)$ and the political frame $(n=2,16.7 \%)$. Only one chair $(8.3 \%)$ used the symbolic frame.

Of the 11 paired-frame chairs, faculty rated that most $(n=6,54.5 \%)$ used a combination of the structural and human resource frames, and two (18.2\%) used a combination of the human resource and political frames. Faculty reported that the 
Table 24

Frequency Distribution by Frame Pattern

\begin{tabular}{|c|c|c|c|}
\hline Category/Pattern & $\mathrm{F}$ & $\begin{array}{c}\% \\
\text { (as to category) }\end{array}$ & $\begin{array}{c}\% \\
\text { (as to total) }\end{array}$ \\
\hline No-frame & 46 & 100.0 & 56.8 \\
\hline \multicolumn{4}{|l|}{ Single-frame } \\
\hline Structural & 4 & 33.3 & 4.9 \\
\hline Human Resource & 5 & 41.7 & 6.2 \\
\hline Political & 2 & 16.7 & 2.5 \\
\hline Symbolic & 1 & 8.3 & 1.2 \\
\hline Total & 12 & 100.0 & 14.8 \\
\hline \multicolumn{4}{|l|}{ Paired-frame } \\
\hline Structural/Human Resource & 6 & 54.5 & 7.4 \\
\hline Structural/Political & 1 & 9.1 & 1.2 \\
\hline Structural/Symbolic & 0 & 0.0 & 0.0 \\
\hline Human Resource/Political & 1 & 9.1 & 1.2 \\
\hline Human Resource/Symbolic & 2 & 18.2 & 2.5 \\
\hline Political/Symbolic & 1 & 9.1 & 1.2 \\
\hline Total & 11 & 100.0 & 13.6 \\
\hline \multicolumn{4}{|l|}{ Multi-Frame } \\
\hline Structural/Human Resource/Political & 3 & 25.0 & 3.7 \\
\hline Structural/Human Recourses/Symbolic & 1 & 8.3 & 1.2 \\
\hline Structural/Political/Symbolic & 2 & 16.7 & 2.5 \\
\hline Human Resource/Political/Symbolic & 0 & 0.0 & 0.0 \\
\hline Structural/Human Resource/ Political/Symbolic & 6 & 50.0 & 7.4 \\
\hline Total & 12 & 100.0 & 14.8 \\
\hline
\end{tabular}


combination of the structural and political frames, the human resource and political frames, and the political and symbolic frames was used each by only one chair (9.1\%). No chairs followed the combined pattern of the structural and symbolic frames according to the faculty ratings.

For the combined patterns of the multiple leadership frames, the four-frame pattern (the structural, humane resource, political and symbolic) was reported to be used by half of the chairs $(n=6)$ in this category. The combination of the structural, human resource, and political frame was used by a quarter of the chairs $(n=3)$ perceived by their faculty. This was followed by the combination of the structural, political, and symbolic frames $(n=2,16.7)$. Only one chair $(8.3 \%)$ adopted the combination of the structural, human resource, and symbolic frames. No chairs used a combination of the human resource, political, and symbolic frames.

As for all patterns, faculty reported that the combination of the four frames and the combination of the structural and human resource frames were the most commonly used frame patterns by chairs. About seven percent each used these patterns. These were followed by the human resource frame (6.2\%), and then the structural frame (4.9\%).

Thus, chairs were reported by faculty to have the highest mean on the human resource frame, followed by closely the structural and political frames. The symbolic frame was the least reported. In terms of the four categories of leadership frames, chairs were perceived to use a no-frame category the most, followed by a single-frame and multi-frame category. A paired-frame category was used the least. As for combinations of leadership frames used by chairs, a combination of the structural and human resource 
frames and the four frames were used the most, followed by a combination of the structural, human resource, and political frames.

Research Question Two. How does the leadership style of chairs vary by academic department, discipline, gender, size of a department, and chairs' length of tenure?

This question was investigated in two parts: an exploration as to whether the selected demographic variables of academic department, a chair's gender, size of department, and chairs' length of tenure in the position as well as the interactions between or among these variables significantly affected their leadership frame utilization reported by faculty; an examination of the frequency distribution of categories (no, single, paired-, and multi-frame) of chairs' leadership frames in relation to these demographic variables.

To examine if the selected demographic variables significantly influenced a chair's leadership frame use, a between-subjects multivariate analysis of variance (MANOVA) was performed on the four dependent variables (frames): the structural, the human resource, the political, and the symbolic frames. The independent variables were academic department type (four levels: C\&I, EDLS, TEd, and EdP), gender (two levels: male and female), size of a department (three levels: the number of faculty is less than 10 , 10 to 20 , and greater than 20), and chairs' length of tenure (three levels: less than 3 years, 3 to 5 years, and longer than 5 years).

Table 25 presents the results of three tests of the effect of each of the five demographic variables (department type, department size, chair's gender, age, and the length in the position), and the four selected interactions (type versus gender, type versus 
Table 25

Effects of Demographic Variables on Chairs' Leadership Frame Use

\begin{tabular}{|c|c|c|c|}
\hline Variable/Interaction & Test & Value & Sig. of F \\
\hline \multirow[t]{3}{*}{ Department Type } & Pillar's Trace & 1.914 & $.030 *$ \\
\hline & Wilks’ Lambda & 1.913 & $.031 *$ \\
\hline & Hotelling's Trace & 1.906 & $.031 *$ \\
\hline \multirow[t]{3}{*}{ Gender } & Pillar's Trace & 4.109 & $.003 * *$ \\
\hline & Wilks' Lambda & 4.109 & $.003 * *$ \\
\hline & Hotelling's Trace & 4.109 & $.003 * *$ \\
\hline \multirow[t]{3}{*}{ Size of a Department } & Pillar's Trace & 1.608 & .120 \\
\hline & Wilks' Lambda & 1.602 & .122 \\
\hline & Hotelling's Trace & 1.596 & .124 \\
\hline \multirow[t]{3}{*}{ Age } & Pillar's Trace & 1.422 & .190 \\
\hline & Wilks' Lambda & 1.414 & .193 \\
\hline & Hotelling's Trace & 1.406 & .196 \\
\hline \multirow[t]{3}{*}{ Length in the Position } & Pillar's Trace & 1.851 & .070 \\
\hline & Wilks' Lambda & 1.893 & .063 \\
\hline & Hotelling's Trace & 1.933 & .057 \\
\hline \multirow[t]{3}{*}{ Department/Gender } & Pillar's Trace & 1.727 & .057 \\
\hline & Wilks' Lambda & 1.751 & .053 \\
\hline & Hotelling's Trace & 1.771 & $.050 *$ \\
\hline \multirow[t]{3}{*}{ Department/Size } & Pillar's Trace & 1.417 & .105 \\
\hline & Wilks' Lambda & 1.426 & .102 \\
\hline & Hotelling's Trace & 1.432 & .099 \\
\hline \multirow[t]{3}{*}{ Gender/Size } & Pillar's Trace & 1.511 & .151 \\
\hline & Wilks' Lambda & 1.513 & .150 \\
\hline & Hotelling's Trace & 1.516 & .150 \\
\hline \multirow[t]{3}{*}{ Age/Length } & Pillar's Trace & 3.018 & $.001 * *$ \\
\hline & Wilks' Lambda & 3.092 & $.000 * *$ \\
\hline & Hotelling's Trace & 3.129 & $.000 * *$ \\
\hline
\end{tabular}

$* \mathrm{p}<.05, * * \mathrm{p}<.01$ 
size, gender versus size, and age versus length) on the chairs' combined use of the four leadership frames reported by faculty. With the use of Wilks' criterion, the chairs' combined use of the four leadership frames (structural, human resource, political, and symbolic) were significantly affected by department type, $F(3,214)=1.913, p<.05$; gender, $F(1,222)=4.109, p<.01$; and the interaction of age and the chairs' length in the position, $F(4,93)=3.092, p<.001$. With the use of Hotelling's criterion (a less conservative test than Wilks' one), besides the above variables or interaction, the interaction of department type and gender also had a significant influence on the chair's leadership frame use, $F(4,202)=1.414, p<.05$. The size of a department, $F(4,202)=$ $1.602, p>.05$, chairs' age, $F(4,93)=, p>.05$, and the chair's length in the position, $F(4$, $93)=1.893, p>.05$, alone did not significantly influence the chairs' use of leadership frames, nor did the interactions between department size and gender $F(4,202)=1.513$, $p>.05$, and department type and size, $F(4,202)=1.426, p>.05$.

To investigate the impact of each of the five demographic variables and the four interactions between the selected demographic variables on each of the four leadership frames rated by faculty, a univariate ANOVA and a Roy-Bargman stepdown analysis were performed on the four frames. The reason why these two types of analysis were conducted was because the dependent variables (four frames) in this study were significantly correlated to each other at a significance level of .01, two tails, as indicated in Table 26. The correlated dependent frames measure overlapping aspects of the same leadership behavior. In other words, if two dependent variables are highly correlated, an independent variable that affects one surely affects the other. Therefore, only reporting univariate $F$ s on leadership frames would lead to a biased conclusion in which a 
demographic variable is reported to have a significant influence on a leadership frame, when it does not have any effect.

Table 26

Correlations between Four Leadership Frames

\begin{tabular}{cllll}
\hline & ST & HR & PO & SY \\
\hline ST & 1.000 & & & \\
HR & $0.768^{*}$ & 1.000 & & \\
PO & $0.748^{*}$ & $0.743^{*}$ & 1.000 & \\
SY & $0.772^{*}$ & $0.823^{*}$ & $0.881^{*}$ & 1.000 \\
\hline
\end{tabular}

$* \mathrm{p}<.01$

As indicated by the univariate $F$ s (see Table 27), there was a significant difference in the chairs' use of all four leadership frames by academic department. As reported by participating faculty members, the EdP chairs scored the highest on all four frames, while the EDLS chairs scored the lowest. This indicated that the EdP chairs were more likely to use leadership frames than were other chairs. EdP faculty reported that their chairs had a mean of 3.74 on the structural frame, which was followed by C\&I $(M=3.5)$, TEd $(M=$ 3.44), and EDLS $(M=3.25)$. The mean of the EdP chairs on the human resource frame was 3.87. The second highest mean was reported for the TEd chairs $(M=3.61)$. This was followed by the C\&I chairs $(M=3.47)$, and then the EDLS chairs $(M=3.25)$. The EdP chairs' means of the political and symbolic frames were 3.73 and 3.48 , respectively. These were followed by the TEd chairs, 3.41 for the political frame and 3.22 for the symbolic frame. The C\&I chairs' means of these two frames were 3.31 and 3.16. The EDLS chairs averaged out at 3.22 on the political frame and 2.85 on the symbolic frame. However, the only significant difference was detected in all the four frames between the 
Table 27

Effects between the Selected Demographic Variables and Leadership Frames

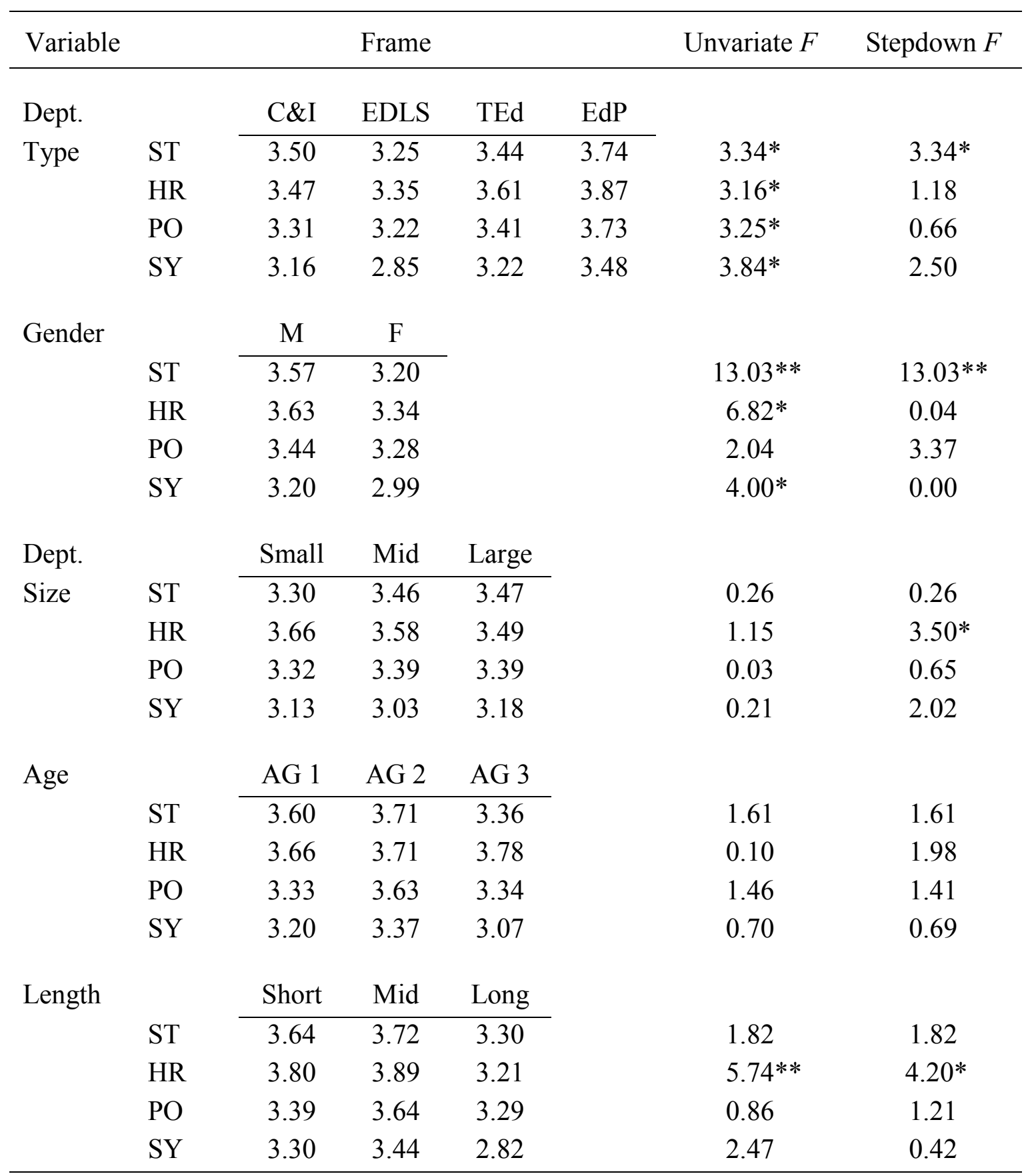

$* p<.05 . * * p<.01$ 
EDLS and EdP chairs with the Scheffe post-hoc test at a significance level of .05. This indicated that the EdP chairs scored significantly higher on all four leadership frames than did the EDLS chairs. The stepdown analysis nevertheless found that a unique contribution to predicting differences between or among the chairs in the different departments was made by the structural frame, $F(3,205)=3.34, p<.05$.

Chairs' gender had a significant influence on the three leadership frames (structural, human resource, and symbolic) as found by the univariate ANOVA (see Table 27). The male chairs scored significantly higher than did the female chairs on these three frames. A stepdown analysis showed, however, that the male chairs $(M=3.57)$ had a significantly higher mean on the structural frame than did the female chairs $(M=3.20)$, $F(3,205)=13.03, p<.01$.

According to univariate analysis, department size did not significantly affect the chairs' use of leadership frames (see Table 27). However, stepdown analysis revealed that there was a significant difference, according to the participating faculty, regarding the department chairs' use of the human resource frame size of departments by size of department, stepdown $F(2,205)=3.50, p<.05$. The chairs of small departments were more likely to use the human resource frame as reported by their faculty.

Univariate and stepdown analysis both showed that chairs with a different length in the position significantly influenced their use of the human resource frame, stepdown $F(2,205)=4.3, p<.05$ (see Table 27). The Scheffe post hoc test found that chairs with a length from three to five years had a significantly higher score on this frame than the chairs who had served for more than five years. The Fisher's LSD test also indicated a 
significant difference between the chairs with a length of one or two year(s) in the position $(M=3.8)$ and those being in the position more than five years $(M=3.89)$.

Table 28 reports the effect of the four selected interactions between the demographic variables on the chairs' leadership frames. While the univariate $F$ s indicated two significant differences, Stepdown analysis found that three of the four interactions significantly influenced the chairs' use of leadership frames. The interaction of department type and gender was found to have a significant effect on the human resource frame, univriate $F=3.22, p<.05$. The female EdP chairs scored the highest on this frame ( $M=4.0, S D=0.74)$, while the female EDLS chairs scored the lowest $(M=2.74, S D$ $=0.92)$.

The interaction of department type and size had a significant influence on the chairs' use of the symbolic frame, stepdown $F=2.67$. The TEd chairs with a small number of faculty scored the highest $(M=3.75)$ while the EDLS chairs with a large number of faculty scored the lowest $(M=2.51)$.

The interaction of gender and department size was found to affect the chairs' use of the human resource frame significantly, stepdown $F=4.02, p<.05$. The female chairs in departments with a small number of faculty had the highest mean $(M=3.79)$ on the human resource frame while the female chairs in departments with a medium number of faculty (10 to 20$)$ were reported to have the lowest score on this frame $(M=3.14)$. 
Table 28

Effects of the Selected Interactions on the Four Leadership Frames

\begin{tabular}{|c|c|c|c|}
\hline Interaction & Frame & Univariate $\mathrm{F}$ & Stepdown F \\
\hline Department Type/ & Structural & 1.13 & 1.13 \\
\hline \multirow[t]{3}{*}{ Gender } & Human Resource & $3.22 *$ & 3.04 \\
\hline & Political & 1.24 & 0.44 \\
\hline & Symbolic & 1.14 & 2.43 \\
\hline Department Type/ & Structural & 1.34 & 1.34 \\
\hline \multirow[t]{3}{*}{ Department Size } & Human Resource & 1.51 & 0.84 \\
\hline & Political & 1.28 & 0.89 \\
\hline & Symbolic & 1.32 & $2.67 *$ \\
\hline Gender/ & Structural & 0.36 & 0.36 \\
\hline \multirow[t]{3}{*}{ Department Size } & Human Resource & 1.47 & $4.02 *$ \\
\hline & Political & 1.75 & 1.51 \\
\hline & Symbolic & 1.78 & 0.22 \\
\hline \multirow[t]{4}{*}{ Age/Length } & Structural & $3.21 *$ & $3.21 *$ \\
\hline & Human Resource & $3.56^{*}$ & 1.37 \\
\hline & Political & 0.34 & $3.45^{*}$ \\
\hline & Symbolic & 1.40 & 1.44 \\
\hline
\end{tabular}

$* p<.05$

The stepdown analysis found a significant difference in the chairs' use of the structural frame, $F=3.28, p<.05$, and the political frame, $F=4.33, p<.05$, among the combined groups of the chairs with a different age and length in the position. The chairs between the ages of 51 to 60 and from three to five years as a chair had the highest mean $(M=3.90)$ on the structural frame, while those with the same age range but more than five years in the position had the lowest rating $(M=3.05)$ on the same frame. The univariate $F$ also indicated that the interaction of age and length had a significant influence on the 
human resource frame, univariate $F=3.56, \mathrm{p}<.05$. The chairs with an age between 51 to 60 and the shortest length in the position had the highest score $(M=4.35, S D=0.58)$ on this frame, while the chairs with the same age range but the longest length in the position had the lowest score $(M=2.68, S D=0.86)$. As for the political frame, the chairs between 51 and 60 years old and in the chair's position for about three to five years scored the highest $(M=3.71$ ), while the younger chairs (below 50 years old) with a longer time in the chair's position (more than 5 years) were rated the lowest $(M=2.62)$.

The second part of this section describes the frequency distributions of the four categories (no-frame, single-frame, paired-frame, and multi-frame) used by chairs (see Table 29) by each of the selected demographic variables: department type, gender, department size, age, and chairs' length in the position. The chairs in all four departments were most likely to espouse a no-frame approach: more than half of the chairs in all departments followed this pattern, with the only exception of EdP chairs (45.5\%). In addition, about 19 percent of the C\&I chairs $(n=3)$ were reported to use the single-frame category, which was followed by the multi-frame category $(n=2,12.5 \%)$ and the pairedframe category $(n=1,6.2 \%)$. Similarly, besides no-frame theories $(n=17,65.4 \%)$, the EDLS chairs tended to espouse single-frame theories $(n=6,23.1 \%)$. This was followed by multi-frame theories $(n=2,7.7 \%)$ and paired-frame theories $(n=1,3.8 \%)$. The TEd and EdP chairs, though, were more likely to have a paired-frame orientation $(n=4,23.7 \%$ for the TEd chairs; $n=5,22.7 \%$ for the EdP chairs) and a multi-frame orientation ( $n=3$, $17.6 \%$ for the TEd chairs; $n=5,22.7 \%$ for the EdP chairs), rather than a single-frame orientation ( $n=1,5.8 \%$ for the TEd chairs; $n=2,9.1 \%$ for the EdP chairs). 
Table 29

Frequency Distribution of Categories of Chairs' Leadership Frames by Demographic Variables

\begin{tabular}{|c|c|c|c|c|c|c|c|c|}
\hline & \multicolumn{2}{|c|}{ No } & \multicolumn{2}{|c|}{ Single } & \multicolumn{2}{|c|}{ Paired } & \multicolumn{2}{|c|}{ Multiple } \\
\hline & $\mathrm{F}$ & $\%$ & $\mathrm{~F}$ & $\%$ & $\mathrm{~F}$ & $\%$ & $\mathrm{~F}$ & $\%$ \\
\hline \multicolumn{9}{|l|}{ Department Type $(\mathrm{n}=81)$} \\
\hline C\&I $(n=16)$ & 10 & 62.5 & 3 & 18.8 & 1 & 6.3 & 2 & 12.5 \\
\hline EDLS $(n=26)$ & 17 & 65.4 & 6 & 23.1 & 1 & 3.8 & 2 & 7.7 \\
\hline $\operatorname{TEd}(\mathrm{n}=17)$ & 9 & 52.9 & 1 & 5.8 & 4 & 23.7 & 3 & 17.6 \\
\hline $\operatorname{EdP}(n=22)$ & 10 & 45.5 & 2 & 9.1 & 5 & 22.7 & 5 & 22.7 \\
\hline \multicolumn{9}{|l|}{ Gender $(\mathrm{n}=81)$} \\
\hline Male $(\mathrm{n}=54)$ & 27 & 50.0 & 9 & 16.7 & 9 & 16.7 & 9 & 16.7 \\
\hline Female $(\mathrm{n}=27)$ & 19 & 70.4 & 3 & 11.1 & 2 & 7.4 & 3 & 11.1 \\
\hline \multicolumn{9}{|l|}{ Age $(n=37)$} \\
\hline Below $51(\mathrm{n}=10)$ & 4 & 40.0 & 3 & 30.0 & 2 & 20.0 & 1 & 10.0 \\
\hline Between 51 and $60(n=19)$ & 8 & 42.1 & 5 & 26.3 & 2 & 10.5 & 4 & 21.1 \\
\hline Above $60(n=8)$ & 4 & 50.0 & 2 & 25.0 & 1 & 12.5 & 1 & 12.5 \\
\hline \multicolumn{9}{|l|}{ Size of Department $(n=81)$} \\
\hline Small (fewer than 10) $(n=10)$ & 6 & 60.0 & 1 & 10.0 & 0 & 0.0 & 3 & 30.0 \\
\hline Medium $(10$ to 20$)(n=26)$ & 16 & 61.5 & 5 & 19.2 & 4 & 15.4 & 1 & 3.8 \\
\hline Large (more than 20$)(n=45)$ & 24 & 53.3 & 6 & 13.3 & 7 & 15.6 & 8 & 17.8 \\
\hline \multicolumn{9}{|l|}{ Length in the Position $(n=37)$} \\
\hline Short-Term $(<3$ years $)(n=10)$ & 3 & 30.0 & 4 & 40.0 & 2 & 20.0 & 1 & 10.0 \\
\hline Medium ( 3 to 5 years) $(n=17)$ & 7 & 41.2 & 3 & 17.6 & 2 & 11.8 & 5 & 29.4 \\
\hline Long-Term $(>=5$ years $)(n=10)$ & 6 & 60.0 & 3 & 30.0 & 1 & 10.0 & 0 & 0.0 \\
\hline
\end{tabular}


As for the chairs' use of leadership styles by their gender, of the 54 male chairs, $27(50.9 \%)$ did not use any frame and nine (16.7\%) each were uniformly distributed across the other three categories. Of the 27 female chairs, 19 (70.4\%) espoused a noframe theory, three (11.1\%) espoused a single-frame theory, two (7.4\%) espoused a paired-frame theory, and three (11.1\%) espoused a multi-frame theory.

With regard to the chairs' leadership styles by age, of 10 chairs below 51 years old, 40 percent $(n=4)$ used a no-frame style, 30 percent $(n=3)$ used a single-frame style, 20 percent $(n=2)$ used a paired-frame style, and 10 percent $(n=1)$ used a multi-frame style. Of the 19 chairs between 51 to 60 years old, about a half $(n=8)$ were reported to follow a no-frame theory, 26.3 percent $(n=5)$ followed a single-frame theory, 10.5 percent $(n=2)$ followed a paired-frame theory, and 21.1 percent $(n=4)$ followed a multiframe theory. Of the eight chairs above 60 years old, four (50\%) did not use any frames, two $(25 \%)$ used one frame, and another two used two frames (12.5\%) and multiple frames $(12.5 \%)$, respectively.

As far as the chairs' leadership styles by department size were concerned, six of the 10 chairs in the small departments (less than 10 faculty members) used a no-frame style (60\%), only one used a single-frame style (10\%), three used a multi-frame style $(30 \%)$, and no chairs used a paired-frame style. Sixteen of the twenty-six chairs in the medium-sized departments (10 to 20 faculty members) used a no-frame style (61.5\%), five used a single-frame style (19.2\%), four used a paired-frame style (15.4\%), and one used a multi-frame style (3.8\%). Twenty-four of the forty-five chairs in the larger departments (more than 20 faculty members) used a no-frame style (53.3\%), six used a 
single-frame style (13.3\%), seven used a paired-frame style (15.6\%), and eight used a multi-frame style (17.8\%).

As for the chairs' endorsement of frame theories by their length in the position, of the 10 chairs with a short term in the position (less than three years), three (30\%) did not endorse any frames, four (40\%) endorsed one frame, two (20\%) endorsed two frames, and only one (10\%) endorsed multiple frames. Of the seventeen chairs with a middle term in the position (three to five years), seven (41.2\%) did not endorse any frames, three (17.6\%) endorsed one frame, two (11.8\%) endorsed two frames, and five (29.4\%) endorsed multiple frames. Of the 10 chairs with a long term in the position (more than five years), six (60\%) did not endorse any frames, three (30\%) endorsed one frame, one $(10 \%)$ endorsed two frames, and no one endorsed multiple frames.

In summary, two of the chairs' demographic variables and two of the selected interactions had a significant influence on their use of combined leadership frames. Department type had a significantly influence on all four frames: the EdP chairs scored the highest on all four frames while the EDLS chairs scored the lowest. A significant influence was also found by chairs' gender in three of the four leadership frames; only the political frame had no significance. Male chairs had a significantly high score on these three frames. Although department size and the chairs' length in the position did not significantly affect chairs' use of the combined leadership frames, they did have a significant influence on chairs' use of the human resource frame: chairs with three to five years in the position scored significantly higher on this frame than did those with less than three years or more than five years in the position; the smaller a department size was, the higher its chair scored on this frame. 
As for the chairs' use of the four categories of leadership frames, the chi-square test was not conducted due to the inadequacy of the subjects in some cells. Therefore, only descriptive statistics were used to report the result. No matter how the chairs were grouped, the highest percentage of chairs was for those using a no-frame leadership style. However, the distributions of chairs across other three categories of leadership frames varied by different demographic variables.

By department type, the EDLS departments had the highest percentage of chairs using a no-frame leadership style; the EdP departments had the highest percentage of chairs using a multi-frame leadership style. By gender, the female chairs were more likely to use a no-frame leadership style, while the male chairs were more likely to use single, paired- or multi-frame leadership styles than their female colleagues. By chairs' age groups, the highest percentage of chairs using a multi-frame leadership style was for those between 51 and 60 years old, while the highest percentage of chairs using a singleor paired-frame orientation was for those below 51 years old. By the size of a department, the highest percentage of the chairs using a multi-frame leadership style was for those in the smaller departments, followed by those in the larger departments. By the chairs' length in the position, the chairs with a length of three to five years in the position were perceived to use the multiple frames most, followed by those with a length less than three years.

Research Question Three. Is there a statistically significant relationship between the leadership frame(s) of department chairpersons and faculty reports of utilization of instructional technology in teaching courses? 
The data used to analyze this question were produced from Leadership Orientation (other) and Faculty Utilization of Instructional Technology (faculty). Descriptive statistics were used to report the participating faculty use of IT. Pearson moment correlations were computed to examine if there was a significant bivariate relationship between chairs' leadership frames reported by faculty and instructional technology use in teaching. Canonical correlation analysis was also conducted to explore whether any combined variables in one set (leadership frames) were significantly correlated to any combined variables in another sets (instructional technology).

According to the participating faculty ratings, all four departments had a considerably good technology infrastructure: more than three quarters of participants rated their infrastructure as good, very good or excellent (78\% of the EDLS faculty, $80.3 \%$ of the C\&I faculty, $81.9 \%$ of the TEd faculty, and $88.1 \%$ of EdP faculty) (see Appendix M). As for the IT use in teaching, slightly over one-quarter of the C\&I and EDLS faculty reported that they often or always used IT in teaching, while nearly onethird of the TEd and EdP faculty rated this scale as often or always. With regard to the technical support, about one-half of the C\&I, TEd, and EdP participating faculty agreed or strongly agreed that their departments provided various technical support for faculty use of IT, while only about 36 percent of the EDLS participating faculty rated the statements on this scale as agree or strongly agree. As for the administrative support for faculty use of IT, approximately 30 percent of the EDLS and TEd faulty, 25 percent of EdP faculty, and 29 percent of C\&I faculty agreed or strongly agreed that their departments provided this support for their use of IT. The overwhelming majority of the participating faculty of all four departments disagreed or strongly disagreed that their 
department provided any administrative support for their use of IT in teaching. About three quarters of the participating faculty of all four departments rated the issues listed in the survey (see Appendix E) as very important or extremely important for them to improve their use of IT.

Table 30 presents the Pearson correlations between the variables in leadership frames and those in instructional technology. Significant correlations are also noted in the table. All four leadership frames of academic department chairs were significantly correlated to instructional technology infrastructure, $\mathrm{r}=+.259$ (the structural frame), $\mathrm{r}=$ +.250 (the human resource frame), $\mathrm{r}=+.272$ (the political frame), and $\mathrm{r}=+.225$ (the symbolic frame), $n=230, p<.01$, two tails. Correlations for the data also revealed that the structural, political, and symbolic frames were significantly related to faculty utilization of instructional technology, $r=+.140$ (the structural frame), $r=+.166$ (the political frame), and $\mathrm{r}=+.196$ (the symbolic frame), $n=230, p<.05$, two tails; but the human resource frame and faculty utilization of instructional technology were not significantly correlated to each other, $\mathrm{r}=+.037, n=230, p>.05$, two tails. The Pearson correlations also indicated that all four leadership frames were significantly related to technical support provided for faculty to assist in the instructional technology use, $r=+$ .282 (the structural frame), $\mathrm{r}=+.321$ (the human resource frame), $\mathrm{r}=+.344$ (the political frame), and $\mathrm{r}=+.344$ (the symbolic frame), $n=230, p<.01$, two tails. Again, the Pearson correlations showed that all four leadership frames and administrative support provided for instructional technology use were significantly related. The four correlations ranged from +.281 to $+.347, n=230, p<.01$, two tails. Correlations for the data revealed that only the structural and human resource frames were significantly 
correlated to the faculty's score on the key issues, $r=+.153$ (the structural frame) and $r=$ +.163 (the human resource frame), $n=222, p<.05$, two tails. However, no significant correlations were found between the political and symbolic frames, and key issues.

Table 30

Correlation Matrix for the Variables between Leadership Frames and Technology

\begin{tabular}{lcccc}
\hline & Structural & Human Resource & Political & Symbolic \\
\hline Technology Infrastructure & $.259^{* *}$ & $.250^{* *}$ & $.272^{* *}$ & $.225^{* *}$ \\
Technology Utilization & $.140^{*}$ & .037 & $.166^{*}$ & $.196^{* *}$ \\
Technical Support & $.282^{* *}$ & $.321^{* *}$ & $.344^{* *}$ & $.344^{* *}$ \\
Administrative Support & $.308^{* *}$ & $.281^{* *}$ & $.344^{* *}$ & $.347^{* *}$ \\
Key Issues & $.153^{*}$ & $.163^{*}$ & .083 & .117 \\
\hline
\end{tabular}

$n=230$

$* p<.05$, two tails. $* * p<.01$, two tails

A canonical correlation analysis was conducted on the leadership frames and instructional technology. Before canonical analysis, the dependent and independent variables were examined for accuracy of data entry, missing values, and fit between their distributions and the assumptions of canonical correlation analysis, such as linearity, normality, and homoscedasticity. The original dataset has 230 records. No missing data were found. Two scatterplots were used for assessing normality, linearity, and homoscedasticity between pairs of canonical variates. The results showed that there were no obvious departures from linearity or homoscedasticity because the overall shapes did not curve and they were of about the same width throughout. In addition, the $0-0$ points in the scatterplots did not depart from the center of the vertical and horizontal axes. Accordingly, normality for both pairs of canonical variates held. 
As indicated in Table 31, four canonical variates were explored between leadership frames and instructional technology. However, only the first two appeared as a significant correlation between the two sets of variables, $\chi^{2}=97.015$ for the first variate, $p<.01, \chi^{2}=31.526$ for the second variate, $p<.01$. Accordingly, only these two canonical variates were analyzed and described in the following sections.

\section{Table 31}

Canonical Variates and Significance

\begin{tabular}{ccccc}
\hline Canonical Variate & Wilk's & $\chi^{2}$ & DF & Significance \\
\hline 1 & 0.638 & 97.015 & 20 & 0.000 \\
2 & 0.864 & 31.526 & 12 & 0.002 \\
3 & 0.964 & 7.855 & 6 & 0.249 \\
4 & 0.984 & 3.554 & 2 & 0.169 \\
\hline
\end{tabular}

The results of the canonical analysis are reported in Table 32, including the correlations between the variables and their canonical variates, standardized canonical coefficients for the variables, within-set variance accounted for by the canonical variates (percent of variance), redundancies, and canonical correlations. With a cutoff correlation of 0.3 (absolute) between a variable and a canonical variate, the variables in the set of leadership frames included all four leadership frames. Among the variables of instructional technology utilization, four were included in the first canonical variate: technology infrastructure, technology use, technical support, and administrative support. The first pair of canonical variables indicated that department chairs using the structural frame (.762), the human resource frame (.694), the political frame (.879), and the 
Table 32

Statistics of Canonical Correlation Analysis

\begin{tabular}{|c|c|c|c|c|}
\hline & \multicolumn{2}{|c|}{ First Canonical Variate } & \multicolumn{2}{|c|}{ Second Canonical Variate } \\
\hline & Correlation & Coefficient & Correlation & Coefficient \\
\hline \multicolumn{5}{|l|}{ Leadership Style } \\
\hline Structural Frame & 0.762 & 0.140 & 0.389 & 0.017 \\
\hline Human Resource Frame & 0.694 & -0.398 & 0.649 & 1.559 \\
\hline Political Frame & 0.879 & 0.072 & 0.343 & 0.787 \\
\hline Symbolic Frame & 0.976 & 1.133 & 0.158 & -1.833 \\
\hline Percent of variance & 0.713 & & 0.167 & \\
\hline Redundancy & 0.187 & & 0.017 & \\
\hline \multicolumn{5}{|l|}{ Instructional Technology Use } \\
\hline Technology Infrastructure & 0.409 & -0.200 & 0.634 & 0.759 \\
\hline Technology Utilization & 0.467 & 0.251 & -0.506 & -0.736 \\
\hline Technical Support & 0.634 & 0.137 & 0.462 & 0.249 \\
\hline Administrative Support & 0.962 & 0.912 & 0.210 & -0.174 \\
\hline Key Issues & 0.187 & -0.004 & 0.294 & 0.229 \\
\hline Percent of variance & 0.355 & & 0.195 & \\
\hline Redundancy & 0.093 & & 0.020 & \\
\hline Canonical correlation & $0.511 * *$ & & $0.322 *$ & \\
\hline
\end{tabular}

$* \mathrm{p}<.05 . * * \mathrm{p}<.01$

symbolic frame (.976) were more likely to construct technology infrastructure (.409), provide technical support (.467), administrative support (.962) for faculty use of instructional technology in teaching courses, and faculty in these departments are more likely to use instructional technology (.467) in teaching. 
The second canonical variate in the leadership style set was composed of the structural, human resource, and political frames and the corresponding canonical variate from the instructional technology included instructional infrastructure, technology utilization and technical support. This pair of canonical variables suggests that a combination of the structural frame (.3893), the human resource frame (.6496), and the political frame (.3437) was associated a combination of the technology infrastructure (.6341), negative of technology utilization (.0.5061), and technical support (.4629). In summary, the chairs' leadership frames were significantly correlated to instructional technology integration into teaching. The structural frame was significantly correlated to all the factors in instructional technology. The human resource frame was significantly correlated to four of the five factors except technology utilization. The political and symbolic frames were also significantly related to four of the five factors in technology utilization with the only exception of the factor, key issues. Faculty whose department chairs more frequently used leadership frames tended to rate higher on technology factors. The four frames together also had a significant correlation to four of the five factors except key issues. However, a combination of the structural, human resource, and political frames positively influenced technology infrastructure and technical support, but negatively affected faculty practice of technology in teaching. Research Question Four. Is there a statistically significant difference between the various categories (no, single, paired, and multiple) of leadership frames of chairpersons and faculty reports of utilization of instructional technology in teaching courses?

This question was answered in two parts. First, faculty reports of utilization of instructional technology in teaching were compared on the basis of their chairs' use of 
four categories of leadership frames (no, single, paired-, and multi-frame). Then, they were compared to examine whether there were any significant differences in faculty utilization of instructional technology in teaching between or among frame patterns within each of the three categories (single, paired-, and multi-frame).

Table 33 presents the means and standard deviations of instructional technology use by category of leadership frames, as well as the results of the ANOVA. The mean of instructional technology infrastructure reported by faculty whose chairs were classified into the paired-frame category was the highest $(M=3.83, S D=0.81)$. This was followed by the single-frame category $(M=3.69, S D=1.69)$, the multi-frame category $(M=3.63$, $S D=0.89)$, and the no-frame category $(M=3.42, S D=0.98)$. However, the analysis of variance showed that there was no statistically significant differences in the means of this variable among the four categories of leadership frames, $F=1.989, p>.05$.

The faculty classified into the paired-frame category also had the highest mean of faculty utilization of instructional technology $(M=2.76, S D=0.74)$; the second highest mean was reported by the faculty classified into the multi-frame category $(M=2.74, S D$ $=0.61)$. The no-frame category $(M=2.55, S D=0.75)$ and the single-frame category $(M=$ 2.48, $S D=0.83$ ) followed it. Again, the ANOVA did not find any statistically significant differences among these means, $F=1.242, p>.05$.

As for technical support provided by a department for faculty utilization of instructional technology, the ANOVA revealed that there was a statistically significant difference of the means among the four categories, $F=2.899, p<.05$. Fisher's Least Significant Difference (LSD) found that the means for the paired-frame category ( $M=$ $3.24, S D=1.25)$ and the multi-frame category $(M=3.37, S D=0.94)$ were significantly 
Table 33

Difference in Instructional Technology Utilization by Category of Leadership Frames

\begin{tabular}{|c|c|c|c|c|c|c|}
\hline \multirow[t]{2}{*}{ Technology } & \multicolumn{4}{|c|}{ Frame Category } & \multirow[t]{2}{*}{$F$} & \multirow[t]{2}{*}{ Post-Hoc Test } \\
\hline & $\begin{array}{c}\text { No } \\
(n=128)\end{array}$ & $\begin{array}{l}\text { Single } \\
(n=35)\end{array}$ & $\begin{array}{l}\text { Paired } \\
(n=29)\end{array}$ & $\begin{array}{c}\text { Multiple } \\
(n=30)\end{array}$ & & \\
\hline \multicolumn{7}{|l|}{ Technology Infrastructure } \\
\hline Mean & 3.42 & 3.69 & 3.83 & 3.63 & 1.989 & \\
\hline SD & 0.98 & 1.05 & 0.81 & 0.89 & & \\
\hline \multicolumn{7}{|l|}{ Faculty Utilization of IT } \\
\hline Mean & 2.55 & 2.48 & 2.76 & 2.74 & 1.242 & \\
\hline SD & 0.75 & 0.83 & 0.74 & 0.61 & & \\
\hline Technical Support & & & & & & LSD \\
\hline Mean & 2.85 & 3.24 & 3.38 & 3.37 & $2.899 *$ & Paired-Frame $>$ No-Frame \\
\hline SD & 1.25 & 1.19 & 1.26 & 0.94 & & Multi-Frame $>$ No-Frame \\
\hline Administrative Support & & & & & & Scheffe \\
\hline Mean & 2.28 & 2.61 & 2.60 & 2.93 & $4.834^{*}$ & Multi-Frame $>$ No-Frame \\
\hline $\mathrm{SD}$ & 0.90 & 1.03 & 0.91 & 0.85 & & \\
\hline \multicolumn{7}{|l|}{ Key Issues } \\
\hline Mean & 3.94 & 4.25 & 4.17 & 4.14 & 1.847 & \\
\hline SD & 0.84 & 0.78 & 0.59 & 0.84 & & \\
\hline
\end{tabular}

$* p<.05$ 
higher than that for the no-frame category $(M=2.85, S D=1.25)$. The mean for the single-frame category $(M=3.24, S D=1.19)$ was not significantly different from the means for others.

The ANOVA also showed a statistically significant difference in the means of administrative support among the four categories, $F=4.834, p<.05$. Scheffe's method indicated that the mean of administrative support provided for faculty use of instructional technology by the departments classified into the multi-frame category based on their chairs' use of leadership frames $(M=2.93, S D=0.85)$ was significantly higher than that for the chairs in the no-frame category $(M=2.28, S D=0.90)$. The means for the singleframe category $(M=2.61, S D=1.03)$ and the paired-frame category $(M=2.60, S D=0.91)$ were not found to be significantly different from those for the no-frame and multi-frame categories. For the key issues, the ANOVA did not find any significant differences among the four categories. The means of this variable for the four categories ranged from 3.94 to 4.25. A further ANOVA test on the two factors, facilities and equipment and plan and support, of key issues did not find any significant differences by category of leadership frames.

A series of comparisons among the different frame patterns by category was also conducted. Table 34 reports the difference in faculty utilization of instructional technology between the structural and human resource frames within the single-frame category. The analysis did not include the data for the political and symbolic frames because there were not enough subjects whose chairs used either of these two frames. The $t$ test found that there was a significant difference in technology infrastructure between the departments whose chairs used the structural and human resource frames, $t$ 
Table 34

Difference in Faculty Instructional Technology Utilization between ST and HR

\begin{tabular}{ccc}
\hline $\mathrm{ST}$ & $\mathrm{HR}$ & $t$ \\
& & (ST versus HR)
\end{tabular}

Technology Infrastructure

$\begin{array}{llll}\text { Mean } & 4.05 & 3.23 & 2.123^{*} \\ \text { SD } & 1.07 & 1.05 & \end{array}$

Faculty Utilization of IT

$\begin{array}{llll}\text { Mean } & 2.40 & 2.32 & 0.286 \\ S D & 0.73 & 0.78 & \end{array}$

Technical Support

$\begin{array}{llll}\text { Mean } & 3.29 & 2.94 & 0.839 \\ S D & 1.12 & 1.12 & \\ \text { Administrative Support } & & & 2.154^{*} \\ \text { Mean } & 2.99 & 2.22 & \\ S D & 1.29 & 0.74 & \end{array}$

Key Issues

\begin{tabular}{llll} 
Mean & 4.59 & 3.84 & $2.725^{*}$ \\
$S D$ & 0.34 & 0.99 & \\
\hline
\end{tabular}

Note: $\mathrm{ST}=$ the structural frame

$\mathrm{HR}=$ the human resource frame

$* p<.05 . * * p<.01$

$=2.123, p<.05$, two tails. A department with a chair using the structural frame had a better instructional technology infrastructure $(M=4.05, S D=1.07)$ than those whose chair espoused the human resource frame $(M=3.23, S D=1.05)$. The $t$ test did not find any significant differences of faculty utilization of instructional technology between the departments whose chairs used the structural frame $(M=2.40, S D=0.73)$ and the human 
resource frame $(M=2.32, S D=0.78), t=0.286, p>.05$, two tails. Again, no significant differences were found in technical support between these two types of departments, $t$ $=0.839, p>.05$, two tails. As for administrative support provided for faculty use of instructional technology, a statistically significant difference was found by the $t$ test, $t=$ $2.154, p<.05$, two tails. A chair using the structural frame $(M=2.99, S D=1.29)$ was more likely to provide administrative support than those using the human resource frame $(M$ $=2.22, S D=0.74)$. The $t$ test also showed that faculty attitude toward to the key issues about instructional technology use was significantly different between these two types of departments, $t=3.84, p<.05$, two tails. Faculty with a department chair using the structural frame $(M=4.59, S D=0.34)$ reported a more important influence of the key issues on their utilization of instructional technology than did faculty with a chair using the human resource frame $(M=3.84, S D=0.99)$.

Table 35 presents differences of faculty instructional technology use by pairedframe pattern. The ANOVA indicated that there was a statistically significant difference in technology infrastructure among the faculty reports in the four types of departments by frame-pattern of their chairpersons, $F=4.156, p<.05$. The post-hoc test of Fisher's LSD found that faculty whose chair followed a combination of the structural and political frames $(M=4.90, S D=0.17)$ reported that they had a better technology infrastructure than did faculty whose chair used a combination of the structural and human resource frames $(M=3.76, S D=0.79)$ or the human resource and symbolic frames $(M=3.18, S D=0.67)$. The mean for faculty utilization of instructional technology reported by faculty with a department chair using the structural and political frames was the highest, 3.33 with a standard deviation of 0.59 . However, the ANOVA did not show any significant 
Table 35

Difference in Faculty Instructional Technology Use by Paired-Frame Pattern

\begin{tabular}{|c|c|c|c|c|c|c|}
\hline & $\mathrm{S} / \mathrm{H}$ & $\mathrm{S} / \mathrm{P}$ & $\mathrm{H} / \mathrm{P}$ & $\mathrm{H} / \mathrm{S}$ & $F$ & $\begin{array}{c}\text { Post-Hoc } \\
\text { Test }\end{array}$ \\
\hline Technology Infrastructure & & & & & & LSD \\
\hline Mean & 3.76 & 4.90 & 4.13 & 3.18 & $4.156^{*}$ & $\mathrm{~S} / \mathrm{P}>\mathrm{S} / \mathrm{H}$ \\
\hline $\mathrm{SD}$ & 0.79 & 0.17 & 0.67 & 0.67 & & $\mathrm{~S} / \mathrm{P}>\mathrm{H} / \mathrm{S}$ \\
\hline \multicolumn{7}{|l|}{ Faculty Utilization } \\
\hline Mean & 2.77 & 3.33 & 2.52 & 2.64 & 0.725 & \\
\hline $\mathrm{SD}$ & 0.93 & 0.59 & 0.47 & 0.50 & & \\
\hline Technical Support & & & & & & Sheffe \\
\hline Mean & 3.17 & 4.72 & 3.75 & 3.00 & $3.605 *$ & $\mathrm{~S} / \mathrm{P}>\mathrm{H} / \mathrm{S}$ \\
\hline $\mathrm{SD}$ & 1.19 & 0.35 & 1.85 & 1.16 & & \\
\hline \multicolumn{7}{|l|}{ Administrative Support } \\
\hline Mean & 2.61 & 3.17 & 2.95 & 2.21 & 0.994 & \\
\hline $\mathrm{SD}$ & 0.94 & 0.45 & 1.05 & 0.72 & & \\
\hline \multicolumn{7}{|l|}{ Key Issues } \\
\hline Mean & 4.09 & 4.48 & 3.94 & 4.15 & 0.482 & \\
\hline SD & 0.61 & 0.13 & 0.64 & 0.68 & & \\
\hline
\end{tabular}

Notes: $\mathrm{S} / \mathrm{H}=$ Structural/Human Resource

$\mathrm{S} / \mathrm{P}=$ Structural $/$ Political

$\mathrm{H} / \mathrm{P}=$ Human Resource/Political

$\mathrm{H} / \mathrm{S}=$ Human Resource/Symbolic

LSD $=$ Least Significant Difference 
differences in this variable among the faculty reports by frame-pattern. With regard to technical support, the ANOVA found that the faculty reports were significantly different among the classifications by frame-pattern, $F=3.605, p<.05$. The post hoc test of Sheffe's method indicated that a department with a chair using the structural and political frames $(M=4.72, S D=0.35)$ was more likely to provide technical support to assist in faculty utilization of instructional technology than was a department with a chair using the human resource and symbolic frames $(M=3.00, S D=1.16)$. The means for administrative support reported by the four classifications of faculty by frame-pattern were not significantly different, ranging from 3.27 (the structural and political frames) to 2.21 (the human resource and symbolic frames). Again, the ANOVA revealed no significant differences in key issues among the four types of faculty reports by framepattern. The means ranged from 4.48 for the combination of the structural and political frames to 3.94 for the combination of the human resource and political frames.

The means and standard deviations of instructional technology use by multi-frame pattern as well as the results of the ANOVA test are presented in Table 36. The ANOVA test exhibited that the different multi-frame patterns used by department chairs had a significant influence on instructional technology infrastructure, $F=3.39, p<.05$. The post hoc test of Fisher's LSD indicated that a department whose chair used a combination of the structural, human resource, and political frames had a better infrastructure $(M=4.83$, $S D=0.15$ ) than did a department with a chair espousing a multi-frame theory combined with the human resource, political, and symbolic $(M=3.09, S D=0.64)$, or the structural, human resource, and symbolic $(M=3.64, S D=0.90)$. The ANOVA test found that chairs' use of different multi-frame patterns did not have a significant influence on faculty 
Table 36

Difference in Faculty Instructional Technology Use by Multi-Frame Pattern

\begin{tabular}{lcccccc}
\hline & $\mathrm{S} / \mathrm{H} / \mathrm{P}$ & $\mathrm{S} / \mathrm{H} / \mathrm{S}$ & $\mathrm{S} / \mathrm{P} / \mathrm{S}$ & $\mathrm{S} / \mathrm{H} / \mathrm{P} / \mathrm{S}$ & $F$ & $\begin{array}{c}\text { Post-Hoc } \\
\text { Test }\end{array}$ \\
\hline Infrastructure & & & & & & $\mathrm{LSD}$ \\
$\quad$ Mean & 4.83 & 3.60 & 3.09 & 3.64 & $3.39^{*}$ & $\mathrm{~S} / \mathrm{H} / \mathrm{P}>\mathrm{S} / \mathrm{P} / \mathrm{S}$ \\
$\quad \mathrm{SD}$ & 0.15 & 0.23 & 0.65 & 0.90 & & $\mathrm{~S} / \mathrm{H} / \mathrm{P}>\mathrm{S} / \mathrm{H} / \mathrm{S}$ \\
Utilization & & & & & & \\
$\quad$ Mean & 2.52 & 2.23 & 2.99 & 2.74 & 0.985 & \\
$\quad$ SD & 0.65 & 0.06 & 0.38 & 0.68 & & \\
Technical Support & & & & & & $\mathrm{Scheffe}$ \\
$\quad$ Mean & 4.44 & 3.11 & 3.55 & 3.42 & $3.051^{*}$ & $\mathrm{~S} / \mathrm{H} / \mathrm{P}>\mathrm{S} / \mathrm{H} / \mathrm{S}$ \\
$\quad$ SD & 0.51 & 0.59 & 0.47 & 1.04 & & \\
Administrative Support & & & & & & \\
$\quad$ Mean & 3.03 & 2.45 & 3.00 & 2.94 & 0.225 & \\
$\quad$ SD & 0.75 & 0.35 & 0.45 & 1.02 & & \\
Key Issues & & & & & & \\
$\quad$ Mean & 4.37 & 4.11 & 3.95 & 4.19 & 0.194 & \\
$\quad$ SD & 0.76 & 0.16 & 1.18 & 0.78 & & \\
\hline
\end{tabular}

Notes: $\mathrm{S} / \mathrm{H} / \mathrm{P}=$ Structural/Human Resource/Political

$\mathrm{S} / \mathrm{H} / \mathrm{S}=$ Structural/Human Recourses/Symbolic

H/P/S = Human Resource/Political/Symbolic

$\mathrm{S} / \mathrm{H} / \mathrm{P} / \mathrm{S}=$ Structural/Human Resource/ Political/Symbolic

LSD $=$ Least Significant Difference 
practice of instructional technology, $F=0.985, p<.05$. The means for the four patterns ranged from 2.23 to 2.99 . The ANOVA test, though, indicated a significant difference in technical support among the faculty reports by multi-frame pattern, $F=3.051, p<.05$. Scheffe's method indicated that the departments with a chair using a combination of the structural, human resource, and political frames $(M=4.44, S D=0.51)$ were more likely to provide technical support for faculty use of instructional technology than were those with a chair using a combination of the structural, human resource, and symbolic frames ( $M$ $=3.11, S D=1.04$ ). It was not found by the ANOVA that chairs' use of different multiframe patterns had a significant influence on administrative support and key issues, $F=$ 0.225 and $F=0.194$, respectively, $p>.05$.

Thus, chairs' leadership styles had a significant influence on technical and administrative support for faculty utilization of instructional technology. Chairs with a multi-frame or paired-frame leadership style were more likely to provide technical and administrative support than those with a no-frame leadership style.

For the single-frame leadership style, the structural frame was significantly better than the human resource for instructional technology integration into teaching: the departments with a chair using this frame had a better technology infrastructure; a chair using this frame was more likely to provide both technical and administrative support; and faculty whose chair used this frame were more likely to consider the key issues (see Appendix E) as important factors to influence their use of IT.

For the paired-frame leadership style, a combination of the structural and political frame was significantly more helpful for chairs to support instructional technology use in teaching: the departments with a chair suing a combination of the structural and political 
frames had a significant better technology infrastructure than those with a chair using a combination of the structural and human resource frames and a combination of the human resource and symbolic; and a chair using this combination also indicated a more willingness in providing technical support for faculty than those using a combination of the human resource and symbolic frames.

For the multi-frame leadership style, departments whose chair used a combination of the structural, human resource, and the political frames had a significantly better technology infrastructure than those with a chair using a combination of the structural, political, and symbolic frames. A chair combining the structural, human resource, and political frames in his or her leadership practice was also more likely to provide technical support for faculty utilization of instructional technology.

Research Question Five. Is there a statistically significant difference in the instructional technology utilization by no, single, paired-, and multi-frame for each of the chairs of the four academic departments, size of departments, age, gender, chairs' length of tenure, and the selected interactions?

The answer to this question consists of two parts. The first part examines the influence of the selected interactions between the four categories of leadership frames and these five demographic variables on instructional technology use by faculty. The second part reports the analysis of differences of instructional technology use by four categories of no, single, paired- and multi-frame for each of the chairs of the academic departments, size of departments, and the chairs' length of tenure, which, along with category, affected faculty use of instructional technology significantly. 
The first part of the answer to this question addressed the influence of the interactions between the four categories of leadership frames (no, single, paired, and multiple) used by chairs and selected demographic variables: department type (C\&I, EDLS, TEd, and EdP), size of departments (small, medium, and large), age, gender, and chairs' length of tenure. Table 37 presents the univariate $F$ s for each of the five interactions. The interaction between category of leadership frames and department type had a significant influence on technology infrastructure, $F=2.194, p<.05$, faculty use of

Table 37

Univariate F's for the Difference of Interactions between Category of Leadership Frame and Chairs' Demographic Variables in Faculty Utilization of Instructional Technology

\begin{tabular}{llllll}
\hline \multirow{2}{*}{ Instructional Technology } & \multicolumn{5}{c}{ Selected Interaction } \\
\cline { 2 - 6 } & C/DT & C/DS & C/A & C/G & C/L \\
\hline Technology Infrastructure & $2.194^{*}$ & $4.239^{* *}$ & 0.837 & 1.181 & 1.562 \\
Technology Utilization & $2.796^{* *}$ & 1.646 & 0.229 & 1.895 & 0.442 \\
Technical Support & $2.042^{*}$ & $4.410^{* *}$ & 0.771 & 0.703 & $2.703^{*}$ \\
Administrative Support & 1.128 & $3.709^{* *}$ & 1.642 & 0.066 & 1.962 \\
Key Issues & 0.362 & 1.020 & 0.980 & 0.248 & 1.167 \\
\hline
\end{tabular}

Notes: $\mathrm{C} / \mathrm{DT}=$ Interaction between category and department type

$\mathrm{C} / \mathrm{DS}=$ Interaction between category and department size

$\mathrm{C} / \mathrm{A}=$ Interaction between category and chairs' age

$\mathrm{C} / \mathrm{G}=$ Interaction between category and chairs' gender

$\mathrm{C} / \mathrm{L}=$ Interaction between category and chairs' length in the position

$* p<.05 . * * p<.01$

instructional technology, $F=2.796, p<.01$, and technical support, $F=2.042, p<.05$. The interaction between category and department size significantly affected technology infrastructure, $F=4.239, p<.01$, technical support, $F=4.410, \mathrm{p}<.01$, and administrative 
support, $F=3.709, p<.01$. The interaction between category and the chairs' length in the position also affected technical support significantly, $F=2.703, p<.05$. However, interactions of category of leadership frames and age, and the gender were not found to have a significant influence on faculty use of instructional technology.

On the basis of the analysis of the effect of the selected interactions on instructional technology use, the ANOVA tests were further conducted to examine the differences of faculty reports on their use of instructional technology by category for each of the academic departments, size of department, and the chairs' length of tenure. The results of the data analysis on instructional technology by category for the four departments are presented in Table 38 .

For C\&I, the ANOVA test found that, among the departments classified by the four categories of leadership frames used by chairs, there was a significant difference in technology infrastructure, $F=3.859, p<.05$, faculty utilization, $F=4.334, p<.05$, and administrative support, $F=3.052, p<.05$. The $\mathrm{C} \& \mathrm{I}$ departments with a chair using a single-frame leadership orientation $(M=4.09, S D=0.97)$ reported by participating faculty had a better infrastructure than those departments with a chair using a no-frame $(M=3.31$, $S D=0.92)$ or multi-frame orientation $(M=3.01, S D=0.69)$. The faculty in the C\&I departments whose chair used a multi-frame approach $(M=3.11, S D=0.38)$ were more likely to utilize instructional technology in teaching than those faculty in the same type of departments but with a chair not using any frames $(M=2.28, S D=0.61)$. The $\mathrm{C} \& \mathrm{I}$ chairs using a multi-frame $(M=3.12, S D=0.62)$ or single-frame approach $(M=2.99, S D=1.13)$ were more likely to provide administrative support for faculty utilization of instructional technology than those not using any frames $(M=2.26, S D=0.97)$. 
Table 38

Difference of Instructional Technology by Category for Each of the Four Departments

\begin{tabular}{|c|c|c|c|c|c|c|c|c|c|c|}
\hline \multirow[t]{2}{*}{ Department } & \multicolumn{2}{|c|}{ No } & \multicolumn{2}{|c|}{ Single } & \multicolumn{2}{|c|}{ Paired } & \multicolumn{2}{|c|}{ Multiple } & \multirow[t]{2}{*}{$\mathrm{F}$} & \multirow[t]{2}{*}{ Post Hoc Test } \\
\hline & $\mathrm{M}$ & SD & $\mathrm{M}$ & SD & $\mathrm{M}$ & SD & $\mathrm{M}$ & SD & & \\
\hline \multicolumn{11}{|l|}{ C\&I } \\
\hline Infrastructure & 3.31 & 0.92 & 4.09 & 0.97 & 3.83 & 0.60 & 3.01 & 0.69 & $3.859^{*}$ & HSD: $\mathrm{S}>\mathrm{M}, \mathrm{N}$ \\
\hline Utilization & 2.28 & 0.61 & 2.52 & 0.78 & 2.91 & 0.72 & 3.11 & 0.38 & $4.334^{*}$ & HSD: $\mathrm{M}>\mathrm{N}$ \\
\hline Technical Support & 3.06 & 1.32 & 3.40 & 0.94 & 2.56 & 0.77 & 3.59 & 0.43 & 1.034 & \\
\hline Administrative Support & 2.26 & 0.97 & 2.99 & 1.13 & 2.97 & 0.85 & 3.12 & 0.62 & $3.052 *$ & LSD: $M>N, S>N$ \\
\hline \multicolumn{11}{|l|}{ EDLS } \\
\hline Infrastructure & 3.48 & 0.98 & 3.15 & 1.05 & - & - & 3.61 & 1.20 & 0.757 & \\
\hline Utilization & 2.73 & 0.67 & 2.20 & 0.67 & - & - & 2.40 & 0.70 & $3.813^{*}$ & HSD: $N>S$ \\
\hline Technical Support & 2.68 & 1.21 & 2.83 & 1.22 & - & - & 2.61 & 1.22 & 0.116 & \\
\hline Administrative Support & 2.23 & 0.80 & 2.09 & 0.79 & - & - & 2.41 & 1.02 & 0.375 & \\
\hline \multicolumn{11}{|l|}{ TEd } \\
\hline Infrastructure & 3.37 & 1.01 & 4.35 & 0.21 & 3.17 & 0.60 & 4.05 & 0.57 & 1.677 & \\
\hline Utilization & 2.49 & 0.78 & 3.86 & 1.61 & 2.86 & 0.52 & 2.57 & 0.45 & 2.533 & \\
\hline Technical Support & 3.01 & 1.09 & 4.98 & 0.71 & 2.7 & 0.87 & 3.67 & 0.45 & $4.874 * *$ & HSD: $\mathrm{S}>\mathrm{N}, \mathrm{P}$ \\
\hline Administrative Support & 2.40 & 0.77 & 3.45 & 0.64 & 2.44 & 0.89 & 2.53 & 0.33 & 1.144 & \\
\hline \multicolumn{11}{|l|}{ EdP } \\
\hline Infrastructure & 3.49 & 1.06 & - & - & 4.3 & 1.06 & 4.03 & 0.63 & $3.815^{*}$ & HSD: $\mathrm{P}>\mathrm{N}$ \\
\hline Utilization & 2.57 & 0.97 & - & - & 2.74 & 0.84 & 2.71 & 0.66 & 0.175 & \\
\hline Technical Support & 2.77 & 1.49 & - & - & 3.96 & 1.32 & 3.57 & 1.02 & $3.385^{*}$ & HSD: $\mathrm{P}>\mathrm{N}$ \\
\hline Administrative Support & 2.29 & 1.22 & - & - & 2.66 & 0.98 & 3.28 & 0.89 & 2.710 & \\
\hline
\end{tabular}
$* \mathrm{p}<.05, * * \mathrm{p}<.01$ 
Among the EDLS departments by four categories, only one significant difference was found in faculty utilization of technology, $F=3.813, p<.05$. Department chairs using no-frame $(M=2.73, S D=0.67)$ were more likely to have higher level of faculty reporting the use of instructional technology in teaching than those chairs using a single-frame orientation $(M=2.20, S D=0.67)$.

Only one significant difference was found in technical support among the TEd departments by four categories, $F=4.874, p<.01$. The TEd department chairs using a single-frame leadership style $(M=4.98, S D=0.71)$ were more likely to provide administrative support for faculty utilization of technology than those adopting a no-frame $(M=3.01, S D=1.09)$ or paired-frame style $(M=2.7, S D=0.87)$.

The ANOVA test found there was a significant difference in technology infrastructure and technical support among EdP departments by the four categories, $F$ $=3.815$ and $F=3.395$, respectively, $p<.05$. An EdP department with a chair following a paired-frame theory $(M=4.3, S D=1.06)$ had a better technology infrastructure than that with a chair following a no-frame theory $(M=3.49, S D=1.06)$. EdP chairs with a pairedframe leadership style $(M=3.96, S D=1.32)$ were more likely to provide administrative support for faculty use of technology than was a chair not using any frame $(M=2.77, S D$ $=1.49)$.

Table 39 presents the differences of faculty instructional technology use by the four categories for each of the three departments classified by size. The ANOVA test indicated a significant difference among small departments by their chairs' use of leadership style in technology infrastructure, $F=5.067, p<.05$, technology utilization, $F=4.251, p<.05$, and technical support, $F=4.875, p<.05$. A small department with a chair using multiple frames 
Table 39

Difference of Instructional Technology by Category for Different Size of Departments

\begin{tabular}{|c|c|c|c|c|c|c|c|c|c|c|}
\hline \multirow[t]{2}{*}{ Department Size } & \multicolumn{2}{|c|}{ No } & \multicolumn{2}{|c|}{ Single } & \multicolumn{2}{|c|}{ Paired } & \multicolumn{2}{|c|}{ Multiple } & \multirow[t]{2}{*}{$\mathrm{F}$} & \multirow[t]{2}{*}{ Post Hoc Test } \\
\hline & $\mathrm{M}$ & SD & $\mathrm{M}$ & SD & $\mathrm{M}$ & SD & $\mathrm{M}$ & SD & & \\
\hline \multicolumn{11}{|l|}{ Small } \\
\hline Infrastructure & 3.07 & 0.88 & 2.27 & 0.31 & - & - & 4.23 & 0.61 & $5.067 *$ & HSD: $\mathrm{M}>\mathrm{S}$ \\
\hline Utilization & 2.09 & 0.63 & 2.33 & 0.43 & - & - & 2.95 & 0.45 & $4.251 *$ & HSD: $M>N$ \\
\hline Technical Support & 2.50 & 1.06 & 1.44 & 0.51 & - & - & 3.75 & 0.74 & $4.875^{*}$ & HSD: $\mathrm{M}>\mathrm{S}$ \\
\hline Administrative Support & 2.36 & 0.77 & 1.46 & 0.45 & - & - & 2.82 & 0.89 & 2.770 & \\
\hline \multicolumn{11}{|l|}{ Medium } \\
\hline Infrastructure & 3.10 & 1.09 & 3.60 & 0.90 & 4.52 & 0.55 & 3.43 & 1.21 & $5.631 * *$ & HSD: $\mathrm{P}>\mathrm{N}$ \\
\hline Utilization & 2.47 & 0.74 & 2.37 & 0.79 & 2.72 & 0.62 & 2.50 & 0.71 & 0.466 & \\
\hline Technical Support & 2.71 & 1.26 & 3.15 & 1.13 & 4.31 & 1.24 & 2.33 & 1.05 & $5.601 * *$ & HSD: $\mathrm{P}>\mathrm{N}, \mathrm{M}$ \\
\hline Administrative Support & 2.10 & 0.81 & 2.16 & 0.78 & 3.10 & 0.76 & 2.32 & 1.08 & $4.262 * *$ & HSD: $\mathrm{P}>\mathrm{N}, \mathrm{S}$ \\
\hline \multicolumn{11}{|l|}{ Large } \\
\hline Infrastructure & 3.51 & 0.92 & 3.94 & 1.04 & 3.37 & 0.62 & 3.57 & 0.82 & 1.574 & \\
\hline Utilization & 2.49 & 0.75 & 2.56 & 0.91 & 2.77 & 0.84 & 2.94 & 0.50 & 2.132 & \\
\hline Technical Support & 3.02 & 1.27 & 3.54 & 1.08 & 2.82 & 0.91 & 3.60 & 0.74 & 2.662 & \\
\hline Administrative Support & 2.35 & 0.97 & 3.01 & 1.01 & 2.37 & 0.83 & 3.14 & 0.71 & $5.788 * *$ & HSD: $M>N, S>N$ \\
\hline
\end{tabular}

$* \mathrm{p}<.05, * * \mathrm{p}<.01$ 
$(M=4.24, S D=0.61)$ had a better technology infrastructure than did that with a chair using only one frame ( $M=2.27, S D=0.31)$. Faculty whose chair followed a multi-frame theory were more likely to use technology in teaching $(M=2.95, S D=0.45)$ than those whose chair adopted a no-frame theory $(M=2.09, S D=0.95)$. Chairs in small departments using a multi-frame leadership style were more likely to provide administrative support for faculty use of technology than a chair using a single-frame leadership style.

The ANOVA test also revealed a significant difference among medium departments by their chairs' use of the four categories in infrastructure, $F=5.631$, technical support, $F$ $=5.601$, and $F=4.262$, all significant at .01 level. A medium department with a chair using a paired-frame leadership style $(M=4.52, S D=0.55)$ had a better technology infrastructure than a department with a chair using a no-frame style $(M=3.10, S D=1.09)$. A medium department chair espousing paired-frame theories $(M=4.31, S D=1.24)$ was more likely to provide technical support for faculty use of technology than those espousing no-frame theories $(M=2.71, S D=1.26)$ or multi-frame theories $(M=2.33, S D=1.05)$. Again, a medium department chair following a paired-frame orientation $(M=3.10, S D=0.76)$ was more likely to provide administrative support for faculty use of technology than those following a no-frame $(M=2.10, S D=0.81)$ or single-frame orientation $(M=2.16, S D$ $=0.78)$.

The ANOVA test found that there was a significant difference among large departments classified by their chairs' use of the four categories in administrative support, $F=5.788, p<.01$. A large department chair using a no-frame leadership style $(M=2.35, S D$ $=0.97$ ) was less likely to provide administrative support for faculty adoption of technology 
into teaching than those using a single-frame $(M=3.01, S D=1.01)$ or multi-frame leadership style $(M=3.14, S D=0.71)$.

The differences of faculty instructional technology use by the four categories for each of the three departments classified by their chairs' length in the position are presented in Table 40. A chair with a short-term (less than 3 years) or mid-term service (3 to 5 years) by the four categories was not found to have a significant influence on faculty utilization of technology. However, the ANOVA test indicated that, among the departments with a chair's length of tenure more than five years, there was a significant difference by category in technical support, $F=6.082, p<.05$, and administrative support, $F=8.665, p<.01$. A chair using a single-frame style was more like to provide both technical $(M=4.19, S D$ $=1.11)$ and administrative support $(M=2.85, S D=0.64)$ for faculty use of technology than those using a no-frame style (technical support: $M=2.89, S D=1.22$; administrative support: $M=2.03, S D=0.62)$.

With respect to this research question, department type, size, and chairs' length in the position together with the four categories of leadership frames used by chairs had a significant influence on faculty utilization of instructional technology. The C\&I departments with a chair using a single-frame leadership style, the EdP departments with a chair using a paired-frame leadership style, small departments with a chair using a multiframe leadership style, and medium departments with a chair using a paired-frame leadership style had a better technology infrastructure. The C\&I faculty and those in a small department with a chair adopting a multi-frame approach were more likely to use instructional technology in their teaching than those with a chair not using any frames. The TEd departments with a chair following a single-frame orientation, the departments 
Table 40

Difference of Instructional Technology by Category for Chairs' Length in the Position

\begin{tabular}{|c|c|c|c|c|c|c|c|c|c|c|}
\hline \multirow[t]{2}{*}{ Department } & \multicolumn{2}{|c|}{ No } & \multicolumn{2}{|c|}{ Single } & \multicolumn{2}{|c|}{ Paired } & \multicolumn{2}{|c|}{ Multiple } & \multirow[t]{2}{*}{$\mathrm{F}$} & \multirow[t]{2}{*}{ Post Hoc Test } \\
\hline & $\mathrm{M}$ & SD & $\mathrm{M}$ & SD & $\mathrm{M}$ & SD & M & SD & & \\
\hline \multicolumn{11}{|l|}{ Short-Term } \\
\hline Infrastructure & 3.49 & 1.12 & 3.01 & 1.11 & 3.22 & 0.69 & 3.60 & 0.00 & 0.451 & \\
\hline Utilization & 2.46 & 9.54 & 2.40 & 0.82 & 2.62 & 0.51 & 2.23 & 0.06 & 0.240 & \\
\hline Technical Support & 2.97 & 1.30 & 2.15 & 0.89 & 2.83 & 0.83 & 3.42 & 0.59 & 1.49 & \\
\hline Administrative Support & 2.52 & 0.79 & 1.88 & 1.01 & 2.32 & 0.82 & 2.45 & 0.35 & 0.968 & \\
\hline \multicolumn{11}{|l|}{ Mid-Term } \\
\hline Infrastructure & 3.83 & 1.09 & 4.48 & 0.48 & 3.57 & 0.55 & 3.85 & 0.89 & 1.875 & \\
\hline Utilization & 2.46 & 0.88 & 2.40 & 0.42 & 3.11 & 0.54 & 2.55 & 0.64 & 1.519 & \\
\hline Technical Support & 3.12 & 1.41 & 3.76 & 0.83 & 2.64 & 0.86 & 3.00 & 1.11 & 1.440 & \\
\hline Administrative Support & 2.53 & 1.05 & 3.28 & 1.01 & 2.98 & 0.82 & 2.81 & 1.07 & 1.357 & \\
\hline \multicolumn{11}{|l|}{ Long Term } \\
\hline Infrastructure & 3.58 & 0.89 & 4.15 & 0.25 & - & - & - & - & 3.112 & \\
\hline Utilization & 2.74 & 0.78 & 3.05 & 0.99 & - & - & - & - & 0.641 & \\
\hline Technical Support & 2.89 & 1.22 & 4.19 & 1.11 & - & - & - & - & $6.082 *$ & $\mathrm{~S}>\mathrm{N}$ \\
\hline Administrative Support & 2.03 & 0.62 & 2.85 & 0.64 & - & - & - & - & $8.665 * *$ & $\mathrm{~S}>\mathrm{N}$ \\
\hline
\end{tabular}

${ }^{*} p<.05 .{ }^{* *} p<.01$ 
with a chair serving more than five years and also following a single-frame orientation, the EdP departments and medium departments with a chair using a paired-frame leadership style, the small departments with a chair holding a multi-frame orientation were more likely provide technical support for faculty utilization of instructional technology. The C\&I chairs using a multi-frame or single-frame leadership style, the chairs in large departments also using a multi-frame or single-frame leadership style, the chairs in medium departments using a paired-frame, and the chairs in the position more than five years and using a single-frame leadership style were more like to provide administrative support for faculty use of instructional technology. The chairs demographic variables did not have any significant influence on faculty overall ratings on key issue, nor did on the two factors of facilities and equipment and, plan and support on this scale.

\section{Summary}

This chapter reported the results of data analysis about the leadership style of department chairs and faculty utilization of instructional technology in their teaching. The data were collected using three instruments from the selected chairs and faculty in departments of C\&I, EDLS, TEd, and EdP in the colleges of education at Doctoral/Research Extensive Public Universities by Carnegie Classifications (Basinger, 2000). After three mailings to invite them to participate in this study, 42 chairs and 238 faculty responded to the survey. However, the valid responses were 41 for chairs and 230 for faculty, respectively. This led to a response rate of 44.4 percent for chairs and 27.3 percent for faculty. The invalid response rate was 3.2 percent. In addition, missing 
values lower than 5 percent in a response were imputed using the methods of cell mean imputation and cold-deck imputation (Lohr, 1999).

Cronbch's alpha analysis was conducted to examine the internal consistency of the three instruments. All the scales embedded in these three instruments had an alpha higher than the acceptable level. All the item-total correlations within each scale were close to or above .30 , so they were all retained for data analysis.

Five predefined research questions were used to guide the data analysis of this study. The statistical procedures used to analyze data included mean, standard deviation, chi-square, ANOVA, MANOVA, canonical analysis, Cronbach's alpha, factor analysis, and Pearson correlation. An alpha level of .05 was the criterion level of significance for inferential statistics in this analysis.

First, chairs were reported by their faculty to use the four frames significantly differently. Most of the chairs were perceived to use a no-frame leadership style, followed by a single- or multi-frame leadership style. The paired-frame style was used the most infrequently. For the single frame utilization by chairs, the human resource and structural frames were used the most while the symbolic frame was used the least. For the chairs' adoption of the combined frames, a combination of the structural and human resource frames and a combination of the four frames were used the most. No chairs used a combination of the structural and symbolic frames, or a combination of the human resource, political, and symbolic frames.

Secondly, chairs' utilization of leadership frames were significantly influenced by the four department types (C\&I, EDLS, TEd, and EdP), chair's gender, chairs' length in the position, the interactions between department type and gender, and age and length. 
Thirdly, chairs' leadership frames were significantly correlated with faculty utilization of instructional technology. The higher the chairs were rated on leadership frames by faculty, the higher were they rated in the scales in instructional technology. Furthermore, it was found by the canonical analysis that a chair using all four frames together had a significant and positive influence on all five components of technology adoption into teaching except key issues. However, when the structural, human resource, and political frames were used together by a chair, he or she significantly and positively influenced the technology infrastructure and technical support, but negatively influenced faculty use of technology in teaching.

Fourthly, chairs' leadership styles (no, single, paired-, and multi-frame) were found to have a significant influence on technical and administrative support. Chairs using frames, in particular multiple frames, were more likely to provide these two types of support for faculty use of instructional technology than those not using any frames. The different patterns of the frames adopted by chairs also had a significant influence on faculty technology use. Chairs using the structural frame, or a combination of the structural and political, or a combination of the structural, human resource, and political frames were more likely to have technology infrastructure better constructed, and provide technical and administrative support than those using other frames or frame patterns.

Lastly, chairs' demographic variables of department type, size, and chairs' length in the position together with a chair's leadership style had a significant effect on faculty utilization of instructional technology. As indicated in Question Five, chairs in different departments, using a different leadership style, and with a different length in the position influenced significantly differently on faculty utilization of instructional technology. 


\section{Chapter 5}

\section{Conclusions and Recommendations}

This chapter forms conclusions based on the major findings relevant to the leadership styles of academic department chairs and the faculty utilization of instructional technology. Recommendations for practice and further studies based on these conclusions are also included.

\section{Conclusions}

The conclusions are based on an analysis of the research questions guiding this study.

\section{General Pattern of Chairs' Leadership Styles}

Faculty participants rated their department chairs as most frequently (56.8\%) not using a particular frame, followed by the single-frame (14.8\%) and multi-frame style $(14.8 \%)$. The paired-frame style was used the least at $13.6 \%$. Compared to other studies of department chairs' leadership, the proportion of department chairs who do not use a particular frame is unusually high. In a recent study of nursing department chairs (Small, 2002), the researcher found that although a conspicuous percentage of respondents lacked a discernible leadership style (31.7\%), the majority used at least one frame (36.1\% were multi-framed, $21 \%$ were single-framed, and $11 \%$ were paired-frame leaders). Similarly, Mosser (2000) reported that almost $40 \%$ of her nursing-chair respondents had no leadership style. Another pertinent study (Turley, 2002) of health science program directors showed an even smaller frequency of no-frame leaders (less than 4\%).

When compared to studies of leaders at higher organizational levels, the ratio of no-frame chairs in colleges of education remains strikingly high. For example, Bensimon 
(1989), in her pioneering study of college presidents, found that all the subjects used at least one style. Similarly in a myriad of studies conducted by Bolman and Deal (1991) themselves, the no-frame style did not surface.

The unusually high proportion of department chairs perceived by their faculty as lacking a predominant leadership style indicates, according to Bolman and Deal, that these unit level administrators have "no windows" or frames to use in guiding their units and may encounter problems in promoting efficiency and effectiveness in the process. Bensimon (989) and Bolman and Deal $(984,99 a)$ point out that the four-frame approach can provide leaders with a more complete organizational image on which leaders can improve their effectiveness. Perhaps, the selection process for choosing chairs in colleges of education as well as the opportunity for administrative development in those settings may contribute to this phenomenon.

The leadership styles for the college of education chairs were spread rather evenly across the other three approaches: multiple, $14.8 \%$, single, $13.6 \%$, and paired $14.8 \%$. Similar to the finding about no-frame styles, the ratio of multi-framed chairs is considerably different from that reported in similar studies. Small (2002) and Mosser (2000) found, for instance, that about one-third of the nursing chairs used multiple frames and Turley (2002) found that about $44 \%$ of health science program directors used this style. At higher organizational levels, one-quarter of college presidents used multipleframe styles (Bensimon, 1989) and nearly half of area campus administrators adopted this approach (Borden, 2001).

Thus, the small number of college of education chairs with multiple leadership frames raises questions about their capacity for successful leadership. Administrators 
who do not have multiple leadership styles are less likely to be successful in their position and this may particularly be a challenge for chairs in Colleges of Education in light of major challenges many of them face in responding to external forces (changing problems at state levels, demographic shift, etc.) and to internal pressures (declining enrollments, improving academic quality, striving to be more efficient).

\section{Demographic Effect on Leadership Styles}

Department type. This study found that chairs with no leadership style tended to come from two academic units: EDLS and C\&I; those with paired and multi-frame styles led TEd and EdP. It is especially surprising to find that the chairs of EDLS units lack even a single leadership style ( $M=3.25$ for the structural frame, $M=3.35$ for the human resource frame, $M=3.22$ for the political frame, and $M=2.85$ for the symbolic frame), given the subject matter of their discipline (administration), the typical experiences of faculty in this area (prior experience as school or college administration), and other background features.

Gender. Gender was a significant variable in this study: females, as perceived by the faculty, displayed no leadership style at the ratio of $70 \%$, a ratio inconsistent with previous studies. Bolman and Deal (1992) found that men and women in comparable positions are actually more alike than different. Although the presence of women administrators in Colleges of Education is no longer a rarity, the pathway to becoming administrators may be different from those of their male counterparts in terms of prior experiences, or training. Like their female faculty counterparts, the pressure from nonacademic responsibilities for female chairs may also explain this disproportionality. 
Chairs' length of tenure. Unlike the findings of previous studies, there was significant relationship between chairs' length of tenure in the position and leadership style. Against the common assumption that the longer the administrative experience, the greater the number of leadership styles, this study found an inverse relationship between plurality of styles and length of service. Those chairs with the longest experience were also those without a single leadership style. With respect to chairs with more than fiveyear length of experiences, the findings of this study are incongruent with Bensimon (1989), who found that most of university presidents with more than five-year service in the presidential position espoused theories classified as paired or multi-frame, while half of the new presidents clustered in the single-frame category. The chairs of Colleges of Education with longer experience, however, were equally as likely to have no style as well as a single style.

Department size. Department size is associated with chairs' leadership styles. Chairs in large departments are more likely to use some types of styles than those in small departments. This is an expected finding. Thus, the chairs of small and mediumsized units are more likely to have no leadership style. As the size of a unit increases, its leaders are expected to have multiple leadership skills in order to be more effective.

Age. The distributions of the chairs by age groups across the four frame categories are not uniform. While most of the chairs are more likely to use a no-frame approach, the middle-age chairs (51 to 60 years old) are ones who demonstrate the multi-frame style. Possibly, the middle-age chairs' stronger administrative background and greater academic experience compared to younger chairs (younger than 51 years old) contribute to this likelihood even though this tendency seems to contradict the previous finding in 
which there is an inverse relationship between the number of styles and the length of administrative experience.

\section{Relationship of Individual Leadership Frames with Faculty Use of IT}

Individual leadership frames (the structural, human resource, political, and symbolic) are significantly related to the faculty responses about their use of IT. The structural frame has a significant correlation with all domains of instructional technology. The strongest correlation is with administrative support. This is an expected finding. Structural leaders are more likely to assign responsibilities to participants and make policies, develop plans, create procedures and hierarchies to coordinate activities. The domain of administrative support denotes chairs' responsibilities to develop a formal plan for instructional technology, create a system of rewards for innovators of new instructional technology, and encourage faculty to share information, expertise, and discoveries about instructional technology. The structural frame is also highly correlated with technical support and technology infrastructure, and these areas are also congruent with the functions typically associated with this frame. These domains relate to a series of activities such as faculty training in instructional technology use and purchase and maintenance of technology equipment, which a chair must coordinate.

The human resource frame is significantly correlated with four of the five domains of instructional technology. It has its highest correlation with technical support. This is not an unexpected finding because providing technical assistance goes beyond structural leadership to include attending to individual needs, motivating personnel, and other forms of consideration for those learning new skills. This frame's second highest correlation is with the domain of administrative support, which is characterized with 
openness of communication between the chair and faculty about the merits of technology and its potential for enhancing instruction.

The political frame is related to four of the five domains of instructional technology and has its highest correlations with providing technical assistance in the form of developing skills and with administrative support in developing an IT plan for the unit and recognizing the relationship of IT to the promotion and tenure process as well as the more general system of rewards in the organization. The political frame focuses on the individual and group interests, and the continuous competition for scarce resources. Political leaders are adept at resolving conflicts, negotiating, and balancing group interests. The political frame is also correlated with the domain of technology infrastructure and the domain of faculty practice of instructional technology in teaching. Political leadership may also be particularly appropriate in acquiring resources to build infrastructure and encourage faculty involvement in this mode of teaching.

The symbolic frame is correlated with four of the five domains of instructional technology. The highest correlation of this frame is with administrative support. This is followed by technical support. According to the symbolic frame, organizations are considered to be held together more by shared values and culture than by goals and policies, and providing a cohesive and shared vision would seem to be important in reaching this objective.

In addition to the correlation of the individual frames with the domains of instructional technology, all four frames together are correlated with four of the five domains of instructional technology (except for key issues). According to Bensimon (1989) and Bolman and Deal $(1984,1991 \mathrm{a})$ when the four frames are used in 
combination, the approach can provide leaders with a more complete organizational image on which leaders can make clear judgments and improve effectiveness. This suggests when all four frames are used, faculty utilization of instructional technology is enhanced.

Leadership Styles and Faculty Use of IT

Leadership styles (no, single, paired, and multi-frame) are associated with faculty use of IT. Chairs using the single-frame or multi-frame approach provided significantly more technical support for faculty use of instructional technology than did those not using any of the leadership frames. Chairs using the multi-frame approach provided significantly more administrative support for faculty use of instructional technology than did those not using any of the leadership frames. This finding is consonant with that of the previous studies indicating that a multi-frame approach contributes to effective leadership. According to Bensimon et al. (1989), each of Bolman and Deal's leadership frames represents a distinctive lens that help leaders to determine what they need to focus on and what can be safely ignored.

Frame patterns are also associated with faculty utilization of IT. For those using the single-frame leadership style, the structural frame is more likely to help them construct a better technology infrastructure. Chairs using this frame are also more likely to provide both technical and administrative support. Faculty view those chairs who use this frame as providing adequate facilities and equipment, developing a plan, and providing support for faculty use of IT as essential improving technology use in teaching.

Not surprisingly, among paired-frame patterns, the structural and political frame pattern is significantly related to faculty use of IT. Departments with their chairs using 
this pattern have a better technology infrastructure. Chairs using this frame combination are more willing to provide technical support for faculty. As already stated, the effective structural leadership is linked to clear organizational goals and strategies. Integrating IT into higher education takes time and a long-term plan should be developed. In addition, technology is developing so rapidly that faculty would be never satisfied with the technology they have been provided. This may lead to competition for scarce resources and conflict among faculty. In this situation, the political frame is useful (Bolman \& Deal, 1997).

Among multi-frame patterns, the pattern of the structural, human resource, and political frames is linked to faculty use of IT. Departments with their chairs using this pattern have a significantly better technology infrastructure. Chairs with this frame pattern are also more likely to provide technical support for faculty utilization of IT. With one more frame adopted, chairs are likely to explore ways to adjust their departments to fit faculty or to adjust the faculty to fit the department through such means as proving development programs or training workshops.

It is concluded on the basis of these findings that chairs need to use multi-frame leadership style to promote faculty use of technology in their teaching. However, for those who can only use a single frame, enhancing their structural behavior would help them better support faculty use of technology. For those who can only use two frames, a combination of the structural and political frames would be helpful for this purpose because success in this area depends at a minimum on both formal and informal approaches. 


\section{Leadership Styles by Demographic Variables and Faculty Use of IT}

Department type. Academic department type along with chairs' leadership styles is associated with faculty utilization of IT. C\&I faculty perceive their chairs to use a single-frame approach in order to have a better technology infrastructure, while EdP faculty are more likely to have their chairs to adopt a paired-frame style for this purpose. In both departments, faculty are not likely to perceive their chairs to use a no-frame approach in order to enhance their use of IT in teaching.

EdP chairs using paired-frame category are more likely to provide technical support for faculty use of technology than are those with no style. It is also found that the TEd chairs using one of the four frames are also more likely to provide technical support than are their counterparts using no style or just the paired frames.

As for the domain of administrative support, consistent with the previous finding in this study, C\&I chairs using multiple frames are more likely to provide administrative support for faculty use of instructional technology than are those not using any of the frames. It is also found that $\mathrm{C} \& \mathrm{I}$ chairs using a single frame are more likely to provide this support than are their counterparts not using any of the frames.

Surprisingly, EDLS faculty whose chairs not using any of the four frames are more likely to utilize technology in teaching than are those with a chair who use one single frame. This phenomenon is as puzzling as the earlier finding that EDLS chairs demonstrate that they do not use a particular leadership style as measured by Bolman and Deal's Leadership Orientation (other). Perhaps, the faculty are more innovative and take the initiative to use technology. 
Department size. Leadership styles by department size are related to faculty use of IT. Small and medium-sized departments with their chairs using a multi- or paired-frame style have a better technology infrastructure. Chairs of small departments adopting a multi-frame approach are more likely to provide technical and administrative support than those using only one of the frames. Medium-sized department chairs using a pairedframe approach are more likely to provide technical and administrative support than those using a no-frame approach. Surprisingly, they are also more likely to provide technical support than those using a multi-frame approach. Medium-sized department faculty with their chairs using multiple frames are also more likely to use technology in their teaching than those with their chairs not using any of the frames. Large department chairs using multi-frame or single-frame approach are more likely to provide administrative support for faculty use of instructional technology than are those not using any of the frames. Thus, chairs with multiple or paired styles have more success in facilitating faculty use of IT.

Chairs' length of tenure. Because of only a very small number of subjects in the paired and multi-frame categories, the comparisons of the faculty use of IT were only conducted between no-frame and single-frame categories. The result indicates one significant influence of chairs' length of tenure and leadership styles on faculty report of technology use. Chairs with long-term service and a single-frame approach are more likely to provide technical and administrative support than those chairs with long-term service but not using any of the four frames.

An overwhelming majority of chairs in any groups by department type, size or their length of tenure would be more likely to provide support for faculty use of IT if they 
use at least one frame than those not using any of the four frames. Particularly, multiple frames provide chairs a more complete picture of leadership to effectively create a strategic plan for IT, provide a successful IT training, and motivate faculty use of IT in teaching.

\section{Recommendations}

\section{Recommendations for Practice}

Academic department chairs are very important in academe and are vital to the operation of higher education institutions. Therefore, chairs' leadership styles are important to study, given the increasing complexity and demands for change in higher education. Among these changes, faculty utilization of instructional technology in teaching is one of the most pressing issues. The literature substantiates how critical it has become for faculty to effectively integrate instructional technology into teaching. This study demonstrates the relationship between leadership styles of department chairs and faculty utilization of instructional technology.

The results indicate that the majority of the chairs in the colleges of education use no leadership style. It is recommended that universities should offer leadership development workshops and training programs for those department chairs who lack formal education in leadership to help them understand their personal leadership strengths and weaknesses and expand their repertoires of leadership skills. Screening and selection procedures as well as opportunities for leadership development can be reformed. One of the most effective leadership development models is simulation and inbasket problem solving. Potential candidates for these positions should be assessed in using this method. 
EDLS chairs may typically have prior experience in administration and have completed graduate studies in the discipline of education; however, they may not have focused on the discipline of leadership. Therefore, workshops and leadership development activities should be made available to enhance their leadership effectiveness.

The fact that department variables (type and size) and demographic variables (gender, age, and chairs' length of tenure) have a significant effect on all or some of the four frames implies that chairs can better understand their leadership frame use and further explore how they can incorporate the various frames into their leadership practice according to their classifications by these variables. For example, chairs having served more than five years should enhance their human resource leadership behavior in order to improve their leadership effectiveness through using multiple frames in dealing with increasingly complicated issues in higher education. Unfortunately, this may not be easy because if they are used to following a specific frame orientation in the past experiences they may resist change, unless they are confronted with alternatives (Brookfield, 1987).

The result of this study indicated that all four frames, to different extent, had a positive correlation with all five domains of instructional technology use in teaching (technology infrastructure, faculty use of technology, technical support, administrative support, and key issues). This suggests that department chairs should adjust their leadership frame use to fit the different situation related to each of the five technology domains in order to expedite faculty use of instructional technology in their teaching. For example, faculty ratings for administrative support for their use of technology were positively correlated with their chairs' use of the human resource frame, so to motivate 
faculty in integrating technology into teaching, chairs should strengthen their use of the human resource frame. In this way, they would be more likely to create environments that foster participation and are open to new ideas. It is quite helpful to create opportunities for faculty to learn about technology use by their colleagues within their own discipline (Frayer, 1998).

The research results may help chairpersons better understand the influence of their leadership styles on faculty utilization of instructional technology in teaching. The findings may assist academic department chairs in Colleges of Education in examining and adapting their own leadership behaviors. Chairs can benefit from knowing what leadership styles are more likely to promote faculty utilization of instructional technology in teaching. Consistent with the previous studies, it was found in this study that chairs with frame orientations, especially a multi-frame orientation, were more likely to provide technical and administrative support for faculty use of technology. Therefore, as a recommendation of this study, chairs are suggested to use multi-frame approaches in order to improve their leadership in promoting faculty use of technology.

The result may contribute to building a more systematic base of information about the chairperson's role in higher education. Undoubtedly, according to the findings of this study that there was a strong relationship between the leadership styles of academic department chairs and faculty use of instructional technology, it is suggested that chairs should consider it as one of their roles in higher education to facilitate faculty use of technology to enhance student learning.

Finally, the result of this study may have implications for college deans and chief information officers. College deans and chief information officers in higher education are 
both important figures to make decisions about technology use in higher education. For this reason, understanding the relationship between leadership frames and faculty use of instructional technology would help them appropriately apply their leadership tactics to promotion of technology use in higher education. Middle-level and executive level administrators may also wish to address the importance of the recruitment selection, development, and evaluation of unit level administrators.

\section{Recommendations for Further Studies}

1. A combination of qualitative and quantitative methods is recommended for measuring the leadership frame use. This would be particularly valuable in probing the lack of leadership styles for many of the chairs.

2. Additional research should be conducted to compare chairs' self-perceived frame use with faculty perceptions of chairs' use of the leadership frame and influence on faculty utilization of instructional technology.

3. Subsequent studies may determine whether the selection culture for the appointment or election of chairs takes into account the leadership capacities and whether leader development training is provided to assist them in strengthening their leadership skills.

4. The unusually high ratio of EDLS chairs with no style may reflect the situational characteristics of these units. Subsequent studies should probe: a) academic structure of the department (whether higher education, foundations are included), and b) the level of maturity and capability of the faculty, particularly, with regard to IT. 
5. Future studies should examine leadership style of women administrators, particularly in light of the surprisingly high percentage of women chairs in this study who lack leadership style. Demographic data should be collected for such studies.

6. The administrative aspiration and organizational orientations of chairs are also areas for future studies, including their local/cosmopolitan modes of accommodation, upward mobility, career plans, etc.

7. Similar studies should be conducted in the departments of the colleges of education at all different types of institutions by Carnegie Classifications to determine what leadership styles a department chair uses and whether they significantly influence faculty utilization of instructional technology in teaching. This would provide support for the conclusions of this research.

8. Comparative studies should be undertaken in academic departments of other colleges or schools at all types of institutions by Carnegie Classifications, especially in colleges of business, which typically contain department chairs with prior administrative experience and previous graduate preparation in leadership studies. This would result in a broader generalization about the relationship of leadership style and faculty utilization of instructional technology in teaching and also assist in determining whether the phenomenon is particular to colleges of education.

9. A study exploring the influence of department chairs who play a role in faculty utilization of instructional technology as a faculty developer, a manager, and a scholar would be useful. The findings would assist academic department chairs in examining and adapting the various roles they play in supporting faculty use of instructional technology. 
10. Further research should be undertaken to explore the relationship of academic department chairs' leadership frame use and the improvement of teaching quality via faculty utilization of instructional technology.

11. This study could be redesigned and conducted with a focus on the relationship of the leadership styles of college deans or chief information officers at institutional level or even vice presidents for information system and faculty utilization of instructional technology. The findings would provide leaders at different institutional levels with knowledge about how to incorporate various leadership frames into their behavior to promote faculty use of instructional technology to enhance faculty teaching and student learning. 


\section{References}

Ashour, A. S. (1973). The contingency model of leadership effectiveness: An evaluation. Organizational behavior and human performance, 9, 339-335.

Austin, A. E. (1994). Understanding and assessing faculty cultures and climate. In M. K. Kinnick (Ed.), Providing useful information for deans and department chairs. New Directions for Institutional Research (pp. 47-63), No. 84.

Bachman, J. D. (1968). Faculty satisfaction and the dean's influence: An organizational study of twelve liberal arts colleges. Journal of applied psychology, 52, 55-61.

Barge, J. K., \& Musambira, G. W. (1992). Turning points in the chair-faculty relationships. Journal of Applied Communication Research, 20, 54-77.

Bass, B. M. (1957). Leadership opinions and related characteristics of salesmen and sales managers. In R. M. Stogdill \& A. E. Coons (Eds.), Leader behavior: Its description and measurement (pp. 134-139). Columbus, OH: The Ohio State University.

Bass, B. M. (1985). Leadership: Good, better, best. Organizational dynamics, 13, 16-40.

Bass, B. M. (1990). Handbook of leadership: Theory, research, and managerial applications (3rd ed.). New York, NY: The Free Press.

Bassinger, J. (2000, August 11). A new way of classifying colleges elates some and perturbs others. The chronicle of higher education, 46 (49), A31 - A42.

Bassoppo-Moyo, S. (1999). The relationship between department chairs' leadership 
frame and usage of academic program review results. (Doctoral dissertation, The University of Memphis, 1999). Dissertation Abstracts International, 60(06A), 1929.

Bates, A. W. (1999). Managing technology change. San Francisco: Jossey-Bass Publishers.

Bates, A. W. (2000). Giving faculty ownership of technological change in the department. In Lucas (ed.), Leading Academic Change. San Francisco: JosseyBass.

Becker, N. J. (2000). Implementing technology in higher education: The leadership role and perspectives of the chief information officer (Doctoral dissertation, Teacher College, Columbia University, 1999). Dissertation Abstracts International, 60(07), 2395.

Bensimon, E. M., Neumann, A., \& Birnbaum, R. (1991). Higher education and leadership theory. In M. W. Peterson (Ed.), Organization and Governance in Higher Education (pp. 389-398).

Bensimon, E.M., Neumann, A., \& Birnbaum, R. (1989b). Making sense of administrative leadership: The " $L$ " word in higher education. (ASHE-ERIC Higher Education Report No. 1). Washington, DC: The George Washington University.

Bennett, J. B. (1988). Department chairs: Leadership in the trenches. In M. F. Green (ed.), Leadership for a new era: Strategies for higher education. New York: Collier Macmillan Publishers.

Bennis, W. (1984). Transformative power and leadership. In T. J. Sergiovanni, \& J. E. Corbally (eds.), Leadership and organizational culture: New perspectives on 
administrative theory and practice (pp. 64-71). Urbana: University of Illinois Press.

Bennis, W. (1998). On becoming a leader, London: Arrow.

Bennis, W., \& Nanus, B. (1985). Leaders: The strategies for taking charge. New York: Harper \& Row.

Bethel, C., (1998). The relationship between presidential leadership orientations and organizational effectiveness in Bible colleges. Unpublished doctoral dissertation, West Virginia University, Morgantown, WV.

Bigham, G., \& Reavis, C. (2001). Preferred leadership frames of principals in implementing a state-wide teacher appraisal system. Contemporary education, 72(2), 52-57.

Birnbaum, R. (1988). How colleges work: The cybernetics of academic organization and leadership. San Francisco: Jossey-Bass.

Blake, R. R., \& Mounton, J. S. (1976). An overview of the grid. In W. R. Lassey \& R. R. Fernandez (Eds.), Leadership and social change ( ${ }^{\text {nd }}$ ed., pp. 197-212). La Jolla, CA: University Associates (Reprinted from Training and Development Journal, 19(5), 1975).

Blau, P. M. (1964). Exchange and power in social life. New York, NY: Wiley.

Bolman, L. G. \& Deal, T. E. (1984). Modern approaches to understanding and managing organizations. San Francisco, CA: Jossey-Bass Publishers.

Bolman, L. G. \& Deal, T. E. (1991a). Image of leadership. (NCEL Occasional Paper No. 7). Nashvile, TN: National Center for Educational Leadership. (ERIC Document Reproduction Service No. ED 332 345). 
Bolman, L. G. \& Deal, T. E. (1991b). Leadership and management effectiveness: A multi frame, multi-sector analysis. Human Resource Management, 30 (4), 509-534.

Bolman, L. G. \& Deal, T. E. (1992). Leading and managing: Effects of context, culture, and gender. Education Administration Quarterly, 28 (3), 314-329.

Bolman, L. G., \& Deal, T. E. (1993). Every day epistemology in school leadership: Patterns and prospects. In P. Hallinger, K. Leithwood, \& J. Murphy (Eds.), Cognitive perspectives on educational leadership (pp. 21-33). New York and London: Teacher College Press.

Bolman, L. G., \& Deal, T. E. (1994). Looking for leadership: Another search party's report Educational administration quarterly, 30(1), 77-96.

Bolman, L. G., \& Deal, T. E. (1997). Reframing organization: Artistry, choice and leadership ( $2^{\text {nd }}$ ed.). San Francisco: Jossey-Bass.

Bolman, L. G., \& Deal, T. E. (1999). Four steps to keeping change efforts heading in the right direction. Journal for quality \& participation, 22(3).

Borden, M. P. (2000). Leadership orientations of area campus administrators in Florida's state university and community college systems: A frame analysis. Dissertation Abstracts International, 61(10A), 3913.

Bowman Jr., R. F. (2002). The Real Work of Department Chair. Clearing House, 75(3), $158-163$.

Brown, J. D. (1977). Departmental and university leadership. In D. E. McHenry， \& Associates (eds.), Academic departments (pp. 12-33), San Francisco: JosseyBass

Bryman, A. (1996). Leadership in organizations. In S. R. Clegg, C. Hardy, \& W. R. Nord 
(Eds.), Handbook for organizational studies (pp. 276-292). London: Sage Publications.

Bullock, C., \& Ory, J. (2000). Evaluating instructional technology implementation in a higher education environment. American Journal of Evaluation, 21(3), 315-329.

Burks, T. D. (1992). The use of organizational frames in leadership development. (Doctoral Dissertation, Peabody College for Teachers of Vanderbilt University, 1992). [On-line]. Dissertation Abstracts International, 53 (05A), 1413. Abstract from Dissertation Abstracts Online File: UMI Dissertation Services Item: 9224297.

Burns, M. J. (1978). Leadership. New York: Harper \& Row, Publishers

Butler, D. L. \& Sellbom, M. (2003). Barriers to adopting technology for teaching and learning. Educause Quarterly, 25(2), p. 22-28.

Carroll, J., \& Gmelch, W.H. (1992). A factor-analytic investigation of the role types and profiles of higher education department chairs. San Francisco: The National Conference of the American Educational Research Association. (ERIC Document reproduction Service No. ED 345 629).

Cameron, K. S., \& Ulrich, D. O. (1986). Transformational leadership in colleges and universities. In C. S. John (ed.), Higher education: Handbook of theory and research, 2, 1-42.

Cantu, D. A. (1997). The leadership frames of academic deans randomly selected and nominated as exceptionally effective at public colleges and universities. (Doctoral dissertation, Arkansas State University, 1997). Dissertation Abstracts International, 5(03A), 650 . 
Chair-faculty distance education partnership. (2002, January). Academic Leader, 18(1), 1.

Charlson, S. (2003, July 18). Offering a leg up online: University of Maryland program provides a boost to the working poor - if they can handle it. The Chronicle of Higher Education.

Childress, G. P. E. (1994). An exploratory study of leadership orientation frames of United States-based Japanese and American leaders in the automotive manufacturing industry (United States). (Doctoral dissertation, Peabody college for Teachers of Vanderbilt University, 1994). [On-line] Dissertation Abstracts International, 56(04A), 1428. Abstract from: Dissertation Abstracts Online File: UMI Dissertation Services Item: 9524817.

Coats, L. T. (2000). Interpersonal behavior and the community college department chairperson. Community college journal of research \& practice, 24(10), 773-784.

Collins, J. C., \& J. Porras. (1994). Built to last: Successful habits of visionary companies. New York: Harper Business.

Conger, J. A. (1989). The charismatic leader: Beyond the mystique of exceptional leadership. San Francisco: Jossey-Bass.

Cote, A. B. (1999). Leadership orientation frames of Florida elementary principals in relationship to school context and principal characteristics. Dissertation Abstracts International, 60(12A), 4257.

Covey, S. R. (1989) The seven habits of highly effective people: restoring the character ethic, New York : Simon and Schuster. 
Creswell, J. W., Wheeler, D. W., Seagren, A. T., Egly, N. J., \& Beyer, K. D. (1990). The academic chairpersons' handbook. Lincoln and London: University of Nebraska Press.

Crist, B. (1999). A study of the relationship of the job satisfaction of chief academic officers of institutions of higher education and the perceived leadership style of the institution's president. Unpublished doctoral dissertation, West Virginia University, Morgantown, WV.

Daniel, W. S. (2002). A model for integrating instructional technology into higher education. Paper presented at the annual meeting of the American Educational Research Association, April, New Orleans, LA.

Department chairs play crucial roles in the success of distance education initiatives. (2002, November). Academic Leader, 18(11), 5.

Dill, D. D. \& Fullagar, P. K. (1987). Leadership and Administrative Style. In M. W. Peterson (Ed.), Key Resource on Higher Education Governance, Management, and Leadership (pp. 390-411). San Francisco: Jossey-Bass Publishers.

Dolence, M. G. \& Norris, D. M. (1995). Transforming higher education: A vision for learning in the $21^{\text {st }}$ century. Society for College and University Planning.

Draude, B. \& Brace, S. (1999). Assessing the impact of technology on teaching and learning: Student perspectives. Proceedings of the Mid-South Instructional Technology Conference, Murfreesboro, TN. (ERIC Document Reproduction Service No. ED436118)

Dyer, D. G. \& Miller, M. (1999). A critical review of literature related to the department chair position. Alabama. (ERIC Document Reproduction Service No. ED432193) 
El-Khawas, E. (1995). Campus trends 1995: New directions for academic programs. Wahington, D. D.: American Council on Education, 1995.

Echols Tobe, D. (1999). The development of cognitive leadership frames among African American female college presidents (women, leadership), Dissertation Abstracts International, 60(07A), 2300.

Eck, P. P. (1997). An analysis of management perspectives and criteria for innovation and adoption decisions in public organizations. (Doctoral dissertation, Arizona State University, 1998). [On-line]. Dissertation Abstracts International, 58 (10A), 4061. Abstract from ProQuest File: UMI Dissertation Services Item: 9812461.

Eckley, M. E. N. (1997). The relationship between teacher and empowerment and principal leadership styles (school organization). (Doctoral dissertation, The Pennsylvania University, 1998). [On-line]. Dissertation Abstracts International, 58, (07A), 2475. Abstract from: Dissertation Abstracts Online File: UMI Dissertation Services Item: 9802625.

Ehrle, E. (1975). Selection and evaluation of department chairmen. Educational Record, 56(1), 29-38.

Ehrle, E. B. \& Bennett, J. B. (1988). Managing the academic enterprise: Case studies for deans and provosts. New York, NY: Macmillan.

Ewing, J., Dowling, J. \& Coutts, N. (1997). Stars: Report on superhighway teams across rural schools project. ED421319.

Fiedler, F. D. (1965). Engineer the job to fit the manager. Harvard business review, $43(5), 115-122$ 
Fiedler, F. E. (1967). A theory of leadership effectiveness, McGraw-Hill, New York, 1967.

Fiedler, F. E. (1971). Leadership. General Learning Press, New York, 1971.

Fiedler, F. E., \& Mhemers, M. M. (1974). Leadership and effective management, Scott, Foresman, Glenview, I11., 1974.

Fiedler, F. E. (1976). A theory of leadership effectiveness. New York: McGraw-Hill, 1976.

Fincher, C. (1987). Administrative Leadership in Higher Education. In J. C. Smart (Ed.), Higher Education: Handbook of Theory and Research, VIII, (pp. 155-198). New York: Agathon Press, Inc.

Fisher, J. L., Tack, M. W., \& Wheeler, K. J. (1988). The effective college president. New York, NY.: Macmillan.

Fleishman, E. A. (1973). Twenty years of consideration and structure. In E. A. Fleishman and J. G. Hunt (Eds.), Current developments in the study of leadership (pp. 1-40). Carbondale, IL: Southern Illinois University Press.

Focus on Distance Education, (2001, March). Update, 7(2).

Fraenkel, Jach R. and Wallen, Norman E. How to Design and Evaluate Research in Education, 5th ed. McGraw-Hill, 2000.

Frayer, D. A. (1999). Creating a campus culture to support a teaching and learning revolution. Cause/Effect, 22(2)

French , J. R. P., Jr., \& Raven, B. (1968). The basis of social power. In D. Cartwright, \& Zander (Eds.), Group dynamics: Research and theory. ( ${ }^{\text {rd }}$ ed. pp. 607-623), New York: Harper \& Row. 
Gardner, H. (1999). Intelligence reframed: Multiple intelligences for the 21th centrury. New York: Basic Books.

Gardiner, L. F. (2000). Monitoring and improving educational quality in the academic department. In A. Lucas (ed.), Leading Academic Change (pp. 165-194), San Francisco: Jossey-Bass.

Gatlin-Wantts, R., \& Arn, J., \& Kordsmeier, W. (1999). Multimedia as an instructional tool: Perceptions of college department chairs. Education, 120(1).

Gilson, J. T. (1994). A leadership study: Public higher education administrators in Missouri compared with the Bolman-Deal database on multi-frame, multi-sector leadership. Dissertation Abstracts International, 55(05A), 1199.

Gmelch, W. H., \& Miskin, V. D. (1993). Leadership skills for department chairs. Bolton, MA.: Anker Publishing Company, Inc.

Green, Kenneth C. (2000). Campus Computing, 2000: The $11^{\text {th }}$ National Survey of Computing and Information Technology in American Higher Education. ERIC Clearinghouse on Higher Education, California, 2001, (ED 451744).

Greenfield, W. D. (1985). Value leadership: The department chair's role in instructional improvement. Illinois School Research and Development, 21(1), 22-27.

Groves, M. M., \& Zemel, P. C. (2000). Instructional technology adoption in higher education, An action research case study. International journal of instructional media, 27(1), 59-66.

Hackman, M. Z., \& Johnson, C. E. (1991). Leadership: A communication perspective. Prospect Heights, IL: Waveland. 
Hains, A. H., Belland, J., Concelcao-Runlee, S., Santos, R. M., \& Rothenberg, D. (2000). Instructional technology and personnel preparation. Topics in Early Childhood Special Education, 20(3), 132-144.

Hall, J. (1980). The competency process: Managing for commitment and creativity. The Woodlands, TX: Teleometrics International.

Halpin, A. W. (1957). The leader behavior and effectiveness of aircraft commanders. In R. M. Stogdill \& A. E. Coons (Eds.), Leader behavior: Its description and measurement (pp. 52-64). Columbus, OH: The Ohio State University.

Halpin, A. W. \& Croft, D. B. (1966). Theory and research in administration. New York, NY: Macmillan.

Halpin, A. W., \& Winer, B. J. (1957). The leader behavior and effectiveness of aircraft commanders. In R. M. Stogdill \& A. E. Coons (Eds.), Leader behavior: Its description and measurement (pp. 39-51). Columbus, OH: The Ohio State University.

Harlow, J. H. (1994). Educational leadership: A frame analysis. (Doctoral dissertation, Seattle University, 1994). [On-line]. Dissertations Abstracts International, 55 (08A), 2227. Abstract from: Dissertation Abstracts Online File: UMI Dissertation Services Item: 9427416.

Hashem, M. E. (2000). Human diversity and cross-culture communication: A global approach. Okalahoma City, Okalahoma: CEI Publishing.

Hashem, M. E., Crawfor, C. B., \& Strohkirch, C. S. (2000). Trends in information technology and future prospects with regard to transforming classroom interaction. Paper presented at the Annual Meeting of the Central States 
Communication Association Detroit, MI, (ERIC Document Reproduction Service No. ED440417).

Hecht, I., Higgerson, M., Gmelch, W., \& Tucker, A. (1999). The department chair as academic leader. Phoenix, AZ: Oryx Press.

Heimler, C. (1972). The college departmental chairperson. In J. Brann \& T. Emmet (Eds.), The academic department or division chairperson: A complex role (pp.198-207). Detroit, Michigan: Balamp Publishing.

Hemphill, J. K. (1995). Leadership behavior associated with the administrative reputation of college departments. Journal of Educational Psychology, 46(7), 385-401.

Hersey, P., \& Blanchard, K. H. (1969). Management of organizational behavior: Utilizing human resource. Engle-wood Cliffs, N. J.: Prentice-Hall.

Hersey, P., \& Blanchard, K. H. (1982). Management of organizational behavior: Utilizing human resource. Engle-wood Cliffs, N. J.: Prentice-Hall.

Hogan, R., Curphy, G. J., \& Hogan, J. (1994). What we know about leadership: Effectiveness and personality. American Psychologist, 49(6), 493-504.

Hollander, E. P. (1993). Legitimacy, power and influence: A perspective on relational features of leadership. In M. M. Chemers \& R. Ayman (eds.), Leadership theory and research: Perspectives and directions (pp. 29-47). San Diego: Academic Press.

House, R. J., \& Mitchell, T. R. (1978). Path-goal theory of leadership. In W. E. Natemeyer (Ed.), Classics of organizational behavior (pp. 226-236). Oak Park, IL: Moore (Reprinted from Journal of contemporary Business, Autumn 1974, pp. 81-97). 
Hoy, W. K. \& Miskel, C. G. (1996). Educational administration: Theory, research, and practice (5th ed.). New York, NY: McGraw-Hill.

Hughes, R. L., Ginnet, R. C., \& Curphy, G. J. (1999). Leadership: Enhancing the lessons of experience ( $3^{\text {rd }}$. ed.). Boston: McGraw-Hill.

Jago, A. G. (1982). Leadership: Perspectives in Theory and Research. Management Science, 28(3), 315-336.

Katz, R. L. (1974). Skills of an Effective Administrator. Harvard Business Review. 52, 90-102.

Kerr, S. (1974). Discussant Comments. In J. G. Hunt, \& L. L. Larson (Eds.), Contingency approaches to leadership (pp. 124-129), Carbondale, Ill.: Southern Illinois University Press.

Kerr, S., \& Harlan, A. (1973). Predicting the effects of leadership training and experience from the contingency model: Some remaining problems. Journal of applied psychology, vol. 57 (1973), 114-117.

Kniewel, V. S. (1999). Leadership orientation of principals and teacher participation in decision-making. Dissertation Abstracts International, 60(09A), 3219.

Knight, W. H., \& Holen, M. C. (1985). Leadership and the perceived effectiveness of department chairpersons. Journal of Higher Education, 56(6), 677-90.

Kouzes, J. M., \& Posner, B. Z. (1995). The Leadership Challenge, San Francisco: JosseyBass.

Lawler, E. J., \& Thye, S. R. (1999). Bringing emotions into social exchange theory. Annual review of sociology, 25(1), 217.

Leaming, D. R. (1998). Academic Leadership. Bolton, MA.: Anker Publishing Co. Inc. 
Lindholm, J. (1999). Preparing department chairs for their leadership roles. Los Angeles, CA.: ERIC Clearinghouse for Community College, (ERIC Document Reproduction Service No. ED433870).

Litechy, L. (1988). The role of the chair in fostering teaching and learning. St. Paul: Faculty Association, Minnesota Community Coll. (ERIC Document Reproduction Service No. ED355987).

Litterst, J. K. (1993). Creativity and the department chairperson: Challenge or oxymoron? Paper presented at the Joint Meeting of the Southern States Communication Association and the Central States Communication Association. Lexington, KY. (ERIC Document Reproduction Service No. ED361794)

Lucas, A. F. (1994). Strengthening departmental leadership: A teach-building guide for chairs in colleges and universities. San Francisco: Jossey-Bass Publishers.

Lucas, A. F., \& Associates. (2000). Leading academic change. San Francisco: JosseyBass Publisher.

Luthans, F. (1992). Organizational behavior (6 ${ }^{\text {th }}$ ed.). new York, NY: McGraw-Hill. Maccoby, M. (2000, January-February). Narcissistic Leaders: The incredible pros, the inevitable cons. Harvard Business Review, 69-77

Madron, T. W., Craig, J. R., \& Mendel, R. M. (1976). Department Morale as a function of the perceived performance of department heads. Research in higher education, 5(1), 83-94.

Markus, H., \& Zajonc, R. B. (1985). The cognitive perspective in social psychology. In G. Lindzey \& E. Aronson (Eds.), Handbook of social psychology ( $3^{\text {rd }}$ ed., Vol. I, pp. 137-230). New York: Random Hours. 
Mathis, S. G. (1999). The Relationship of Leadership Frame Use of Departmental Chairs to Faculty Job Satisfaction as Perceived by Selected Departmental Faculty Members Dissertation, West Virginia University, [On-line Abstract]. Available: http://etd.wvu.edu/templates/showETD.cfm?recnum=535

McArthur, R. C. (2002). Democratic leadership and faculty empowerment at the community college: A theoretical model for the department chair. Community college review, 30(3), 1-11.

McClellan-Holt, J. E. (2000). Leadership orientations of student personnel professionals. Dissertation Abstracts International, 61(07A), 2623.

McMahon, J. T. (1972). The contingency theory: Logic and method revisited. Personal psychology, 25, 697-711.

Messer, J. E. (2002). Elementary principal leadership orientations and selected professional and school variables. Dissertation Abstracts International, 63(02A), 450.

Metz. B. A. (1998). True partnerships: The key to technology infrastructure challenges. Cause/Effect, 20(4), p. 46-51, 67.

Miller, P. A. (1998). Directors/chairpersons of occupational therapy professional programs: A study of leadership in higher education. Dissertation Abstracts International, 59(01), 0041A.

Mintzberg, H. (1973). The nature of managerial work. New York: Harper \& Row.

Miro, A. M. (1993). A comparative study of the leadership orientation frames between public high school principals serving in schools that applied and did not apply for California senate bill 1274 restructuring grants. (Doctoral dissertation, University 
of La Verne, 1993). [On-line]. Dissertation Abstracts International, 55 (05A), 1158. Abstracts from: Dissertation Abstracts Online File: UMI Dissertation Services Item: 9426160.

Mosser, N. R. (2000). A study of the relationship between the perceived leadership style of nursing chairpersons and the organizational climate of baccalaureate nursing programs. (Doctoral dissertation, West Virginia University, 2000).

Muffoletto, R. (1994). Technology and restructuring education: Constructing a context. Educational Technology, 34(2), 24-28.

National Commission on the Cost of Higher Education (1998). Straight talk about college costs and prices. The American council on Education. http://www.acenet.edu/programs/dgr/costreport.html

Netemeyer, R. G., Bearden, W. O., \& Sharma S. (2003). Scaling procedures: Issue and applications. Sage Publications: Thousand Oaks.

Parsons, J., \& Beauchamp, L. (2000). Using computer technology in teaching. (ERIC Document Reproduction Service No. ED446489).

Peterson, M. W., Chaffee, E. E., \& White, T. H. (1991). Organization and Governance in higher education $\left(4^{\text {th }}\right.$ ed. $)$, Needham Heights, MA: Simon \& Schuster Custom Publishing

Pfeffer, J. (1981). Power in organization. Marshfield, Mass.: Pitman, 1981.

Redman, M. D. (1991). A comparative study of the leadership orientation frames of administrators in private Japanese and American institutions of higher education (private institutions). (Doctoral dissertation, University of La Verne, 1991). [On line]. Dissertation Abstracts International, 52 (09A), 2431. Abstract from: 
Dissertation Abstracts Online File: UMI Dissertation Services Item: 9205508.

Rice, R. W. (1978). Psychometric properties of the esteem for least preferred co-worker (LPC) scale. Academic management review, 3(1978), 106-118.

Reichard, L. A. (1990). Relationship between presidential leadership styles in small public four-year colleges and job satisfaction, job anxiety, and job performance among deans of academic affairs. Doctoral Dissertation: West Virginia University.

Roach, J. (1976). The academic department chairpersons: Functions and responsibilities. Educational record, 57, 13-23.

Russel, T. (1999). The no significant difference phenomenon. Raleigh, NC: North Carolina State University.

Schein, E. H. (1985). Organizational culture and leadership. San Francisco: Jossey-Bass Publishers.

Schermerhorn, J. R. (1997). Organization behavior ( $6^{\text {th }}$ ed.). New York: John Wiley and Sons.

Schriescheim, C. A., \& Kerr, S. (1977a). Theories and measures of leadership: A critical appraisal of current and future directions. In J. G. Hunt, \& L. L. Larson (Eds.), Leadership: The cutting edge (pp. 9-45), Carbondale, Ill.: Southern Illinois University Press,

Schriescheim, C. A., \& Kerr, S. (1977b). R. I. P. LPC: A response to Fiedler. In J. G. Hunt, \& L. L. Larson (Eds.), Leadership: The cutting edge (pp. 51-56), Carbondale, Ill.: Southern Illinois University Press.

Scott, D. K. (1997). An exploratory study of leadership and organizational 
climate/culture of NCAA and NAIA finalists for the 1995-1996 Sear's directors' cup. (Dissertation Abstracts Online), Dissertation Abstracts International, 58(08A), 3063.

Seagre, Alan T., Creswell, J. W., \& Wheeler, D. W. (1993). The department chair: New roles, responsibilities and challenges. Washington, D.C.: The George Washington University.

Seels, B. B., \& Rchey, R. C. (1994). Instructional technology: The definition and domains of the field. Washington, DC: Association for Education Communications and Technology.

Selznick, P. (1957). Leadership in administration: A sociological interpretation. New York: Harper \& Row, 1957.

Shiflett, S. C. (1975). The contingency model of leadership effectiveness: Some implications of its statistical and methodological properties. Behavioral Science, 18(1973), 429-440.

Shiflett, S. C. (1974). Stereotyping and esteem for one's least preferred co-worker. Journal of social psychology, 93(1974), 55-65.

Siegel, M. E. (2003). Instructional infrastructure planning: Innovation theory, systems theory, and computer modeling. Available online: Http://horizon.unc.edu/projects/monograph/CD/Change_Innovation/siegel.asp. Sinetar, M. (1985) SMR forum: Entrepreneurs, chaos, and creativity—Can creative people really survive large company structure? Sloan Management Review, 57-62 Small, T. T. (2002). A study of the relationship between the perceived leadership style of nursing chairpersons and the organizational effectiveness of baccalaureate 
nursing programs. Dissertation, West Virginia University, [On-line Abstract]. Available: http://etd.wvu.edu/templates/showETD.cfm?recnum=2424

Smith, P. B., \& Peterson, M. F. (1988). Leadership, organizations and culture: An event management model. London: SAGE

Spotts, T. H., \& Bowman, M. A. (1995). Faculty use of instructional technologies in higher education. Educational Technology, 35(2), 56-64.

Stark, J. S., Griggs, C. L., \& Rowland-Poplawski, J. (2002). Curriculum leadership roles of chairs in "continuously planning" departments. Research in Higher Education, 43(3), 329-57.

Stinson, J. E., \& Tracy, L. (1974). Some disturbing characteristics of the LPC score. Personal psychology, 27(1974), 471-485.

Stodgill, R. M. (1948). Personal factors associated with leadership: A survey of the literature. Journal of Psychology, 25, 35-71.

Stodgill, R. M. (1981). Traits of leadership: A follow-up to 1970. In B. M. Bass (Ed.), Stodgill's handbook of leadership (pp. 73-82). New York, NY: Free Press.

Stogdill, R. M., \& Coons, A. E. (1957). Leader behavior: Its description and measurement. Columbus, OH: The Ohio State University.

Strickland, J. S. (1992). Leadership perspectives of Tennessee school leaders (organizational frames). (Doctoral dissertation, East Tennessee State University, 1992). [On-line]. Dissertation Abstracts International, 53 (04A), 1018. Abstract from: Dissertation Abstracts Online File: UMI Dissertation Services Item: 9222256.

Survey on How Technology Infrastructure Is Financed. (2003). Retrieved from 
http://www.luminafoundation.org/Publications/New\%20Agenda\%20Series/Appe ndixASurvey.PDF

Suzuki, Y. C. (1994). A comparative study of leadership orientation frames of California Asian and other public school principals. (Doctoral dissertation, Univeristy of La Verne, 1994). [On-line]. Dissertation Abstracts International, 55 (07A), 1708. Abstract from: Dissertation Abstracts Online File: UMI Dissertation Services Item: 9426165.

Taylor, P. (1994). Leadership in education. Emergence Librarian, 21(3), 9.

The Nation's Leading Online University (n.d.). Retrieved July 25, 2003), from http://www.uopxonline.com/aboutus.asp

Thibault, J. W., \& Kelley, H. H. (1952)., The Social Psychology of Groups. New York: John Wiley \& Sons.

Tichy, N. M. \& Devanna, M. A. (1986). The transformational leader. New York: Wiley. Tierney, W. G. (1989). Symbolism and presidential perceptions of leadership. Review of Higher Education, 12(2), 153-166.

Treadwell, D. F. (1997). The department chair: A symbolic perspective and some implication. Journal of the Association for Communication Administration (JACA), 3, 218-24.

Trow, M. (1977). Departments as contexts for teaching and learning. In D. E. McHenry, \& Associates (eds.), Academic departments (pp. 12-33), San Francisco: JosseyBass

Tucker, A. (1984). Chairing the academic department: Leadership among peers. Washington D. C.: American Council on Education. 
Turley, C. L. (2002) Radiation Therapy Program Directors: A Frames Analysis of Leadership in Higher Education. Dissertation, the George Washington University U. S. Department of Education (1996). Getting America's students ready for the $21^{\text {st }}$ century: Meeting the technology literacy challenge. [Online]. Available: http://www.ed.gov/Technology /Plan/.

Vacik, S. M. (1997). Critical incidents impacting the role and development of the academic department chair, 1870-1925. Unpublished doctoral dissertation., The University of Alabama, Tuscaloosa, AL.

Van der Veer, G. (1991). Cognitive complexity and the career achievement of higher education administration (Dissertation Abstracts Online). Dissertation Abstracts International, 53(07A), 2270.

Van Dusen, G. C. (1998). Technology: Higher education's magic bullet. Thought \& Action Journal. [Online]. http://www.nea.org/he/heta98/spring98.html

Vecchio, R. P. (1977). An empirical examination of the validity of Fiedler's model of Leadership effectiveness. Organizational behavior and human performance, vol. 19(1977), pp. 180-206.

Vroom, V. H., \& Yetton, P. (1973). Leadership and decision making. Pittsburgh, Pa.: University of Pittsburgh Press, 1973.

Wilson, W. (2003). Faculty perceptions and uses of instructional technology. Educause Quarterly, 2, p. 60-62.

Yukl, G. A. (1981). Leadership in organizations. Englewood Cliffs, NJ: Prentice-Hall. Yukl, G. A. (1998). Leadership in organizations ( $4^{\text {th }}$ ed.) Upper Saddle River, NJ: Prentice Hall. 
Appendices

A. Letter to Dr. Bolman for Permission of Use of the Leadership Orientations Instrument

WestVirginiaUniversity

Colloge of Human Resources and Education

April 16, 2003

Dr. Lee G. Bolman

Bloch School of Business and Public Administration

University of Missouri - Kansas City

5100 Rockhill Road

Kansas City, Missouri 64110

Dear Dr. Bolman:

I am a doctoral candidate in Higher Education Administration at West Virginia University and am preparing my dissertation prospectus. The title is "A Study of the Relationship of Academic Department Chairs and Faculty Utilization of Instructional Technology in Teaching." I am hoping to use your Leadership Orientations (SELF) instrument to investigate the leadership style of academic department chairs in the Colleges of Education at Doctoral/Research Universities - Extensive by Carnegic Classification. I understand that, should you grant me permission to use your instrument, I will provide you with a copy of any reports, publications, papers or theses resulting from this research. I also agree to provide you a copy of the data file from this research if you request it.

If you have any questions, you can reach me by E-mail at tchang(a mix.wvu.edu or my mailing address is:

\section{Newton Ave Apt 101 \\ Morgantown WV 26505}

1 am looking forward to hearing from you. Thank you for your time.

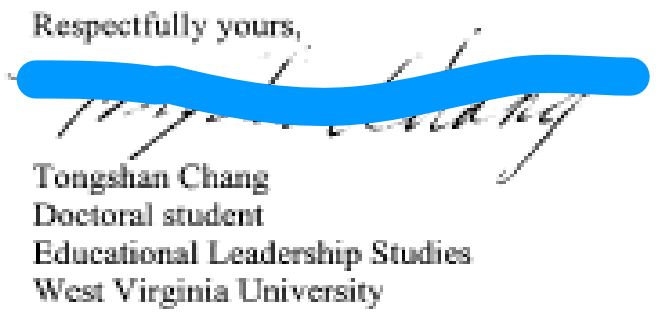

\footnotetext{
Department of Actvanced Educational Studies Educational Leadership Studies, Educational Psychology. Social and Cultural Foundations, Technology Education 


\section{B. Permission to Use the Leadership Orientations Instrument}

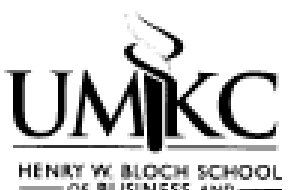

HENAY W BLOCM SCHOOL

PUBLIC ADMINISTRATION

Lee G. Bolman

Monion H. Bloch Missuri

Coar is Leaderatig

April 28, 2003

Mr. Tongshan Chang

Educational Leadership Studies

College of Human Resources and Education

Allen Hall, PO Box 6122

Morgantown, WV 26506-6122

Dear Mr. Chang:

Thanks for your interest in the Leadership Orientations instrument. I am pleased to offer you permission to use the instrument in your doctoral research, subject to the following conditions: (a) you agree to provide us a copy of your thesis and of any publication that reports data based on the instrument, and (b) you agree to provide, if we request it, a copy of your data file.

The instruments and Information about their use, including data on internal reliability, and a list of research using the Bolman and Deal Four Frames Model, can be found at:

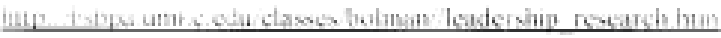

Best wishes in your research.
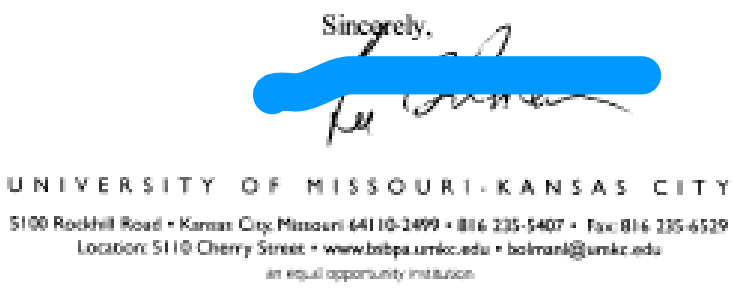
C. Bolman and Deal Leadership Orientations (others) 


\section{LEADERSHIP ORIENTATIONS (OTHERS) ${ }^{1}$}

This questionnaire asks you to describe the chairperson, or head of your department, in terms of leadership behavior. You are asked to indicate how often each item is true of the person you are rating. Please use the following scale in answering each item.
1
Never
2
3
4
Often
5
Always

So, you would answer ' 1 ' for an item that is never true of the person you are describing, '2' for one that is occasionally true, ' 3 ' for one that is sometimes true, and so on.

1.__ Thinks very clearly and logically.

2.___ Shows high levels of support and concern for others.

3.___ Shows exceptional ability to mobilize people and resource to get things done.

4. Inspires others to do their best.

5. Strongly emphasizes careful planning and clear time lines.

6._B__ Builds trust through open and collaborative relationships.

7.___ Is a very skillful and shrewd negotiator.

8._Is highly charismatic.

9.___ Approaches problems through logical analysis and careful thinking.

10._Shows high sensitivity and concern for others' needs and feelings.

11. Is unusually persuasive and influential.

12. Is an inspiration to others.

13. Develops and implements clear, logical policies and procedures.

14.___ Fosters high levels of participation and involvement in decisions.

15.___ Anticipates and deals adroitly with organizational conflict.

16. Is highly imaginative and creative.

17._Approaches problems with facts and logic.

18._Is consistently helpful and responsive to others.

19. Is very effective in getting support from people with influence and power.

20._Communicates a strong and challenging vision and sense of mission.

21._Sets specific, measurable goals and holds people accountable for results.

22._L_L Listens well and is unusually receptive to other people's ideas and input.

23. Is politically very sensitive and skillful.

24. Sees beyond current realities to create exciting new opportunities.

25. Has extraordinary attention to detail.

26._ Gives personal recognition for work well done.

27.___ Develops alliances to build a strong base of support.

28. Generates loyalty and enthusiasm.

29.___ Strongly believes in clear structure and a chain of command.

30._Is a highly participative manager.

31._Succeeds in the face of conflict and opposition.

32.___ Serves as an influential model of organizational aspirations and values.

1. Copyright 1990, Lee G. Bolman and Terence E. Deal 
D. Faculty Utilization of Instructional Technology in Teaching Courses (chair version) 


\section{FACULTY UTILIZATION OF INSTRUCTIONAL TECHNOLOGY (CHAIR)}

\section{A. Please rate the quality of the "technology infrastructure" in your department by circling the appropriate number for each item.}

$$
1=\text { Poor } \quad 2=\text { Fair } \quad 3=\text { Good } \quad 4=\text { Very Good } \quad 5=\text { Excellent }
$$

1. Facilities for instructional technology utilizatio

2. Equipment for instructional technology

3. Operating system

4. Application software

5. Computer networks

6. Video and audio system

7. Telecommunications and phone system

8. Faculty access to instructional technology

9. User support service

10. Instructional technology training for faculty

\begin{tabular}{lllll}
1 & 2 & 3 & 4 & 5 \\
1 & 2 & 3 & 4 & 5 \\
1 & 2 & 3 & 4 & 5 \\
1 & 2 & 3 & 4 & 5 \\
1 & 2 & 3 & 4 & 5 \\
1 & 2 & 3 & 4 & 5 \\
1 & 2 & 3 & 4 & 5 \\
1 & 2 & 3 & 4 & 5 \\
1 & 2 & 3 & 4 & 5 \\
1 & 2 & 3 & 4 & 5 \\
\hline
\end{tabular}

\section{B. Please rate your utilization of the following technologies in your course teaching by circling} the appropriate number.

$$
1=\text { Never } \quad 2=\text { Occasionally } 3=\text { Frequently } 4=\text { Often } 5=\text { Always }
$$

\footnotetext{
11. Internet/World Wide Web

12. Presentation software

13. Computer spreadsheet

14. Statistical computing

15. Electronic discussion lists

16. Chat room

17. Multimedia use in class

18. Computer conferencing

19. Video

20. Audio

21. Distance education
}

$\begin{array}{lllll}1 & 2 & 3 & 4 & 5 \\ 1 & 2 & 3 & 4 & 5 \\ 1 & 2 & 3 & 4 & 5 \\ 1 & 2 & 3 & 4 & 5 \\ 1 & 2 & 3 & 4 & 5 \\ 1 & 2 & 3 & 4 & 5 \\ 1 & 2 & 3 & 4 & 5 \\ 1 & 2 & 3 & 4 & 5 \\ 1 & 2 & 3 & 4 & 5 \\ 1 & 2 & 3 & 4 & 5 \\ 1 & 2 & 3 & 4 & 5\end{array}$

C. Please assess the technical support for instructional technology use in your department by circling the appropriate number.

$$
\text { 1=Strongly Disagree 2=Disagree 3=Don't Know 4=Agree 5=Strongly Agree }
$$

\begin{tabular}{lllllll|}
\hline 22. & My department offers faculty training in instructional technology use. & 1 & 2 & 3 & 4 & 5 \\
23. My department offers faculty training in the design of curricula for distance education courses. & 1 & 2 & 3 & 4 & 5 \\
\hline 24. $\begin{array}{l}\text { My department has instructional technology support staff to provide assistance for faculty in } \\
\text { solving technology problems. }\end{array}$ & 1 & 2 & 3 & 4 & 5 \\
25. My department provides continuous maintenance of instructional technology equipment. & 1 & 2 & 3 & 4 & 5 \\
\hline $\begin{array}{l}\text { 26. } \\
\text { My department provides technical assistance to assist faculty in developing instructional }\end{array}$ & 1 & 2 & 3 & 4 & 5 \\
27. My department provides technical assistance to assist faculty in developing a course Web page. & 1 & 2 & 3 & 4 & 5 \\
\hline
\end{tabular}




\section{Please assess the administrative support for instructional technology use in your} department by circling the appropriate number.

I=Strongly Disagree 2=Disagree 3=Don't Know 4=Agree 5=Strongly Agree

\begin{tabular}{|c|c|c|c|c|c|c|}
\hline 28. & My department has a formal plan for integrating instructional technology into teaching. & 1 & 2 & 3 & 4 & \\
\hline 29 & $\begin{array}{l}\text { My department has a plan for teaching faculty how to make effective use of instructional } \\
\text { technology as a tool to support teaching. }\end{array}$ & 1 & 2 & 3 & 4 & 5 \\
\hline 30. & $\begin{array}{l}\text { My department provides rewards (e.g. funding, release time) to assist faculty in developing } \\
\text { instructional software. }\end{array}$ & 1 & 2 & 3 & 4 & 5 \\
\hline 31. & $\begin{array}{l}\text { My department provides rewards (e.g. funding, release time) to assist faculty in developing } \\
\text { course Web page. }\end{array}$ & 1 & 2 & 3 & 4 & 5 \\
\hline 32. & $\begin{array}{l}\text { My department has developed a system of rewards for innovators of new instructional } \\
\text { technology. }\end{array}$ & 1 & 2 & 3 & 4 & 5 \\
\hline 33. & $\begin{array}{l}\text { My department formally recognizes the use of instructional technology as part of the faculty } \\
\text { tenure and promotion process. }\end{array}$ & 1 & 2 & 3 & 4 & 5 \\
\hline 34. & $\begin{array}{l}\text { There are funding opportunities available within my department for development of distance } \\
\text { education curriculum. }\end{array}$ & 1 & 2 & 3 & & 5 \\
\hline 35. & $\begin{array}{l}\text { My department has a faculty member or staff person primarily responsible } \\
\text { development of distance education course curricula. }\end{array}$ & 1 & 2 & 3 & & 5 \\
\hline 36. & $\begin{array}{l}\text { I frequently inform the department members about positive uses of technology by the } \\
\text { colleagues. }\end{array}$ & 1 & 2 & 3 & & 5 \\
\hline & llty to share information, expertise, and c & 1 & 2 & 3 & & \\
\hline
\end{tabular}

\section{E. How important is each of the following issues affecting faculty utilization of instructional technology in teaching? Please circle the appropriate number.

$$
1=\text { Not Important } 2 \text { =Somewhat Important } 3=\text { Important }
$$$$
4=\text { Very Important } 5=\text { Extremely Important }
$$

\begin{tabular}{|l|lllll|}
\hline 38. Providing adequate instructional technology equipment & 1 & 2 & 3 & 4 & 5 \\
39. Providing timely repair of instructional technology facilities and equipment & 1 & 2 & 3 & 4 & 5 \\
40. Providing continuous maintenance of instructional technology equipment & 1 & 2 & 3 & 4 & 5 \\
41. Financing the replacement of aging hardware/software & 1 & 2 & 3 & 4 & 5 \\
\hline 42. Creating a vision for instructional technology integration into teaching & 1 & 2 & 3 & 4 & 5 \\
43. Developing a plan for instructional technology integration into teaching & 1 & 2 & 3 & 4 & 5 \\
\hline $\begin{array}{l}\text { 44. Providing incentives and rewards for faculty to support instructional technology integration } \\
\text { into teaching }\end{array}$ & 1 & 2 & 3 & 4 & 5 \\
45. Providing adequate instructional technology training for faculty & 1 & 2 & 3 & 4 & 5 \\
\hline $\begin{array}{l}\text { 46. Providing adequate technical support for integration of instructional technology into } \\
\text { teaching }\end{array}$ & 1 & 2 & 3 & 4 & 5 \\
\hline
\end{tabular}

\section{F. Demographic Information}

\begin{tabular}{|llll|}
\hline 43. & Your age: & 44. Your gender: \\
45. & Your degree: & 46. Your discipline: \\
47. & Your tenure status: & 48. Number of years in the current position as chair: \\
49. & Number of faculty (full time faculty: prof., associate prof., assistant prof., and instructor): \\
\hline
\end{tabular}

Please return the completed survey using the enclosed envelope before November 12. Thank you for your assistance. 
E. Faculty Utilization of Instructional Technology in Teaching Courses (faculty version) 


\section{FACULTY UTILIZATION OF INSTRUCTIONAL TECHNOLOGY (FACULTY)}

\section{A. Please rate the quality of the "technology infrastructure" in your department by circling the appropriate number for each item.}

$$
1=\text { Poor } \quad 2=\text { Fair } \quad 3=\text { Good } \quad 4=\text { Very Good } \quad \text { =Excellent }
$$

\begin{tabular}{|ll|rrrrr|}
\hline 1. & Facilities for instructional technology utilization & 1 & 2 & 3 & 4 & 5 \\
2. & Equipment for instructional technology & 1 & 2 & 3 & 4 & 5 \\
3. & Operating system & 1 & 2 & 3 & 4 & 5 \\
4. & Application software & 1 & 2 & 3 & 4 & 5 \\
5. & Computer networks & 1 & 2 & 3 & 4 & 5 \\
6. & Video and audio system & 1 & 2 & 3 & 4 & 5 \\
7. & Telecommunications and phone system & 1 & 2 & 3 & 4 & 5 \\
8. & Faculty access to instructional technology & 1 & 2 & 3 & 4 & 5 \\
9. & User support service & 1 & 2 & 3 & 4 & 5 \\
10. & Instructional technology training for faculty & 1 & 2 & 3 & 4 & 5 \\
\hline
\end{tabular}

\section{B. Please rate your utilization of the following technologies in your course teaching by circling the appropriate number.}

$$
1=\text { Never } 2=\text { Occasionally } 3=\text { Frequently } 4=\text { Often } 5=\text { Always }
$$

\begin{tabular}{|c|c|c|c|c|c|}
\hline 11. Internet/World Wide Web & 1 & 2 & 3 & 4 & 5 \\
\hline 12. Presentation software & 1 & 2 & 3 & 4 & 5 \\
\hline 13. Computer spreadsheet & 1 & 2 & 3 & 4 & 5 \\
\hline 14. Statistical computing & 1 & 2 & 3 & 4 & 5 \\
\hline 15. Electronic discussion lists & 1 & 2 & 3 & 4 & 5 \\
\hline 16. Chat room & 1 & 2 & 3 & 4 & 5 \\
\hline 17. Multimedia use in class & 1 & 2 & 3 & 4 & 5 \\
\hline 18. Computer conferencing & 1 & 2 & 3 & 4 & 5 \\
\hline 19. Video & 1 & 2 & 3 & 4 & 5 \\
\hline 20. Audio & 1 & 2 & 3 & 4 & 5 \\
\hline 21. Distance education & 1 & 2 & 3 & 4 & 5 \\
\hline
\end{tabular}

\section{Please assess the technical support for instructional technology use in your department by circling the appropriate number.}

1=Strongly Disagree 2=Disagree 3=Don't Know 4=Agree 5=Strongly Agree

22. My department offers faculty training in instructional technology use.

23. My department offers faculty training in the design of curricula for distance education

23. courses.

24. My department has instructional technology support staff to provide assistance for faculty in solving technology problems.

25. My department provides continuous maintenance of instructional technology equipment.

26. My department provides technical assistance to assist faculty in developing instructional software.

27. My department provides technical assistance to assist faculty in developing a course Web page.

\begin{tabular}{lllll}
1 & 2 & 3 & 4 & 5 \\
1 & 2 & 3 & 4 & 5 \\
1 & 2 & 3 & 4 & 5 \\
1 & 2 & 3 & 4 & 5 \\
1 & 2 & 3 & 4 & 5 \\
1 & 2 & 3 & 4 & 5 \\
\hline
\end{tabular}




\section{Please assess the administrative support for instructional technology use in your department by circling the appropriate number.}

\section{1=Strongly Disagree 2=Disagree 3=Don't Know 4=Agree 5=Strongly Agree}

28. My department has a formal plan for integrating instructional technology into teaching.

29. My department has a plan for teaching faculty how to make effective use of instructional

29. technology as a tool to support teaching.

30. My department provides rewards (e.g. funding, release time) to assist faculty in developing instructional software.

31. My department provides rewards (e.g. funding, release time) to assist faculty in developing course Web page.

32. My department has developed a system of rewards for innovators of new instructional technology.

$\begin{array}{lllll}1 & 2 & 3 & 4 & 5 \\ 1 & 2 & 3 & 4 & 5 \\ 1 & 2 & 3 & 4 & 5 \\ 1 & 2 & 3 & 4 & 5 \\ 1 & 2 & 3 & 4 & 5 \\ 1 & 2 & 3 & 4 & 5 \\ 1 & 2 & 3 & 4 & 5 \\ 1 & 2 & 3 & 4 & 5 \\ 1 & 2 & 3 & 4 & 5 \\ 1 & 2 & 3 & 4 & 5\end{array}$

33. My department formally recognizes the use of instructional technology as part of the faculty tenure and promotion process.

34. There are funding opportunities available within my department for development of distance education curriculum.

35. My department has a faculty member or staff person primarily responsible for the development of distance education course curricula.

36. My department chair frequently informs the department members about positive uses of technology by the colleagues.

37. My department chair frequently encourages faculty to share information, expertise, and discoveries about instructional technology.

\section{E. How important is each of the following issues affecting faculty utilization of instructional technology in teaching? Please circle the appropriate number.

$$
1=\text { Not Important } 2=\text { Somewhat Important } 3=\text { Important }
$$$$
4=\text { Very Important 5=Extremely Important }
$$

\begin{tabular}{|c|c|c|c|c|}
\hline 8. Providing adequate instructional technology equipment & 12 & 3 & 4 & \\
\hline 39. Providing timely repair of instructional technology facilities and equipment & 12 & 3 & 4 & \\
\hline 40. Providing continuous maintenance of instructional technology equipment & 12 & 3 & 4 & \\
\hline 41. Financing the replacement of aging hardware/software & 12 & 3 & 4 & 5 \\
\hline 42. Creating a vision for instructional technology integration into teaching & 12 & 3 & 4 & 5 \\
\hline 43. Developing a plan for instructional technology integration into teaching & 12 & 3 & 4 & 5 \\
\hline $\begin{array}{l}\text { 44. Providing incentives and rewards for faculty to support instructional technology integration } \\
\text { into teaching }\end{array}$ & & 3 & 4 & 5 \\
\hline 45. Providing adequate instructional technology training for faculty & 12 & 3 & 4 & 5 \\
\hline $\begin{array}{l}\text { 46. Providing adequate technical support for integration of instructional technology into } \\
\text { teaching }\end{array}$ & & 3 & & 5 \\
\hline
\end{tabular}

\section{F. Demographic Information}
47. Your age:
48. Your gender:
49. Your degree:
50. Your discipline:
51. Your academic status:
Please return the completed survey using the enclosed envelope within two weeks. Thank you for your assistance.




\section{F. A Cover Letter for Pilot Test Participants}

w

WestVirginiaUniversity

Culleye of Hunan Resuurees and Exducation

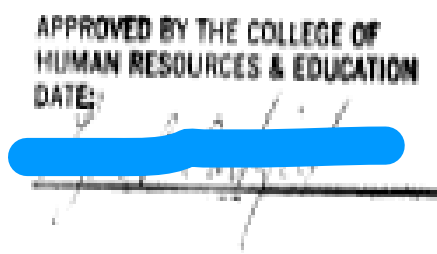

August 28, 2003

Dear Department Chair or Faculty:

I am a graduate student and am currently completing my doctorate in Higher Education Leadership at West Virginia University. I am writing to enlist your support for a pilot test on the instrument of Faculty Utilization of Instructional Technology for a study entitled "Leadership Style of Department Chairs and Faculty Utilization of Instructional Technology." This research is the focus of my doctoral dissertation in Higher Education Leâdêrship.

The purpose of this pilot test is to examine the clarity of the cover letter, the instrument layout, and the instructions to respondents; the applicability and the understandability of the survey items; and the capability of the survey to accurately yield the information about faculty utilization of instructional technology in teaching courses.

The participation in this pilot test is voluntary. You may choose not to respond to any or part of the study. The pilst tast includes sever letter, instrument of faculty utilization of instructional technology, and pilot test questionnaire. It takes approximately 10 to 15 minutes to complete. The collected data will be reported in aggregated form and will not idtentify you. Striet eunfidentiality will be maintained.

As a graduate research assistant, 1 understand bow valuable your time is and greatly appreciate your cooperation with this pilot test. If you have any questions, you may email me at tchang@mix.wru.edu-

Thank you for your time and assistance with this pilot test.

Sincerply,

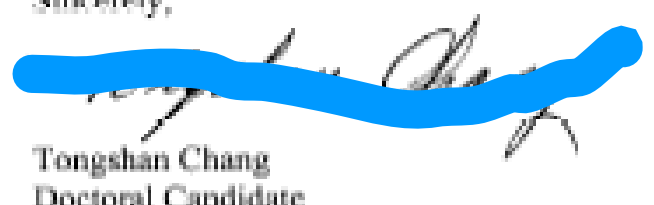

Doctoral Candidate 
G. Pilot Test Questionnaire for Utilization of Instructional Technology

(chair version and faculty version)

Pilot Test Questionnaire for Utilization of Instructional Technology in Teaching Courses

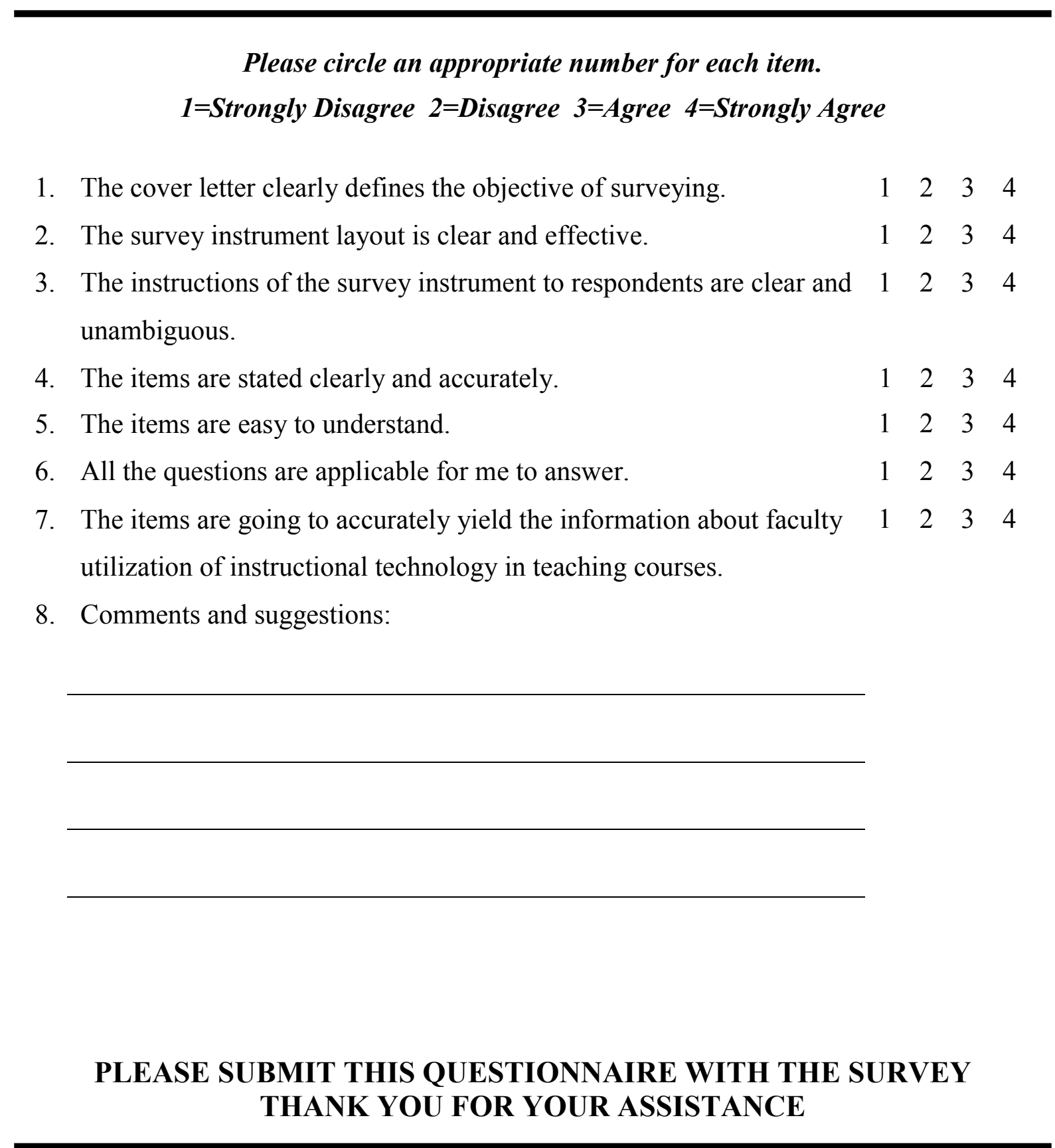




\section{H. Cover Letter to the Selected Faculty}

\section{WesthrginiaUniversity \\ College of Human Resources and Education}

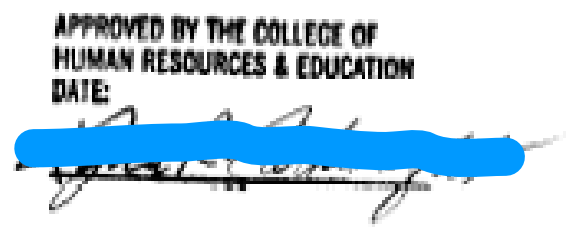

August 28, 2003

Dear Faculty:

$1 \mathrm{am}$ a graduate student and am eurrently completing my doctorate in Higher Fducation Leadership at West Virginia University, I am writing to enlist your support for a study entitled "Leadership Style of Department Chairs and Faculty Utilization of Instructional Technology:" This research is the foous of my doctoral disoertation in Higher Education Leadership.

The purprese of this study is to exannine the relationship betweta tie leadershiy style of academic department chairs and faculty utilization of instructional technology in their course teaching. I believe that the research results may help chairs better understand the influence of their leadership styles on faculty utilization of instructional technology. Chairpersons may benefit from knowing what leadership frames are more likely to promote faculty utilization of instructional technology.

The participation in this study is voluntary. You may choose not to respond to any or part of the study. The survey includes a leadership instrument, faculty utilization of instructional technology. It takes approximately 10 minutes to complete. The collected data will be reported in aggregated form and will not identify you, or your chairperson, or your college, on you institutiun. Stict confidentiality will be maintained.

As a graduate research assistant, I understand how valuable your time is and greatly appreciate your cooperation with this research. It you have any questions, you may email me at tchang@mix.wvu.edu. Please retum the completed survey in the enclosed envelope within the next two weeks.

Thank you for your time and assistance with this study.

Sincerely,

Tongshan Chang

Doctoral Candidate 


\section{A Cover Letter to the Selected Chairs}

\section{WesthrginiaUniversity \\ College of Human Resources and Education}

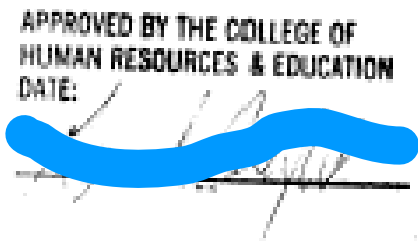

August 28, 2003

Dear Department Chair:

I am a graduate student and am currently completing my doctorate in Higher Education Leadership at West Virginia University. I am writing to enlist your support for a study entitled "Leadership Style of Department Chairs and Faculty Utilization of Instructional Technology." This research is the focus of my doctoral dissertation in Higher Education Leadership.

The purpose of this study is to examine the relationship between the leadership style of academic department chairs and faculty utilization of instructional technology in their course teaching. I believe that the research results may help chairs better understand the influence of their leadership styles on faculty utilization of instructional technology. Chairpersons may benefit from knowing what leadership frames are more likely to promote faculty utilization of instructional technology.

The participation in this study is voluntary. You may choose not to respond to any or part of the study. The survey includes the instrument of faculty utilization of instructional technology. It takes approximately 10 minutes to complete. The collected data will be reported in aggregated form and will not identify you, or your chairperson, or your college, or your institution. Strict confidentiality will be maintained.

As a graduate research assistant, I understand how valuable your time is and greatly appreciate your cooperation with this research. If you have any questions, you may email me at tchang@mix.wvu.cdu. Please return the completed survey in the enclosed envelope within the next two weeks.

Thank you for your time and assistance with this study.

Sincerely,

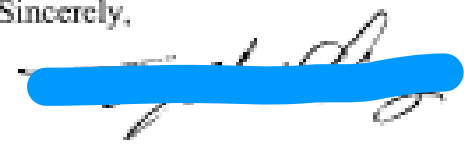

Tongshan Chang

Doctoral Candidate 


\section{J. Item-Total Correlations on the Scale of Leadership Orientations}

\begin{tabular}{|l|c|c|}
\hline Section/Item Number & $\begin{array}{c}\text { Corrected Item-Total } \\
\text { Correlation }\end{array}$ & Alpha If Item Deleted \\
\hline The Structural Frame & & \\
\hline Item 1 & .7216 & .9070 \\
\hline Item 5 & .7529 & .9028 \\
\hline Item 9 & .7729 & .9015 \\
\hline Item 13 & .8103 & .8977 \\
\hline Item 17 & .7542 & .9025 \\
\hline Item 21 & .7054 & .9067 \\
\hline Item 25 & .7238 & .9054 \\
\hline Item 29 & .5817 & .9166 \\
\hline The Human Resource Frame & & \\
\hline Item 2 & .8413 & .9284 \\
\hline Item 6 & .8307 & .9283 \\
\hline Item 10 & .8215 & .9290 \\
\hline Item 14 & .7339 & .9353 \\
\hline Item 18 & .8393 & .9278 \\
\hline Item 22 & .8054 & .9302 \\
\hline Item 26 & .7269 & .9355 \\
\hline Item 30 & .6949 & .9381 \\
\hline The Political Frame & & \\
\hline Item 3 & .7897 & .9202 \\
\hline Item 7 & .7268 & .9250 \\
\hline Item 11 & .7822 & .9210 \\
\hline Item 15 & .7112 & .9264 \\
\hline Item 19 & .7566 & .9227 \\
\hline Item 23 & .7564 & .9229 \\
\hline Item 27 & .7863 & .9207 \\
\hline Item 31 & .7999 & .9196 \\
\hline The Symbolic Frame & .8410 & .9410 \\
\hline Item 4 & .7011 & .9389 \\
\hline Item 8 & .8708 & .9430 \\
\hline Item 12 & .8099 & .9438 \\
\hline Item 16 & .7977 & \\
\hline Item 20 & .8155 & .8468 \\
\hline Item 24 & & \\
\hline Item 28 & & \\
\hline Item 32 & & \\
\hline
\end{tabular}


K. Item-Total Correlations on the Scale of Faculty Utilization of IT (chair version)

\begin{tabular}{|c|c|c|}
\hline Section/Item Number & $\begin{array}{c}\text { Corrected Item-Total } \\
\text { Correlation }\end{array}$ & Alpha If Item Deleted \\
\hline \multicolumn{3}{|c|}{ Technology Infrastructure } \\
\hline Item 1 & .8470 & .9432 \\
\hline Item 2 & .8715 & .9421 \\
\hline Item 3 & .8037 & .9453 \\
\hline Item 4 & .8254 & .9445 \\
\hline Item 5 & .8128 & .9450 \\
\hline Item 6 & .7687 & .9469 \\
\hline Item 7 & .6678 & .9507 \\
\hline Item 8 & .8281 & .9441 \\
\hline Item 9 & .7471 & .9478 \\
\hline Item 10 & .7436 & .9478 \\
\hline \multicolumn{3}{|l|}{ Utilization of IT } \\
\hline Item 11 & .4671 & .8002 \\
\hline Item 12 & .5373 & .7931 \\
\hline Item 13 & .5581 & .7917 \\
\hline Item 14 & .4565 & .8012 \\
\hline Item 15 & .3740 & .8097 \\
\hline Item 16 & .5010 & .7972 \\
\hline Item 17 & .5311 & .7938 \\
\hline Item 18 & .5240 & .7959 \\
\hline Item 19 & .3002 & .8153 \\
\hline Item 20 & .4549 & .8014 \\
\hline Item 21 & .5653 & .7900 \\
\hline \multicolumn{3}{|l|}{ Technical Support } \\
\hline Item 22 & .7232 & .8979 \\
\hline Item 23 & .6986 & .9009 \\
\hline Item 24 & .7993 & .8867 \\
\hline Item 25 & .7473 & .8941 \\
\hline Item 26 & .7829 & .8890 \\
\hline Item 27 & .7466 & .8943 \\
\hline
\end{tabular}


Appendix K (Cont'd)

Item-Total Correlations on the Scale of Faculty Utilization of IT (chair version)

\begin{tabular}{|c|c|c|}
\hline Section/Item Number & $\begin{array}{c}\text { Corrected Item-Total } \\
\text { Correlation }\end{array}$ & Alpha If Item Deleted \\
\hline \multicolumn{3}{|l|}{ Administrative Support } \\
\hline Item 28 & .5828 & .8678 \\
\hline Item 29 & .7131 & .8575 \\
\hline Item 30 & .6590 & .8622 \\
\hline Item 31 & .6137 & .8656 \\
\hline Item 32 & .6626 & .8624 \\
\hline Item 33 & .4519 & .8767 \\
\hline Item 34 & .5838 & .8678 \\
\hline Item 35 & .5958 & .8668 \\
\hline Item 36 & .6417 & .8633 \\
\hline Item 37 & .5396 & .8722 \\
\hline \multicolumn{3}{|l|}{ Key Issues } \\
\hline Item 38 & .6382 & .8646 \\
\hline Item 39 & .6663 & .8624 \\
\hline Item 40 & .6279 & .8654 \\
\hline Item 41 & .5908 & .8686 \\
\hline Item 42 & .6028 & .8677 \\
\hline Item 43 & .6248 & .8658 \\
\hline Item 44 & .5115 & .8765 \\
\hline Item 45 & .6805 & .8610 \\
\hline Item 46 & .6796 & .8612 \\
\hline
\end{tabular}


L. Item-Total Correlations on the Scale of Faculty Utilization of IT (faculty version)

\begin{tabular}{|c|c|c|}
\hline Section/Item Number & $\begin{array}{c}\text { Corrected Item-Total } \\
\text { Correlation }\end{array}$ & Alpha If Item Deleted \\
\hline \multicolumn{3}{|c|}{ Technology Infrastructure } \\
\hline Item 1 & .8534 & .9424 \\
\hline Item 2 & .8740 & .9415 \\
\hline Item 3 & .7978 & .9450 \\
\hline Item 4 & .8206 & .9441 \\
\hline Item 5 & .8138 & .9445 \\
\hline Item 6 & .7705 & .9463 \\
\hline Item 7 & .6647 & .9503 \\
\hline Item 8 & .8247 & .9437 \\
\hline Item 9 & .7404 & .9476 \\
\hline Item 10 & .7387 & .9475 \\
\hline \multicolumn{3}{|l|}{ Utilization of IT } \\
\hline Item 11 & .4885 & .8058 \\
\hline Item 12 & .5423 & .8006 \\
\hline Item 13 & .5582 & .7995 \\
\hline Item 14 & .4599 & .8085 \\
\hline Item 15 & .4010 & .8144 \\
\hline Item 16 & .5258 & .8028 \\
\hline Item 17 & .5341 & .8014 \\
\hline Item 18 & .5354 & .8027 \\
\hline Item 19 & .3073 & .8222 \\
\hline Item 20 & .4685 & .8077 \\
\hline Item 21 & .5559 & .7991 \\
\hline \multicolumn{3}{|l|}{ Technical Support } \\
\hline Item 22 & .7569 & .9098 \\
\hline Item 23 & .7422 & .9114 \\
\hline Item 24 & .8236 & .9005 \\
\hline Item 25 & .7658 & .9083 \\
\hline Item 26 & .7860 & .9056 \\
\hline Item 27 & .7764 & .9069 \\
\hline
\end{tabular}


Appendix N (Cont'd)

Item-Total Correlations on the Scale of Faculty Utilization of IT (faculty version)

\begin{tabular}{|c|c|c|}
\hline Section/Item Number & $\begin{array}{c}\text { Corrected Item-Total } \\
\text { Correlation }\end{array}$ & Alpha If Item Deleted \\
\hline \multicolumn{3}{|l|}{ Administrative Support } \\
\hline Item 28 & .6217 & .8775 \\
\hline Item 29 & .7168 & .8705 \\
\hline Item 30 & .6807 & .8734 \\
\hline Item 31 & .6615 & .8747 \\
\hline Item 32 & .6882 & .8734 \\
\hline Item 33 & .4824 & .8866 \\
\hline Item 34 & .5930 & .8796 \\
\hline Item 35 & .5990 & .8791 \\
\hline Item 36 & .6469 & .8757 \\
\hline Item 37 & .5624 & .8823 \\
\hline \multicolumn{3}{|l|}{ Key Issues } \\
\hline Item 38 & .6367 & .8659 \\
\hline Item 39 & .6607 & .8641 \\
\hline Item 40 & .6295 & .8665 \\
\hline Item 41 & .6051 & .8686 \\
\hline Item 42 & .6108 & .8682 \\
\hline Item 43 & .6277 & .8668 \\
\hline Item 44 & .5229 & .8767 \\
\hline Item 45 & .6766 & .8626 \\
\hline Item 46 & .6718 & .8631 \\
\hline
\end{tabular}




\section{Profile for Faculty Utilization of IT by Department}

Profile for Faculty Utilization of IT by Department-Technology Infrastructure

\begin{tabular}{|c|c|c|c|c|c|c|c|c|c|c|}
\hline \multirow[t]{2}{*}{ Item } & \multicolumn{2}{|c|}{ Poor } & \multicolumn{2}{|c|}{ Fair } & \multicolumn{2}{|c|}{ Good } & \multicolumn{2}{|c|}{ Very Good } & \multicolumn{2}{|c|}{ Excellent } \\
\hline & $\mathrm{N}$ & $\%$ & $\mathrm{~N}$ & $\%$ & $\mathrm{~N}$ & $\%$ & $\mathrm{~N}$ & $\%$ & $\mathrm{~N}$ & $\%$ \\
\hline & \multicolumn{10}{|c|}{ Department: Curriculum and Instruction } \\
\hline 1 & 2 & 3.5 & 8 & 14.0 & 19 & 33.3 & 15 & 26.3 & 13 & 22.8 \\
\hline 2 & 4 & 7.0 & 6 & 10.5 & 17 & 29.8 & 15 & 26.3 & 15 & 26.3 \\
\hline 3 & 3 & 5.3 & 9 & 15.8 & 18 & 31.6 & 12 & 21.1 & 15 & 26.3 \\
\hline 4 & 2 & 3.5 & 11 & 19.3 & 15 & 26.3 & 13 & 22.8 & 16 & 28.1 \\
\hline 5 & 2 & 3.5 & 6 & 10.5 & 16 & 28.1 & 17 & 29.8 & 16 & 28.1 \\
\hline 6 & 4 & 7.0 & 11 & 19.3 & 16 & 28.1 & 16 & 28.1 & 10 & 17.5 \\
\hline 7 & 1 & 1.8 & 8 & 14.0 & 14 & 24.6 & 22 & 38.6 & 12 & 21.1 \\
\hline 8 & 3 & 5.3 & 10 & 17.5 & 13 & 22.8 & 16 & 28.1 & 15 & 26.3 \\
\hline 9 & 6 & 10.5 & 5 & 8.8 & 18 & 31.6 & 16 & 28.1 & 12 & 21.1 \\
\hline 10 & 3 & 5.3 & 8 & 14.0 & 15 & 26.3 & 20 & 35.1 & 11 & 19.3 \\
\hline \multirow[t]{2}{*}{ Total } & 30 & 5.3 & 82 & 14.4 & 161 & 28.2 & 162 & 28.4 & 135 & 23.7 \\
\hline & \multicolumn{10}{|c|}{ Department: Educational Leadership Studies } \\
\hline 1 & 9 & 11.7 & 14 & 18.2 & 15 & 19.5 & 22 & 28.6 & 17 & 22.1 \\
\hline 2 & 7 & 9.1 & 14 & 18.2 & 16 & 20.8 & 25 & 32.5 & 15 & 19.5 \\
\hline 3 & 4 & 5.2 & 10 & 13.0 & 20 & 26.0 & 27 & 35.1 & 16 & 20.8 \\
\hline 4 & 3 & 3.9 & 8 & 10.4 & 23 & 29.9 & 27 & 35.1 & 16 & 20.8 \\
\hline 5 & 3 & 3.9 & 7 & 9.1 & 21 & 27.3 & 27 & 35.1 & 19 & 24.7 \\
\hline 6 & 11 & 14.3 & 12 & 15.6 & 26 & 33.8 & 16 & 20.8 & 12 & 15.6 \\
\hline 7 & 5 & 6.5 & 11 & 14.3 & 23 & 29.9 & 24 & 31.2 & 14 & 18.2 \\
\hline 8 & 6 & 7.8 & 9 & 11.7 & 16 & 20.8 & 24 & 31.2 & 22 & 28.6 \\
\hline 9 & 6 & 7.8 & 11 & 14.3 & 25 & 32.5 & 19 & 24.7 & 16 & 20.8 \\
\hline 10 & 9 & 11.7 & 10 & 13.0 & 20 & 26.0 & 26 & 33.8 & 12 & 15.6 \\
\hline \multirow[t]{2}{*}{ Total } & 63 & 8.2 & 106 & 13.8 & 205 & 26.6 & 237 & 30.8 & 159 & 20.6 \\
\hline & \multicolumn{10}{|c|}{ Department: Teacher Education } \\
\hline 1 & 5 & 11.4 & 6 & 13.6 & 11 & 25.0 & 13 & 29.5 & $\overline{9}$ & 20.5 \\
\hline 2 & 4 & 9.1 & 6 & 13.6 & 10 & 22.7 & 17 & 38.6 & 7 & 15.9 \\
\hline 3 & 3 & 6.8 & 3 & 6.8 & 19 & 43.2 & 13 & 29.5 & 6 & 13.6 \\
\hline 4 & 1 & 2.3 & 3 & 6.8 & 19 & 43.2 & 13 & 29.5 & 8 & 18.2 \\
\hline 5 & 1 & 2.3 & 3 & 6.8 & 15 & 34.1 & 15 & 34.1 & 10 & 22.7 \\
\hline 6 & 5 & 11.4 & 4 & 9.1 & 15 & 34.1 & 15 & 34.1 & 5 & 11.4 \\
\hline 7 & 1 & 2.3 & 5 & 11.4 & 14 & 31.8 & 20 & 45.5 & 4 & 9.1 \\
\hline 8 & 4 & 9.1 & 3 & 6.8 & 13 & 29.5 & 16 & 36.4 & 8 & 18.2 \\
\hline 9 & 6 & 13.6 & 5 & 11.4 & 10 & 22.7 & 15 & 34.1 & 8 & 18.2 \\
\hline 10 & 2 & 4.5 & 10 & 22.7 & 9 & 20.5 & 12 & 27.3 & 11 & 25.0 \\
\hline \multirow{2}{*}{ Total } & 32 & 7.3 & 48 & 10.9 & 135 & 30.7 & 149 & 33.9 & 76 & 17.3 \\
\hline & \multicolumn{10}{|c|}{ Department: Educational Psychology } \\
\hline 1 & 1 & 2.2 & 5 & 11.1 & 7 & 15.6 & 15 & 33.3 & 17 & 37.8 \\
\hline 2 & 1 & 2.2 & 3 & 6.7 & 11 & 24.4 & 14 & 31.1 & 16 & 35.6 \\
\hline 3 & 1 & 2.2 & 2 & 4.4 & 9 & 20.0 & 17 & 37.8 & 16 & 35.6 \\
\hline 4 & 1 & 2.2 & 3 & 6.7 & 6 & 13.3 & 18 & 40.0 & 17 & 37.8 \\
\hline 5 & 1 & 2.2 & 3 & 6.7 & 5 & 11.1 & 17 & 37.8 & 19 & 42.2 \\
\hline 6 & 4 & 8.9 & 5 & 11.1 & 8 & 17.8 & 13 & 28.9 & 15 & 33.3 \\
\hline 7 & 0 & 0.0 & 6 & 13.3 & 7 & 15.6 & 14 & 31.1 & 18 & 40.0 \\
\hline 8 & 1 & 2.2 & 5 & 11.1 & 10 & 22.2 & 13 & 28.9 & 16 & 35.6 \\
\hline 9 & 3 & 6.7 & 2 & 4.4 & 9 & 20.0 & 16 & 35.6 & 15 & 33.3 \\
\hline 10 & 1 & 2.2 & 6 & 13.3 & 12 & 26.7 & 15 & 33.3 & 11 & 24.4 \\
\hline Total & 14 & 3.1 & 40 & 8.9 & 84 & 18.7 & 152 & 33.8 & 160 & 35.6 \\
\hline
\end{tabular}


Profile for Faculty Utilization of IT by Department—Faculty Use of IT

\begin{tabular}{|c|c|c|c|c|c|c|c|c|c|c|}
\hline \multirow[t]{2}{*}{ Item } & \multicolumn{2}{|c|}{ Never } & \multicolumn{2}{|c|}{ Occasionally } & \multicolumn{2}{|c|}{ Frequently } & \multicolumn{2}{|c|}{ Often } & \multicolumn{2}{|c|}{ Always } \\
\hline & $\mathrm{N}$ & $\%$ & $\mathrm{~N}$ & $\%$ & $\mathrm{~N}$ & $\%$ & $\mathrm{~N}$ & $\%$ & $\mathrm{~N}$ & $\%$ \\
\hline & \multicolumn{10}{|c|}{ Department: Curriculum and Instruction } \\
\hline 11 & 2 & 3.5 & 20 & 35.1 & 9 & 15.8 & 14 & 24.6 & 12 & 21.1 \\
\hline 12 & 7 & 12.3 & 18 & 31.6 & 11 & 19.3 & 16 & 28.1 & 5 & 8.8 \\
\hline 13 & 16 & 28.1 & 11 & 19.3 & 19 & 33.3 & 9 & 15.8 & 2 & 3.5 \\
\hline 14 & 20 & 35.1 & 16 & 28.1 & 13 & 22.8 & 4 & 7.0 & 4 & 7.0 \\
\hline 15 & 14 & 24.6 & 19 & 33.3 & 9 & 15.8 & 11 & 19.3 & 4 & 7.0 \\
\hline 16 & 27 & 47.4 & 16 & 28.1 & 6 & 10.5 & 8 & 14.0 & 0 & 0.0 \\
\hline 17 & 7 & 12.3 & 19 & 33.3 & 14 & 24.6 & 10 & 17.5 & 7 & 12.3 \\
\hline 18 & 29 & 50.9 & 11 & 19.3 & 11 & 19.3 & 6 & 10.5 & 0 & 0.0 \\
\hline 19 & 6 & 10.5 & 5 & 8.8 & 18 & 31.6 & 16 & 28.1 & 12 & 21.1 \\
\hline 20 & 14 & 24.6 & 18 & 31.6 & 14 & 24.6 & 6 & 10.5 & 5 & 8.8 \\
\hline 21 & 26 & 45.6 & 8 & 14.0 & 12 & 21.1 & 8 & 14.0 & 3 & 5.3 \\
\hline \multirow[t]{2}{*}{ Total } & 168 & 26.8 & 161 & 25.7 & 136 & 21.7 & 108 & 17.2 & 54 & 8.6 \\
\hline & \multicolumn{10}{|c|}{ Department: Educational Leadership Studies } \\
\hline 11 & 4 & 5.2 & 20 & 26.0 & 6 & 7.8 & 32 & 41.6 & 15 & 19.5 \\
\hline 12 & 8 & 10.4 & 24 & 31.2 & 8 & 10.4 & 18 & 23.4 & 19 & 24.7 \\
\hline 13 & 20 & 26.0 & 30 & 39.0 & 11 & 14.3 & 12 & 15.6 & 4 & 5.2 \\
\hline 14 & 27 & 35.1 & 21 & 27.3 & 13 & 16.9 & 10 & 13.0 & 6 & 7.8 \\
\hline 15 & 13 & 16.9 & 16 & 20.8 & 23 & 29.9 & 19 & 24.7 & 6 & 7.8 \\
\hline 16 & 30 & 39.0 & 22 & 28.6 & 13 & 16.9 & 9 & 11.7 & 3 & 3.9 \\
\hline 17 & 14 & 18.2 & 20 & 26.0 & 11 & 14.3 & 16 & 20.8 & 16 & 20.8 \\
\hline 18 & 34 & 44.2 & 28 & 36.4 & 9 & 11.7 & 5 & 6.5 & 1 & 1.3 \\
\hline 19 & 16 & 20.8 & 25 & 32.5 & 16 & 20.8 & 16 & 20.8 & 4 & 5.2 \\
\hline 20 & 23 & 29.9 & 28 & 36.4 & 16 & 20.8 & 9 & 11.7 & 1 & 1.3 \\
\hline 21 & 27 & 35.1 & 17 & 22.1 & 14 & 18.2 & 12 & 15.6 & 7 & 9.1 \\
\hline \multirow[t]{2}{*}{ Total } & 216 & 25.5 & 251 & 29.6 & 140 & 16.5 & 158 & 18.7 & 82 & 9.7 \\
\hline & \multicolumn{10}{|c|}{ Department: Teacher Education } \\
\hline 11 & 0 & 0.0 & 8 & 18.2 & 9 & 20.5 & 17 & 38.6 & 10 & 22.7 \\
\hline 12 & 4 & 9.1 & 7 & 15.9 & 12 & 27.3 & 13 & 29.5 & 8 & 18.2 \\
\hline 13 & 13 & 29.5 & 8 & 18.2 & 11 & 25.0 & 7 & 15.9 & 5 & 11.4 \\
\hline 14 & 20 & 45.5 & 14 & 31.8 & 3 & 6.8 & 5 & 11.4 & 2 & 4.5 \\
\hline 15 & 12 & 27.3 & 11 & 25.0 & 7 & 15.9 & 7 & 15.9 & 7 & 15.9 \\
\hline 16 & 24 & 54.5 & 7 & 15.9 & 9 & 20.5 & 2 & 4.5 & 2 & 4.5 \\
\hline 17 & 3 & 6.8 & 11 & 25.0 & 10 & 22.7 & 13 & 29.5 & 7 & 15.9 \\
\hline 18 & 26 & 59.1 & 8 & 18.2 & 5 & 11.4 & 3 & 6.8 & 2 & 4.5 \\
\hline 19 & 6 & 13.6 & 10 & 22.7 & 10 & 22.7 & 12 & 27.3 & 6 & 13.6 \\
\hline 20 & 8 & 18.2 & 15 & 34.1 & 9 & 20.5 & 5 & 11.4 & 7 & 15.9 \\
\hline 21 & 23 & 52.3 & 5 & 11.4 & 6 & 13.6 & 7 & 15.9 & 3 & 6.8 \\
\hline \multirow[t]{2}{*}{ Total } & 139 & 28.7 & 104 & 21.5 & 91 & 18.8 & 91 & 18.8 & 59 & 12.2 \\
\hline & \multicolumn{10}{|c|}{ Department: Educational Psychology } \\
\hline 11 & 7 & 15.6 & 9 & 20.0 & 6 & 13.3 & 9 & 20.0 & 14 & 31.1 \\
\hline 12 & 5 & 11.1 & 8 & 17.8 & 11 & 24.4 & 8 & 17.8 & 13 & 28.9 \\
\hline 13 & 12 & 26.7 & 13 & 28.9 & 12 & 26.7 & 5 & 11.1 & 3 & 6.7 \\
\hline 14 & 13 & 28.9 & 10 & 22.2 & 9 & 20.0 & 9 & 20.0 & 4 & 8.9 \\
\hline 15 & 17 & 37.8 & 8 & 17.8 & 8 & 17.8 & 6 & 13.3 & 6 & 13.3 \\
\hline 16 & 30 & 66.7 & 4 & 8.9 & 6 & 13.3 & 3 & 6.7 & 2 & 4.4 \\
\hline 17 & 8 & 17.8 & 8 & 17.8 & 10 & 22.2 & 14 & 31.1 & 5 & 11.1 \\
\hline 18 & 26 & 57.8 & 10 & 22.2 & 5 & 11.1 & 1 & 2.2 & 3 & 6.7 \\
\hline 19 & 6 & 13.3 & 7 & 15.6 & 12 & 26.7 & 11 & 24.4 & 9 & 20.0 \\
\hline 20 & 12 & 26.7 & 10 & 22.2 & 9 & 20.0 & 9 & 20.0 & 5 & 11.1 \\
\hline 21 & 21 & 46.7 & 3 & 6.7 & 10 & 22.2 & 3 & 6.7 & 8 & 17.8 \\
\hline Total & 157 & 31.7 & 90 & 18.2 & 98 & 19.8 & 78 & 15.8 & 72 & 14.5 \\
\hline
\end{tabular}


Profile for Faculty Utilization of IT by Department-Technical Support

\begin{tabular}{|c|c|c|c|c|c|c|c|c|c|c|}
\hline \multirow[t]{2}{*}{ Item } & \multicolumn{2}{|c|}{ Strongly Disagree } & \multicolumn{2}{|c|}{ Disagree } & \multicolumn{2}{|c|}{ Don't Know } & \multicolumn{2}{|c|}{ Agree } & \multicolumn{2}{|c|}{ Strongly Agree } \\
\hline & $\mathrm{N}$ & $\%$ & $\mathrm{~N}$ & $\%$ & $\mathrm{~N}$ & $\%$ & $\mathrm{~N}$ & $\%$ & $\mathrm{~N}$ & $\%$ \\
\hline & \multicolumn{10}{|c|}{ Department: Curriculum and Instruction } \\
\hline 22 & 8 & 14.0 & 9 & 15.8 & 4 & 7.4 & 18 & 31.6 & 18 & 31.6 \\
\hline 23 & 14 & 24.6 & 13 & 22.8 & 10 & 17.5 & 12 & 21.1 & 8 & 14.0 \\
\hline 24 & 3 & 5.3 & 12 & 21.1 & 6 & 10.5 & 24 & 42.1 & 12 & 21.1 \\
\hline 25 & 7 & 12.3 & 13 & 22.8 & 7 & 12.3 & 18 & 31.6 & 12 & 21.1 \\
\hline 26 & 18 & 31.6 & 12 & 21.1 & 8 & 14.0 & 10 & 17.5 & 9 & 15.8 \\
\hline 27 & 11 & 19.3 & 12 & 21.1 & 4 & 7.0 & 19 & 3 & 11 & 19.3 \\
\hline \multirow[t]{2}{*}{ Total } & 61 & 17.8 & 71 & 20.8 & 39 & 11.4 & 101 & 29.5 & 70 & 20.5 \\
\hline & \multicolumn{10}{|c|}{ Department: Educational Leadership Studies } \\
\hline 22 & 24 & 31.2 & 18 & 23.4 & 4 & 5.2 & 17 & 22.1 & 14 & 18.2 \\
\hline 23 & 24 & 31.2 & 21 & 27.3 & 13 & 16. & 11 & 14.3 & 8 & 10.4 \\
\hline 24 & 21 & 27.3 & 14 & 18.2 & 6 & 7.8 & 28 & 36.4 & 8 & 10.4 \\
\hline 25 & 19 & 24.7 & 17 & 22.1 & 9 & 11.7 & 26 & 33.8 & 6 & 7.8 \\
\hline 26 & 25 & 32.5 & 21 & 27.3 & 8 & 0.4 & 16 & 20.8 & 7 & 9.1 \\
\hline 27 & 25 & 32.5 & 15 & 19.5 & 10 & 3.0 & 16 & 20.8 & 11 & 14.3 \\
\hline Total & 138 & 29.9 & 106 & 22.9 & 50 & 10.8 & 114 & 24.7 & 54 & 11.7 \\
\hline \multicolumn{11}{|c|}{ Department: Teacher Education } \\
\hline 22 & 3 & 6.8 & 8 & 18.2 & 2 & 4.5 & 22 & 50.0 & 9 & 20.5 \\
\hline 23 & 10 & 22.7 & 10 & 22.7 & 8 & 18.2 & 14 & 31.8 & 2 & 4.6 \\
\hline 24 & 6 & 13.6 & 11 & 25.0 & 0 & 0.0 & 18 & 40.9 & 9 & 20.5 \\
\hline 25 & 7 & 15.9 & 12 & 27.3 & 2 & 4.5 & 16 & 36.4 & 7 & 15.9 \\
\hline 26 & 12 & 27.3 & 11 & 25.0 & 2 & 4.5 & 17 & 38.6 & 2 & 4.6 \\
\hline 27 & 8 & 18.2 & 10 & 22.7 & 5 & 11.4 & 16 & 3.4 & 5 & 11.4 \\
\hline Total & 46 & 17.4 & 62 & 23.5 & 19 & 7.2 & 103 & 39.0 & 34 & 12.9 \\
\hline \multicolumn{11}{|c|}{ Department: Educational Psychology } \\
\hline 22 & 8 & 17.8 & 6 & 13.3 & 3 & 6.7 & 12 & 26.7 & 16 & 35.6 \\
\hline 23 & 11 & 24.4 & 5 & 11 & 8 & 17.8 & 10 & 22.2 & 11 & 24.4 \\
\hline 24 & 9 & 20.0 & 5 & 11.1 & 2 & 4.4 & 16 & 35.6 & 13 & 28.8 \\
\hline 25 & 6 & 13.3 & 7 & 15.6 & 5 & 11.1 & 11 & 24.4 & 16 & 35.6 \\
\hline 26 & 11 & 24.4 & 9 & 20.0 & 6 & 13.3 & 9 & 20.0 & 10 & 22.2 \\
\hline 27 & 9 & 20.0 & 10 & 22.2 & 4 & 8.9 & 9 & 20.0 & 13 & 28.9 \\
\hline Total & 54 & 20.0 & 42 & 15.6 & 28 & 10.4 & 67 & 24.8 & 79 & 29.3 \\
\hline
\end{tabular}


Profile for Faculty Utilization of IT by Department - Administrative Support

\begin{tabular}{|c|c|c|c|c|c|c|c|c|c|c|}
\hline \multirow[t]{2}{*}{ Item } & \multicolumn{2}{|c|}{$\begin{array}{l}\text { Strongly } \\
\text { Disagree }\end{array}$} & \multicolumn{2}{|c|}{ Disagree } & \multicolumn{2}{|c|}{ Don't Know } & \multicolumn{2}{|c|}{ Agree } & \multicolumn{2}{|c|}{ Strongly Agree } \\
\hline & $\mathrm{N}$ & $\%$ & $\mathrm{~N}$ & $\%$ & $\mathrm{~N}$ & $\%$ & $\mathrm{~N}$ & $\%$ & $\mathrm{~N}$ & $\%$ \\
\hline & \multicolumn{10}{|c|}{ Department: Curriculum and Instruction } \\
\hline 28 & 12 & 21.1 & 23 & 40.4 & 9 & 15.8 & 7 & 12.3 & 6 & 10.5 \\
\hline 29 & 12 & 21.1 & 19 & 33.3 & 4 & 7.0 & 14 & 24.6 & 8 & 14.0 \\
\hline 30 & 24 & 42.1 & 11 & 19.3 & 5 & 8.8 & 13 & 22.8 & 4 & 7.0 \\
\hline 31 & 19 & 33.3 & 14 & 24.6 & 7 & 12.3 & 12 & 21.1 & 5 & 8.8 \\
\hline 32 & 19 & 33.3 & 22 & 38.6 & 3 & 5.3 & 6 & 10.5 & 7 & 12.3 \\
\hline 33 & 17 & 29.8 & 24 & 42.1 & 6 & 10.5 & 8 & 14.0 & 2 & 3.6 \\
\hline 34 & 23 & 40.4 & 6 & 10.5 & 9 & 15.8 & 14 & 24.6 & 5 & 8.8 \\
\hline 35 & 22 & 38.6 & 11 & 19.3 & 7 & 12.3 & 11 & 19.3 & 6 & 10.5 \\
\hline 36 & 16 & 28.1 & 11 & 19.3 & 3 & 5.3 & 20 & 35.1 & 7 & 12.3 \\
\hline 37 & 14 & 2436 & 17 & 29.8 & 3 & 5.3 & 15 & 26.3 & 8 & 14.0 \\
\hline \multirow[t]{2}{*}{ Total } & 178 & 31.2 & 158 & 27.7 & 56 & 9.8 & 120 & 21.1 & 58 & 10.2 \\
\hline & \multicolumn{10}{|c|}{ Department: Educational Leadership Studies } \\
\hline 28 & 28 & 36.4 & 24 & 31.2 & 9 & 11.7 & 15 & 19.5 & 1 & 1.3 \\
\hline 29 & 27 & 35.1 & 19 & 24.7 & 9 & 11.7 & 22 & 28.6 & 0 & 0.0 \\
\hline 30 & 32 & 41.6 & 20 & 26.0 & 12 & 15.6 & 13 & 16.9 & 0 & 0.0 \\
\hline 31 & 35 & 45.5 & 25 & 32.5 & 8 & 10.4 & 7 & 9.1 & 2 & 2.6 \\
\hline 32 & 36 & 46.8 & 26 & 33.8 & 8 & 10.4 & 6 & 7.8 & 1 & 1.3 \\
\hline 33 & 23 & 29.9 & 23 & 29.9 & 17 & 22.1 & 12 & 15.6 & 2 & 2.6 \\
\hline 34 & 24 & 31.2 & 23 & 29.9 & 15 & 19.5 & 10 & 13.0 & 5 & 6.5 \\
\hline 35 & 33 & 42.9 & 21 & 27.3 & 13 & 16.9 & 8 & 10.4 & 2 & 2.6 \\
\hline 36 & 29 & 37.7 & 26 & 33.8 & 6 & 7.8 & 14 & 18.2 & 2 & 2.6 \\
\hline 37 & 23 & 29.9 & 27 & 35.1 & 7 & 9.1 & 17 & 22.1 & 3 & 3.9 \\
\hline \multirow{2}{*}{ Total } & 290 & 37.7 & 234 & 30.4 & 104 & 13.5 & 124 & 16.1 & 18 & 2.3 \\
\hline & \multicolumn{10}{|c|}{ Department: Teacher Education } \\
\hline 28 & 11 & 25.0 & 12 & 27.3 & 7 & 15.9 & 13 & 29.5 & 1 & 2.3 \\
\hline 29 & 12 & 27.3 & 13 & 29.5 & 4 & 9.1 & 13 & 29.5 & 2 & 4.5 \\
\hline 30 & 14 & 31.8 & 13 & 29.5 & 6 & 13.6 & 11 & 25.0 & 0 & 0.0 \\
\hline 31 & 15 & 34.1 & 17 & 38.6 & 4 & 9.1 & 8 & 18.2 & 0 & 0.0 \\
\hline 32 & 16 & 36.4 & 16 & 36.4 & 5 & 11.4 & 7 & 15.9 & 0 & 0.0 \\
\hline 33 & 13 & 29.5 & 11 & 25.0 & 7 & 15.9 & 10 & 22.7 & 3 & 6.8 \\
\hline 34 & 11 & 25.0 & 13 & 29.5 & 6 & 13.6 & 9 & 20.5 & 5 & 11.4 \\
\hline 35 & 14 & 31.8 & 14 & 31.8 & 5 & 11.4 & 9 & 20.5 & 2 & 4.5 \\
\hline 36 & 9 & 20.5 & 17 & 38.6 & 1 & 2.3 & 15 & 34.1 & 2 & 4.5 \\
\hline 37 & 8 & 18.2 & 15 & 34.1 & 2 & 4.5 & 15 & 34.1 & 4 & 9.1 \\
\hline \multirow[t]{2}{*}{ Total } & 123 & 28.0 & 141 & 32.0 & 47 & 10.7 & 110 & 25.0 & 19 & 4.3 \\
\hline & \multicolumn{10}{|c|}{ Department: Educational Psychology } \\
\hline 28 & 12 & 26.7 & 13 & 28.9 & 6 & 13.3 & 6 & 13.3 & 8 & 17.8 \\
\hline 29 & 11 & 24.4 & 13 & 28.9 & 4 & 8.9 & 8 & 17.8 & 9 & 20.0 \\
\hline 30 & 13 & 28.9 & 12 & 26.7 & 4 & 8.9 & 11 & 24.4 & 5 & 11.1 \\
\hline 31 & 21 & 46.7 & 9 & 20.0 & 1 & 2.2 & 8 & 17.8 & 6 & 13.3 \\
\hline 32 & 15 & 33.3 & 12 & 26.7 & 6 & 13.3 & 10 & 22.2 & 2 & 4.4 \\
\hline 33 & 11 & 24.4 & 13 & 28.9 & 5 & 11.1 & 13 & 28.9 & 3 & 6.7 \\
\hline 34 & 17 & 37.8 & 12 & 26.7 & 1 & 2.2 & 9 & 20.0 & 6 & 13.3 \\
\hline 35 & 19 & 42.2 & 10 & 22.2 & 1 & 2.2 & 9 & 20.0 & 6 & 13.3 \\
\hline 36 & 8 & 17.8 & 11 & 24.4 & 5 & 11.1 & 13 & 28.9 & 8 & 17.8 \\
\hline 37 & 5 & 11.1 & 15 & 33.3 & 6 & 13.3 & 11 & 24.4 & 8 & 17.8 \\
\hline Total & 132 & 29.3 & 120 & 26.7 & 39 & 8.7 & 98 & 21.8 & 61 & 13.6 \\
\hline
\end{tabular}


Profile for Faculty Utilization of IT by Department— Key Issues

\begin{tabular}{|c|c|c|c|c|c|c|c|c|c|c|}
\hline \multirow[t]{2}{*}{ Item } & \multicolumn{2}{|c|}{ Not Important } & \multicolumn{2}{|c|}{$\begin{array}{l}\text { Somewhat } \\
\text { Important }\end{array}$} & \multicolumn{2}{|c|}{ Important } & \multicolumn{2}{|c|}{ Very Important } & \multicolumn{2}{|c|}{$\begin{array}{l}\text { Extremely } \\
\text { Important }\end{array}$} \\
\hline & $\mathrm{N}$ & $\%$ & $\mathrm{~N}$ & $\%$ & $\mathrm{~N}$ & $\%$ & $\mathrm{~N}$ & $\%$ & $\mathrm{~N}$ & $\%$ \\
\hline & \multicolumn{10}{|c|}{ Department: Curriculum and Instruction } \\
\hline 38 & 2 & 3.5 & 2 & 3.5 & 4 & 7.0 & 15 & 26.3 & 34 & 59.6 \\
\hline 39 & 2 & 3.5 & 4 & 7.0 & 2 & 3.5 & 17 & 29.8 & 32 & 56.1 \\
\hline 40 & 3 & 5.3 & 4 & 7.0 & 2 & 3.5 & 17 & 29.8 & 31 & 54.4 \\
\hline 41 & 1 & 1.8 & 3 & 5.3 & 4 & 7.0 & 16 & 28.1 & 33 & 57.9 \\
\hline 42 & 2 & 3.5 & 5 & 8.8 & 8 & 14.0 & 15 & 2.3 & 27 & 47.4 \\
\hline 43 & 2 & 3.5 & 9 & 15.8 & 5 & 8.8 & 17 & 29.8 & 24 & 42.1 \\
\hline 44 & 4 & 7.0 & 3 & 5.3 & 9 & 15.8 & 13 & 22.8 & 28 & 49.1 \\
\hline 45 & 3 & 5.3 & 4 & 7.0 & 9 & 15.8 & 7 & 12.3 & 34 & 59.6 \\
\hline 46 & 3 & 5.3 & 1 & 1.8 & 8 & 14.0 & 12 & 21.1 & 33 & 57.9 \\
\hline \multirow[t]{2}{*}{ Total } & 22 & 4.3 & 35 & 6.8 & 51 & 9.9 & 129 & 25.1 & 276 & 53.8 \\
\hline & \multicolumn{10}{|c|}{ Department: Educational Leadership Studies } \\
\hline 38 & 2 & 2.6 & 8 & 10.4 & 14 & 18.2 & 15 & 19.5 & 38 & 49.4 \\
\hline 39 & 1 & 1.3 & 4 & 5.2 & 8 & 10.4 & 28 & 36.4 & 36 & 46.8 \\
\hline 40 & 2 & 2.6 & 7 & 9.1 & 12 & 15.6 & 21 & 27.3 & 35 & 45.5 \\
\hline 41 & 1 & 1.3 & 7 & 9.1 & 13 & 16.9 & 25 & 32.5 & 31 & 40.3 \\
\hline 42 & 2 & 2.6 & 10 & 13.0 & 21 & 27.3 & 21 & 27.3 & 23 & 29.9 \\
\hline 43 & 3 & 3.9 & 11 & 14.3 & 17 & 22.1 & 28 & 36.4 & 18 & 23.4 \\
\hline 44 & 4 & 5.2 & 9 & 11.7 & 13 & 16.9 & 26 & 33.8 & 25 & 32.5 \\
\hline 45 & 2 & 2.6 & 7 & 9.1 & 10 & 13.0 & 17 & 22.1 & 41 & 53.2 \\
\hline 46 & 3 & 5.3 & 1 & 1.8 & 8 & 14.0 & 12 & 21.1 & 33 & 57.9 \\
\hline Total & 20 & 3.0 & 64 & 9.5 & 116 & 17.2 & 193 & 28.7 & 280 & 41.6 \\
\hline \multicolumn{11}{|c|}{ Department: Teacher Education } \\
\hline 38 & 3 & 6.8 & 2 & 4.5 & 4 & 9.1 & 9 & 20.5 & 26 & 59.1 \\
\hline 39 & 3 & 6.8 & 3 & 6.8 & 4 & 9.1 & 10 & 22.7 & 24 & 54.5 \\
\hline 40 & 3 & 6.8 & 4 & 9.1 & 5 & 11.4 & 11 & 25.0 & 21 & 47.7 \\
\hline 41 & 2 & 4.5 & 3 & 6.8 & 4 & 9.1 & 17 & 38.6 & 18 & 40.9 \\
\hline 42 & 2 & 4.5 & 9 & 20.5 & 7 & 15.9 & 12 & 27.3 & 14 & 31.8 \\
\hline 43 & 6 & 13.6 & 6 & 13.6 & 7 & 15.9 & 16 & 36.4 & 9 & 20.5 \\
\hline 44 & 4 & 9.1 & 8 & 18.2 & 10 & 22.7 & 9 & 20.5 & 13 & 29.5 \\
\hline 45 & 0 & 0.0 & 3 & 6.8 & 7 & 15.9 & 12 & 27.3 & 22 & 50.0 \\
\hline 46 & 2 & 4.5 & 2 & 4.5 & 4 & 9.1 & 13 & 29.5 & 23 & 52.3 \\
\hline Total & 25 & 6.3 & 40 & 10.1 & 52 & 13.1 & 109 & 27.5 & 170 & 42.9 \\
\hline \multicolumn{11}{|c|}{ Department: Educational Psychology } \\
\hline 38 & 2 & 4.4 & 0 & 0.0 & 0 & 0.0 & 20 & 44.4 & 23 & 51.1 \\
\hline 39 & 3 & 6.7 & 0 & 0.0 & 1 & 2.2 & 12 & 26.7 & 29 & 64.4 \\
\hline 40 & 1 & 2.2 & 2 & 4.4 & 2 & 4.4 & 16 & 35.6 & 24 & 53.3 \\
\hline 41 & 4 & 8.9 & 2 & 4.4 & 4 & 8.9 & 14 & 31.1 & 21 & 46.7 \\
\hline 42 & 3 & 6.7 & 2 & 4.4 & 9 & 20.0 & 11 & 24.4 & 20 & 44.4 \\
\hline 43 & 3 & 6.7 & 2 & 4.4 & 12 & 26.7 & 8 & 17.8 & 20 & 44.4 \\
\hline 44 & 3 & 6.7 & 4 & 8.9 & 8 & 17.8 & 10 & 22.2 & 20 & 44.4 \\
\hline 45 & 2 & 4.4 & 1 & 2.2 & 4 & 8.9 & 18 & 40.0 & 20 & 44.4 \\
\hline 46 & 3 & 6.7 & 0 & 0.0 & 4 & 8.9 & 14 & 31.1 & 24 & 53.3 \\
\hline Total & 24 & 5.9 & 13 & 3.2 & 44 & 10.9 & 123 & 30.4 & 201 & 49.6 \\
\hline
\end{tabular}




\section{Curriculum Vita}

\section{Tongshan Chang}

Tongshan Chang was born in a very small village in Gansu Province, China. After graduating from high school, he went to Zhangye Teacher's School in 1980. He earned his B. A. in English Language and M. A. in Educational Psychology from Shaanxi Normal University in 1990 and 1997, respectively. He also earned his M. A. in Higher Educational Administration in 2000 and M. S. in Computer Science in 2002 from West Virginia University

The author taught in Shandan High School, China from 1982 to 1986. He was employed as a World Bank project manager in education in Shaanxi Province from 1990 to 1997. He served as a graduate research assistant in West Virginia University from 1998 to 2003 . He will start his new academic career as an institutional research analyst at the University of Kansas Medical Center. 